\title{
Ferrocyanide Safety Project: Comparison of Actual and Simulated Ferrocyanide Waste Properties
}
R. D. Scheele
L. L. Burger
R. L. Sell
P. R. Bredt
R. J. Barrington

September 1994

Prepared for the U.S. Department of Energy under Contract DE-AC06-76RLO 1830

Pacific Northwest Laboratory Richland, Washington 99352

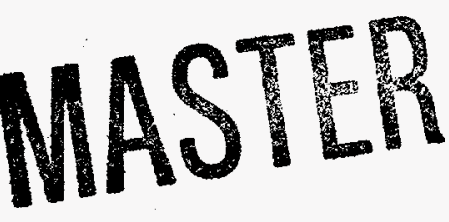





\section{DISCLAIMER}

This report was prepared as an account of work sponsored by an agency of the United States Government. Neither the United States Government nor any agency thereof, nor any of their employees, make any warranty, express or implied, or assumes any legal liability or responsibility for the accuracy, completeness, or usefulness of any information, apparatus, product, or process disclosed, or represents that its use would not infringe privately owned rights. Reference herein to any specific commercial product, process, or service by trade name, trademark, manufacturer, or otherwise does not necessarily constitute or imply its endorsement, recommendation, or favoring by the United States Government or any agency thereof. The views and opinions of authors expressed herein do not necessarily state or reflect those of the United States Government or any agency thereof. 


\section{DISCLAIMER}

Portions of this document may be illegible in electronic image products. Images are produced from the best available original document. 


\section{Summary}

In the 1950 s, additional high-level radioactive waste storage capacity was needed to accommodate the wastes that would result from the production of recovery of additional nuclear defense materials. To provide this additional waste storage capacity, the Hanford Site operating contractor developed a process to decontaminate aqueous wastes by precipitating radiocesium as an alkali nickel ferrocyanide; this process allowed disposal of the aqueous waste. The radiocesium scavenging process as developed was used to decontaminate 1) first-cycle bismuth phosphate $\left(\mathrm{BiPO}_{4}\right)$ wastes, 2$)$ acidic wastes resulting from uranium recovery operations, and 3 ) the supernate from neutralized uranium recovery wastes. The radiocesium scavenging process was often coupled with other scavenging processes to remove radiostrontium and radiocobalt. Because all defense materials recovery processes used nitric acid solutions, all of the wastes contained nitrate, which is a strong oxidizer. The variety of wastes treated, and the occasional coupling of radiostrontium and radiocobalt scavenging processes with the radiocesium scavenging process, resulted in ferrocyanide-bearing wastes having many different compositions.

In the early 1980 s, concern arose about the potential for energetic chemical reactions occurring in the ferrocyanide wastes between the ferrocyanide and nitrates and/or nitrite constituents. The nitrite in Hanford wastes is principally due to radiolytic degradation of nitrate. As a result of this concern, experimental studies were initiated to identify the conditions necessary for these energetic and rapid reactions to occur. Given the difficulties associated with obtaining representative samples of wastes stored in the Hanford underground storage tanks, the experimental studies used mixtures of synthetic representative ferrocyanide precipitates and nitrates and/or nitrites, and simulated ferrocyanide wastes prepared using the different process flowsheets used in the radiocesium scavenging campaigns.

In the early 1990s, Westinghouse Hanford Company (WHC) prepared several different simulated ferrocyanide wastes; WHC characterized the thermal behavior of these simulants and their sensitivity to reaction initiation by nonthermal events, and measured selective chemical and physical properties. Because the simulants represent the wastes at the time of their generation 30 years ago, the potential exists that the simulants are not representative of the ferrocyanide wastes as they now exist. As a result of this potential, WHC asked the Pacific Northwest Laboratory (PNL) to compare the measured properties of samples obtained from Hanford Tanks 241-C-109 (C-109) and 241-C-112 (C-112) that were characterized in 1992 and 1993 with the ferrocyanide simulant most representative of the ferrocyanide waste added to these tanks. As part of this process, staff at the PNL performed supplemental analyses.

The ferrocyanide wastes stored in these two tanks were generated using the so-called INFARM flowsheet. The INFARM flowsheet was used to decontaminate supernates from neutralized uranium recovery wastes. These supernates were essentially basic sodium nitrate solutions with traces of soluble nitrite and sulfate. The WHC simulant most representative of the wastes added to C-109 and C-112 is INFARM-2, which was prepared using $0.005 \mathrm{M}$ sodium ferrocyanide and nickel nitrate and was centrifuged for the equivalent of $30 \mathrm{~g}$-a to simulate 30 years of storage.

In terms of bulk physical properties such as density, water content, and $\mathrm{pH}$, the INFARM-2 simulant is roughly, representative of the wastes from $\mathrm{C}-109$ and $\mathrm{C}-112$. The density of the INFARM-2 simulant is higher than that of the waste in $\mathrm{C}-109$, but is both greater than or less than those observed in $\mathrm{C}-112$ depending on the location within the tank. The pHs of the wastes from $\mathrm{C}-109$ range from 8.8 up to 11 , and the pHs of the waste samples from C-112 range from 8.9 to 10.5 ; compared to the $\mathrm{pH}$ of 9.1 for the mother solution for INFARM-2, the pHs of the wastes are typically higher. The water 
contents for the waste samples from C-109 range from 19 to $60 \mathrm{wt} \%$ and those for the waste samples from $\mathrm{C}-112$ range from 34 to $60 \mathrm{wt} \%$ depending on depth, compared to $50 \mathrm{wt} \%$ for INFARM-2; in general the INFARM-2 has a higher water content than the waste from C-109 but near that of the waste from $\mathrm{C}-112$.

In general, the chemical similarities between INFARM-2 simulant and the wastes stored in C-109 and $\mathrm{C}-112$ indicate that these two tanks contain largely ferrocyanide wastes resulting from use of a flowsheet similar to that used to prepare the INFARM-2 simulant. The concentrations of iron and nickel within the tanks are not always consistent with the presence or past existence of disodium nickel ferrocyanide; there is often an excess of one or the other. This comparison also indicates that much of the cyanide added to the tank has disappeared during the over 30 years of storage. The distributions of the different elements within each tank suggests that substantial mixing of wastes has occurred and that the composition of the waste within the tank varies depending on location.

The radiochemical results indicate the following: 1) The water-leach results from all the cores suggest that sufficient ferrocyanide remains to prevent the solubilization of the normally soluble cesium. 2) The leach results from core 36 from C-112 indicate that ferrocyanide has distributed itself throughout the waste in $\mathrm{C}-112$ assuming that ferrocyanide is responsible for the lack of cesium solubility. 3) The strontium distributions in C-109 indicate that little physical mixing occurred during years of storage. 4) Distributions of strontium in C-112 indicate that, near the tank inlet, little physical mixing occurred, but on the opposite side of the tank physical mixing of the waste occurred.

In terms of particle size, the particles in the INFARM-2 simulant and the waste samples from C-109 and C-112 are of similar sizes, with the bulk of the particles less than $5 \mu$ in diameter. The waste from the two tanks tends to have slightly larger sizes.

In the original characterization of the simulated ferrocyanide wastes, the rheological and settling behavior were not measured. To provide this information, we obtained a sample of INFARM-1 simulant from WHC and measured settling and rheological properties of its 1:1 and 3:1 water dilutions by volume. In terms of settling behavior, the INFARM-1 dilutions did not settle over four days in contrast to equivalent water dilutions of the waste samples from C-109 and C-112. After two days, the solids in the 1:1 water-to-waste dilutions of the C-109 and C-112 wastes settled to 88 and 77 vol\%, respectively. After two days, the solids in the 3:1 dilutions of the C-109 and C-112 wastes settled to 41 and 74 vol\%, respectively. The INFARM-1 simulant does not exhibit the same settling properties as the wastes from $\mathrm{C}-109$ and $\mathrm{C}-112$.

The rheological or flow properties exhibited by the $1: 1$ and $3: 1$ water volume dilutions of INFARM-1 simulant is qualitatively similar to that exhibited by the wastes from C-109 and C-112 that were analyzed; however, quantitatively the simulant exhibits different rheological behavior. In general, the dilutions for all materials exhibit yield-pseudoplastic behavior. In general, the INFARM-1 simulant dilution 1:1 dilution is about twice as viscous as the $1: 1$ dilution of the core 47 composite sample from C-109, and substantially greater than the $2 \mathrm{cP}$ viscosity of the 3:1 dilution of core 47 . The simulant also exhibits a much higher viscosity than the $1: 1$ dilution of the core 36 composite taken from $\mathrm{C}-112,580$ versus $80 \mathrm{cP}$, respectively.

As would be expected based on the lower cyanide concentrations found in the wastes from C-109 and C-112 relative to the cyanide concentration in the INFARM-2 simulant, the energy released from thermally induced reactions within wastes from C-109 and C-112 is much smaller than measured for the simulant. Qualitatively, the thermal behaviors observed by differential scanning calorimetry (DSC) 
and thermogravimetric analysis (TGA) for the actual wastes are significantly different than those observed for the simulant; for the majority of the C-109 subsegment samples, strong endothermic peaks occur in the wastes where the strong exotherm would be expected based on the simulant behavior, or for both C-109 and C-112 in the absence of this endotherm, only a weak exotherm occurs.

Overall, the results indicate that the representativeness of the simulated INFARM wastes relative to the wastes in C-109 and C-112 depends on the property. For example, the INFARM simulants exhibit greater thermal reactivity, have similar qualitative rheological properties, but differ in quantitative rheological properties. 



\section{Contents}

Summary $\ldots \ldots \ldots \ldots \ldots \ldots \ldots \ldots \ldots \ldots \ldots \ldots \ldots \ldots \ldots \ldots$ iii

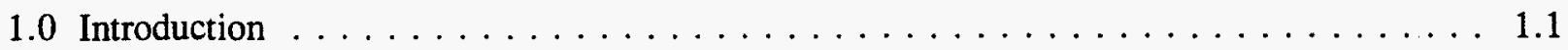

2.0 Brief Histories of Wastes Stored in $\mathrm{C}-109$ and $\mathrm{C}-112 \ldots \ldots \ldots \ldots \ldots \ldots \ldots \ldots$

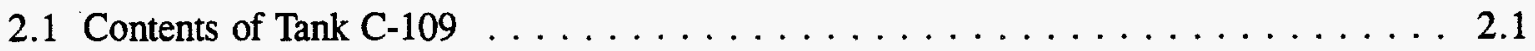

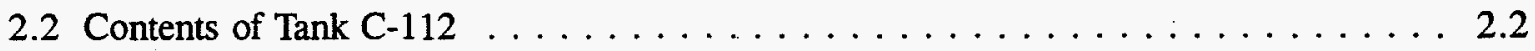

2.3 Sampling and Analysis Strategy for Wastes from C-112 and C-109 . . . . . . 2.2

2.4 Samples Taken from $\mathrm{C}-112$ and $\mathrm{C}-109 \ldots \ldots \ldots \ldots \ldots \ldots \ldots$

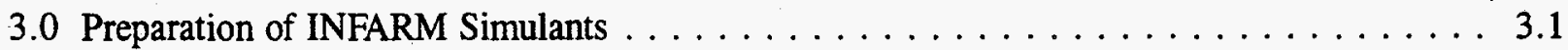

4.0 Chemical and Radiochemical Properties of INFARM-2 Simulated

Waste and Wastes From $\mathrm{C}-109$ and $\mathrm{C}-112 \ldots \ldots \ldots \ldots \ldots \ldots \ldots$

4.1 Comparison of Chemical Compositions $\ldots \ldots \ldots \ldots \ldots \ldots \ldots \ldots \ldots$

4.1.1 Comparison of INFARM-2 and C-109 Chemical Compositions $\ldots \ldots \ldots . . .4 .2$

4.1 .2 Chemical Composition of Waste from $\mathrm{C}-112 \ldots \ldots \ldots \ldots . \ldots \ldots$

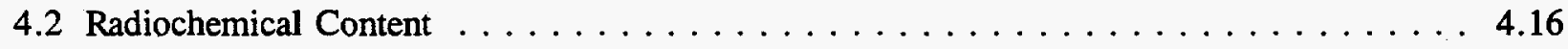

5.0 Physical Properties of Actual and INFARM Simulants $\ldots \ldots \ldots \ldots \ldots \ldots$

5.1 Density, Water Content, and Other Bulk Physical Properties $\ldots \ldots \ldots \ldots . \ldots$

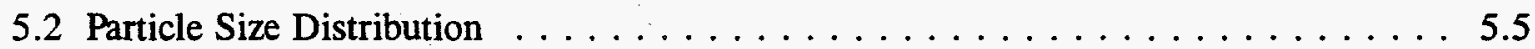

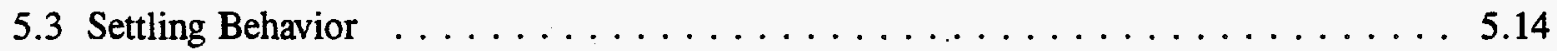

5.4 Comparison of Rheological Properties $\ldots \ldots \ldots \ldots \ldots \ldots \ldots \ldots \ldots \ldots$

5.5 Thermal and Chemical Reactivity Behavior $\ldots \ldots \ldots \ldots \ldots \ldots \ldots \ldots \ldots \ldots$

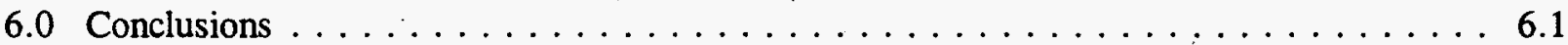

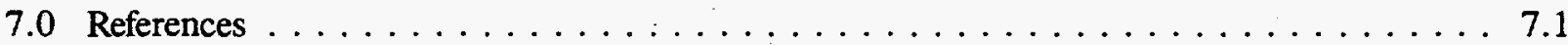


Appendix A Comparison of Weight Percent Elemental Concentration on a Dry Basis in Simulated INFARM Waste and Waste from Tank 241-C-109

Appendix B Comparison of Weight Percent Anion Concentration on a Dry Basis in Simulated INFARM Waste and Waste from Tank 241-C-109

Appendix C Comparison of Weight Percent Elemental Concentration on a Dry Basis in Simulated INFARM Waste and Waste from Tank 241-C-112.

Appendix D Comparison of Weight Percent Anion Concentration on a Dry Basis in Simulated INFARM Waste and Waste from Tank 241-C-112 


\section{Figures}

5.1 Particle Size Distributions, by Number and Volume, of the Simulated Ferrocyanide Waste INFARM $-2 \ldots \ldots \ldots \ldots \ldots \ldots \ldots \ldots$

5.2 Particle Size Distribution, by Number and Volume, of Waste from Tank $241-\mathrm{C}-109$ (Core 47$) \ldots \ldots \ldots \ldots \ldots \ldots \ldots \ldots$

5.3 Particle Distribution, by Number and Volume, of Waste from Tank 241-C-109

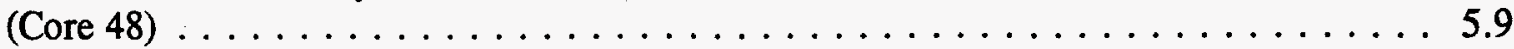

5.4 Particle Size Distribution, by Number and Volume, of Waste Obtained from Tank 241-C-109 (Core 49) . . . . . . . . . . . . . . . . . . . . . . 5.10

5.5 Particle Size Distribution, by Number and Volume, of Waste from the Tank 241-C-112 (Core 34)

5.6 Particle Size Distribution of Waste from Tank 241-C-112 (Core 35) $\ldots \ldots \ldots$. . . . 5.12

5.7 Particle Size Distribution, by Number, of Waste from Tank 241-C-112 (Core 36) . . . . 5.13

5.8 Settling Behavior of Solids in 1:1 and 3:1 Water-to-Waste Dilutions of Waste from

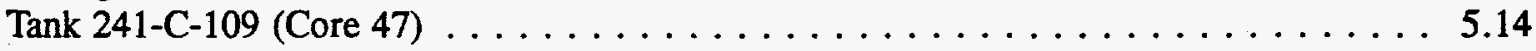

5.9 Settling Behavior of Solids in 1:1 and 3:1 Water-to-Waste Dilutions of Waste from Tank 241-C-112 (Core 36)

5.10 Rheological Behavior of 1:1 Water-to-Waste Dilution of Waste from Tank 241-C-109 at $30^{\circ} \mathrm{C}$

5.11 Rheological Behavior of a 1:1 Water-to-Waste Dilution of Waste from Tank $241-\mathrm{C}-112($ Core 36$)$ at 30 and $95^{\circ} \mathrm{C}$

5.12 Rheological Behavior of a 1:1 Water to Simulated INFARM-1 Waste Dilution at

5.13 Rheological Behavior of 3:1 Water to Simulated INFARM-1 Waste at 30 and $90^{\circ} \mathrm{C} \ldots \ldots 5.22$

5.14 Thermal Behavior as Measured by DSC and TGA/DTG of Dried INFARM-2 Simulated Ferrocyanide Waste

5.15 Thermal Behavior as Measured by ARC of Dried INFARM-2 Simulated Ferrocyanide Waste . . . . . . . . . . . . . . . . . . 5.26

5.16 Thermal Behavior as Measured by DSC and TGA/DTG of As-Received Waste from Core 47 Composite Obtained from 241-C-109 
5.17 Thermal Behavior as Measured by DSC and TGA/DTG of As-Received Waste from Core 47 Subsegment $1 B$ Obtained from the 241-C-109

5.18 Thermal Behavior as Measured by DSC and TGA/DTG of As-Received Waste from Core 47 Subsegment 1C Obtained from 241-C-109

5.19 Thermal Behavior as Measured by DSC and TGA/DTG of As-Received Waste from Core 48 Subsegment 1D Obtained from 241-C-109

5.20 Thermal Behavior as Measured by DSC and TGA/DTG of As-Received Waste from Core 48 Subsegment 1D Obtained from 241-C-109

5.21 Thermal Behavior as Measured by DSC and TGA/DTG of As-Received Waste from Core 49 Obtained from 241-C-109

5.22 Thermal Behavior as Measured by DSC and TGA/DTG of As-Received Waste from Core 49 Subsegment 1B Obtained from 241-C-109

5.23 Thermal Behavior as Measured by DSC and TGA/DTG of As-Received Waste from Core 49 Subsegment 1C Obtained from 241-C-109

5.24 Thermal Behavior as Measured by DSC and TGA/DTG of As-Received Waste from Core 49 Subsegment 1D Obtained from 241-C-109

5.25 Thermal Behavior as Measured by DSC and TGA/DTG of As-Received Waste from Core 34 Subsegment 2D Taken from 241-C-112 .

5.26 Thermal Behavior as Measured by DSC and TGA/DTG of As-Received Waste from Core 35 Composite Taken from $241-\mathrm{C}-112 \ldots \ldots \ldots \ldots . . \ldots \ldots$

5.27 Thermal Behavior as Measured by DSC and TGA/DTG of As-Received Waste from Core 36 Composite Taken from 241-C-112

5.28 Thermal Behavior as Measured by DSC and TGA/DTG of As-Received Waste from Core 36 Subsegment $1 \mathrm{C}$ Taken from 241-C-112

5.29 Thermal Behavior as Measured by DSC and TGA/DTG of As-Received Waste from Core 36 Subsegment 1D Taken from 241-C-109.

5.30 Thermal Behavior as Measured by DSC and TGA/DTG of As-Received Waste from Core 36 Subsegment 2 A Taken from $241-C-112 \ldots \ldots \ldots \ldots \ldots \ldots$. . . . . . . . . .

5.31 Thermal Behavior as Measured by DSC and TGA/DTG of As-Received Waste from Core 36 Subsegment 2B Taken from 241-C-112 
5.32 Thermal Behavior as Measured by DSC and TGA/DTG of As-Received Waste from Core 36 Subsegment $2 C$ Taken from $241-C-112 \ldots \ldots \ldots \ldots \ldots . \ldots \ldots$

5.33 Thermal Behavior as Measured by DSC and TGA of a Sample of As-Received Waste from Core 36 Subsegment of 2D Taken from 241-C-112 


\section{Tables}

3.1 Recipes for Preparation of Simulated INFARM Flowsheet Wastes $\ldots \ldots \ldots \ldots . \ldots$

3.2 Comparison of Predicted and Measured Compositions of WHC-prepared INFARM

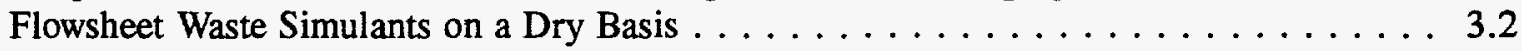

4.1 Comparison of Element Concentrations on a Dry Basis (as Measured by ICP)

of INFARM-2 Simulant with Waste from C-109 (Core 47) . . . . . . . . . . . . .

4.2 Comparison of Anion Concentrations on a Dry Basis in INFARM-2 Simulants and Wastes from C-109 (Core 47)

4.3 Comparison of Element Concentrations on a Dry Basis (as Measured by ICP) of INFARM-2 Simulant with Waste from Core 48 Taken from C-109

4.4 Comparison of Anion Concentrations on a Dry Basis in INFARM-2 Simulants

4.5 Comparison of Element Concentrations on a Dry Basis (as Measured by ICP) of INFARM-2 Simulant with Waste from Core 49 Taken from C-109

4.6 Comparison of Anion Concentrations on a Dry Basis in INFARM-2 Simulants and Wastes from $\mathrm{C}-109$ (Core 49$) \ldots \ldots \ldots \ldots \ldots \ldots \ldots \ldots$

4.7 Comparison Element Concentrations on a Dry Basis in INFARM-2 Simulants and Waste from Core 34, C-112

4.8 Comparison of Anion Concentrations on a Dry Basis in INFARM-2 Simulant and in Waste from C-112 Core 34

4.9 Comparison of Element Concentrations on a Dry Basis in INFARM-2 and Waste from Core $35, \mathrm{C}-112$

4.10 Comparison of Anion Concentrations on a Dry Basis in INFARM-2 Simulant and in Waste from C-112 Core 35

4.11 Comparison of Element Concentrations on a Dry Basis in INFARM-2 and Waste from Core 36, C-112

4.12 Comparison of Anion Concentrations on a Dry Basis in INFARM-2 Simulant and in Waste from C-112 Core 36

4.13 Water Solubility of ${ }^{137} \mathrm{Cs}$ in Waste from $\mathrm{C}-109 \ldots \ldots \ldots \ldots \ldots$

4.14 Water Solubility of ${ }^{137} \mathrm{Cs}$ in Waste from $\mathrm{C}-112 \ldots \ldots \ldots \ldots \ldots \ldots$ 
4.15 Radionuclide Content of Waste (As-Received) from C-109 . . . . . . . . . . . . . 4.19

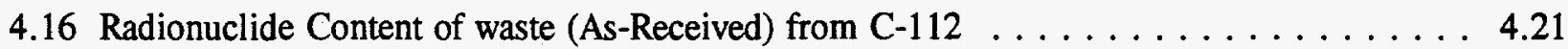

5.1 Comparison of Densities of Simulated INFARM Wastes and Core 47 from

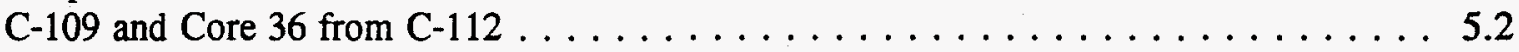

5.2 Comparison of Water Contents and pHs of Simulated INFARM-2 Waste and

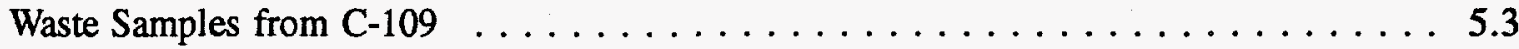

5.3 Comparison of Water Contents and pHs of Simulated INFARM-2 Waste and

Waste Samples from $\mathrm{C}-112 \ldots \ldots \ldots \ldots \ldots \ldots \ldots \ldots$

5.4 Mean and Median Particle Size Summary Statistics for Solids in INFARM-2

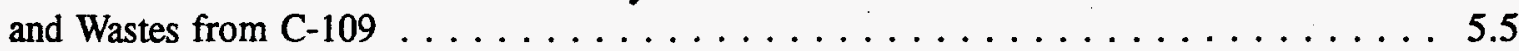

5.5 Mean and Median Particle Size Summary Statistics for Solids in INFARM-2

Simulant and Waste Samples from $\mathrm{C}-112 \ldots \ldots \ldots \ldots \ldots \ldots \ldots \ldots$

5.6 Shear Strengths of INFARM-1 Simulant and Wastes from C-109 (Sprouse 1993)

and $\mathrm{C}-112$ (Bell 1993) . . . . . . . . . . . . . . . . . . . . . 5.16

5.7 Apparent Viscosities of Diluted INFARM-1 Simulant and Wastes and Diluted

Wastes from C-109 (Sprouse 1993) and C-112 (Bell 1993) $\ldots \ldots \ldots \ldots \ldots . \ldots \ldots$

5.8 Power-Law Model Parameters $\left(S_{\tau}=\alpha+B \gamma^{n}\right)$ for INFARM-1 Simulant and Wastes

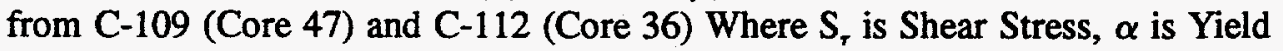

Stress, B is the Consistency Factor, $\delta$ is the Shear Rate $\left(0\right.$ to $\left.468 \mathrm{~s}^{-1}\right)$ and $n$ is the

Flow Behavior Index . . . . . . . . . . . . . . 5.20

5.9 Reaction Ranges, Onset Temperatures, and Reaction Enthalpies Due to Thermally

Induced Reactions for INFARM-2 Simulated Waste as Measured by DSC $\left(5^{\circ} \mathrm{C} / \mathrm{min}\right.$,

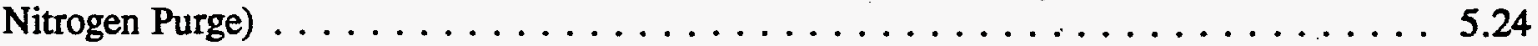

5.10 Reaction Ranges and Mass Losses due to Thermally Induced Reactions for INFARM-2

Simulated Waste as Measured by TGA $\left(5^{\circ} \mathrm{C} / \mathrm{min}\right.$, Nitrogen Purge $) \ldots \ldots \ldots . \ldots .24$

5.11 Thermal Behavior of Simulated INFARM-2 Wastes as Measured by DTA/TGA/MS $\ldots \ldots$ 5.25

5.12 Reaction Ranges, Onset Temperatures, and Mass Losses for Thermally Induced

Reactions in Wastes from C-109 (Cores 47, 48, and 49) by Subsegment . . . . . . . . 5.28

5.13 Peak Maximum and Minimum Temperatures, and Reaction Enthalpies for Wastes

from C-109 (Cores 47, 48, and 49) as Measured by DSC . . . . . . . . . . . 5.29 
5.14 Reaction Ranges, Onset Temperatures, and Mass Losses for Thermally Induced Reactions in Wastes from C-112 (Cores 34, 35, and 36) by Subsegment

5.15 Onset Temperatures, Peak Maximum and Minimum Temperatures, and Reaction Enthalpies for wastes from C-112 (Cores 34, 35, and 36) as measured by DSC

5.16 Comparison of Predicted and DSC Measured Reaction Enthalpies on a Dry Basis for INFARM-2 Simulant and Waste Samples from C-109 and C-112 Based on Total Cyanide Concentration 


\subsection{Introduction}

The research performed for this project is part of an effort that started in the mid-1980s to characterize the materials stored in the single-shell waste storage tanks (SSTs) at the U.S. Department of Energy (DOE) Hanford Site. Various radioactive wastes from defense operations have accumulated at the Hanford Site in underground waste tanks since the early 1940s.

During the 1950 s, additional tank storage space was required to support the defense mission. Hanford Site scientists developed two procedures to obtain this additional storage volume within a short time period without constructing additional storage tanks. One procedure involved the use of evaporators to concentrate the waste by removing water. The second procedure involved developing precipitation processes for scavenging radiocesium and other soluble radionuclides from tank waste liquids. The scavenging processes used sodium and potassium ferrocyanide and nickel sulfate to precipitate radioactive. cesium from solutions containing nitrates and nitrites. Radioactive strontium and cobalt were scavenged from some of the solutions using calcium or strontium nitrate and sodium sulfide, respectively. After allowing the radioactive precipitates to settle, the decontaminated solutions were pumped to disposal cribs, providing additional tank storage volume. Later, some of the tanks were found to be leaking, so pumpable liquids were removed from these tanks, leaving behind a wet solid (sludge) residue containing the ferrocyanide precipitates (Burger et al. 1991). In implementing this process, approximately 140 metric tons of ferrocyanide, [calculated as $\mathrm{Fe}(\mathrm{CN})_{6}^{4}$ ], was added to waste that was later routed to 24 large underground (2.85- to 3.8-ML) SSTs.

The explosive nature of ferrocyanides in the presence of oxidizers has been known for decades, but the conditions under which impure mixtures containing nitrates and nitrites can undergo propagating reactions have not been thoroughly studied. At the Hanford Site, the potential reactivity of mixtures of ferrocyanides, nitrates, and nitrites was first recognized when the radiocesium scavenging process using ferrocyanide was investigated for application to radioactive wastes produced by the next generation processing technology. The investigation found that cesium zinc ferrocyanide and nitrate exploded when heated (Hepworth et al. 1957). In the laboratory, mixtures of ferrocyanide and oxidizing materials, such as nitrates and nitrites, have been shown to undergo rapid; energetic reactions when heated to high temperatures (exceeding $270^{\circ} \mathrm{C}$ ) (Scheele et al. 1993) or exposed to an electrical spark of sufficient energy to heat the mixture (Scheele and Cady 1989). Because the scavenging process precipitated ferrocyanide from solutions containing nitrate and nitrite, an intimate mixture of ferrocyanides and nitrates and/or nitrites is likely to exist in some regions of the ferrocyanide tanks.

Efforts have been underway since the mid-1980s to evaluate the potential for ferrocyanide reactions in Hanford Site SSTs (Burger 1984; Burger and Scheele 1988, 1990; Scheele and Cady 1989; Scheele et al. 1991; Cady 1992; Hallon et al. 1992; Scheele et al. 1992 a,b,c; Jeppson and Wong 1993; Dodd and Thompson 1994 a,b; and Jeppson and Simpson 1994). The 1987 Environmental Impact Statement (EIS), Final Environmental Impact Statement, Disposal of Hanford Defense High-Level Transuranic and Tank Waste, Hanford Site, Richland, Washington (USDOE 1987), included an environmental impact analysis of potential explosions involving ferrocyanide-nitrate mixtures. The EIS postulated that an explosion could occur during mechanical retrieval of saltcake or sludge from a ferrocyanide waste tank. The EIS concluded that this worst-case accident could create enough energy to release radioactive material to the atmosphere through ventilation openings, exposing persons offsite to a short-term radiation dose of approximately $200 \mathrm{mrem}$. A General Accounting Office (GAO) study 
(Peach 1990) postulated a greater worst-case accident, with independently calcu-lated doses of one to two orders of magnitude greater than postulated in the DOE EIS. Uncertainties regarding the safety envelope of the Hanford Site ferrocyanide waste tanks led to the declaration of the ferrocyanide unreviewed safety question (USQ) in October 1990.

Despite the fact that the measured temperatures in these tanks continue to drop $\left(3^{\circ} \mathrm{C} /\right.$ year) and the highest temperature currently recorded is $53^{\circ} \mathrm{C}$ (Hanlon 1994), there has been a good deal of speculation as to the possibility of "hot spots" forming in the tanks due to radiolytic heating. In order to address these concerns, a number of studies have been conducted by Westinghouse Hanford Company (WHC), Pacific Northwest Laboratory (PNL), ${ }^{\text {(a) }}$ and others in an effort to identify the reaction(s) that occur, and to quantify the magnitude of the energy released during reaction(s) (Burger 1984; Burger and Scheele 1988; Scheele et al. 1991; Burger and Scheele 1990; Scheele and Cady 1989; Hallen et al. 1991; Scheele et al. 1992a; Jeppson and Wong 1993; Dodds and Thomson 1994a, 1994b). Although these studies have yielded many insights, the specific reactions have yet to be identified and the prevailing reaction rates have yet to be quantified.

All of these studies employed laboratory preparations of sodium nickel ferrocyanide, which is the likely form of ferrocyanide precipitated during scavenging operations, and/or simulated Hanford ferrocyanide wastes produced using the scavenging flowsheets (Burns et al. 1954; Smith and Coppinger 1954; Stedwell 1954; Sloat 1955). Given that the Hanford ferrocyanide wastes have been stored more than 30 years in a harsh chemical environment and exposed to high doses of radiation, the potential is great that the chemical nature of the originally precipitated ferrocyanide will have changed or aged. Waste management operations, including addition of concentrated caustic solutions and other waste types, happened during the years of storage. The effects of these additions and waste management operations is unknown, with aging potentially proceeding via many alternative routes, including 1) radiolytic oxidation, 2) hydrolysis, 3) solubilization, 4) oxidation by oxidizing species in the waste, and 5) substitution reactions. Because of the potential for aging, Lilga et al. $(1992,1993)$ have been investigating the effects of exposure to hydroxide and radiation, and have found that elevated concentrations of hydroxide cause degradation of ferrocyanide; Lilga is investigating the effects of radiation in FY 1994 (Meacham et al. 1994).

In 1992 and 1993, WHC prepared simulated wastes using the various flowsheets that were used to scavenge radiocesium and extensively characterized them (Jeppson and Wong 1993). Four simulated wastes were prepared using two variations of the "U-Plant" flowsheet and two variations of the "INFARM" flowsheets. The physical and chemical properties determined include particle size, thermal behavior, elemental content, and anion content. PNL later performed supplemental analyses to determine rheological or flow behavior and to provide additional information on thermal behavior.

In general, these radiocesium-scavenging processes removed the radiocesium by adding sodium or potassium ferrocyanide and nickel nitrate or sulfate to aqueous radioactive waste solutions. This solution led to precipitation of insoluble alkali nickel ferrocyanides, principally sodium nickel ferrocyanide (Hallen et al. 1991). Often these radiocesium scavenging operations were combined with other

(a) Operated for the U.S. Department of Energy by Battelle Memorial Institute under contract DE-AC06-76RLO 1830. 
scavenging processes to remove other radionuclides such as ${ }^{90} \mathrm{Sr}$ or ${ }^{60} \mathrm{Co}$. The radiostrontium was coprecipitated with calcium or strontium phosphate, and the radiocobalt was scavenged by precipitating nickel sulfide.

The two principal radiocesium-scavening processes, the U-Plant and INFARM processes, varied principally in the nature of the aqueous waste scavenged. The U-Plant flowsheet(s) were used to scavenge radiocesium and from the acidic waste resulting from uranium recovery operations; these acidic waste solutions contained significant quantities of dissolved materials and would be expected to result in a lower ferrocyanide concentration than the wastes resulting from the INFARM process(es). The INFARM flowsheet(s) were used to scavenge radiocesium from supernates of unscavenged, neutralized wastes resulting from U-Plant operations, which were essentially solutions of sodium nitrate with minor amounts of other soluble materials such as sodium sulfate.

During 1992, several core samples of wastes stored in Tanks 241-C-109 (C-109) and 241-C-112 (C-112), two of the tanks on the Ferrocyanide Watch List, were taken and characterized to determine selected physical properties, selected chemical and radiochemical contents, and chemical reactivity as measured by differential scanning calorimetry (DSC) and thermogravimetric analysis (TGA). The wastes stored in these tanks were generated using the INFARM flowsheet, which should contain the highest concentration of cyano species and thus should represent the most reactive systems.

There continues to be a lack of ferrocyanide wastes available for characterization to determine reactivity, thus hampering the operating contractor's efforts to fully establish safe operating parameters. To complete the definition of waste tank operating criteria for those tanks containing ferrocyanide wastes, the operating contractor must rely on the limited characterizations of actual ferrocyanide wastes and those studies that employ simulants. It is therefore important to establish whether the simulants are representative of and/or bound the reactivities of actual wastes.

In this report, we compare selected physical, chemical, and radiochemical properties measured for Tanks C-109 and C-112 wastes and selected physical and chemical properties of simulated ferrocyanide wastes to assess the representativeness of simulants prepared by WHC. 


\subsection{Brief Histories of Wastes Stored in C-109 and C-112}

To date, wastes stored in Hanford Site Tanks C-109 and C-112, listed on the Ferrocyanide Tank Safety Watch List (Hanlon 1994), have been sampled for physical, chemical, and radiochemical characterization. Several wastes have been introduced and removed from these two tanks, potentially affecting the compositions of the wastes stored in them. Their histories are thus important to the expected compositions.

These two tanks have similar pasts, which began with the generation of ferrocyanide waste using the INFARM radiocesium scavenging process. This section provides a brief history of these tanks. Simpson, Borsheim, Jensen (1993a and 1993b), and Agnew (1993) offer more extensive histories.

Both tanks were the third in a cascade in the $\mathrm{C}$ tank farm. Agnew states that these tanks first received first- and second-cycle $\mathrm{BiPO}_{4}$ wastes, unlike the $\mathrm{C}-101$ through $\mathrm{C}-103$ and $\mathrm{C}-104$ through C-106 cascades, which received wastes from U-Plant operations. Thus C-109 and C-112 would initially have had low activity (fission product) levels. Because there was little uranium in C-109 and $\mathrm{C}-112$, these tanks were not included in the uranium recovery campaign. Instead they became settling and storage facilities for ferrocyanide during the cesium scavenging campaign. The third major campaign for $\mathrm{C}$ farm involved cesium and strontium recovery (B-Plant operation). Agnew's survey suggests that these wastes were directed to tanks C-101 through C-106, but it is possible that all received some. He further indicates that these were low-level B-Plant wastes; some supernate from the B-Plant process apparently went to the C-110 cascade.

Many C-farm tanks later received PUREX aluminum cladding waste and organic wash wastes. Other details for tanks C-109 and C-112 are described below.

\subsection{Contents of Tank C-109}

Bismuth phosphate first-decontamination-cycle wastes were added from 1946 to 1952 . The supernate was removed and replaced with unscavenged uranium recovery wastes in 1953 . The solids at this point contained aluminum, bismuth, phosphate, uranium, and iron with relatively low heat-producing constituents. The tank was next used in 1956 for settling the ferrocyanide scavenging waste, from which the supernate was sent to cribs. After two years, in 1958, the solids content was calculated to be $220 \mathrm{~kL}$ ( $44.5 \mathrm{~cm}$ in depth) out of a total waste volume of $414 \mathrm{~kL}$. Solids estimates by the waste farm operators vary considerably for this period of time.

The ferrocyanide wastes deposited in C-109 were typically created by treating the waste solution with $0.005 \underline{M}$ ferrocyanide and nickel; if the analysis of the feed solution indicated a high radiostrontium level, calcium nitrate was added to scavenge the strontium by co-precipitating it with calcium phosphate. Occasionally, the ${ }^{60} \mathrm{Co}$ was scavenged by co-precipitation with nickel sulfide.

Cladding wastes and tank evaporator bottoms were added during 1957 through 1960 , providing a volume of $521 \mathrm{~kL}$ with an estimated solids content of $340 \mathrm{~kL}$, or $71 \mathrm{~cm}$. Small transfers containing high concentrations of ${ }^{90} \mathrm{Sr}$ were added in 1962, as was waste from the strontium semiworks/hot semiworks, bringing the total waste volume up to $2.03 \mathrm{ML}$. The solids volume data at this point seem 
rather uncertain, probably in the vicinity of 230 to $420 \mathrm{~kL}$ (roughly 51 to $89 \mathrm{~cm}$ ). Agnew's (1993) analysis of the data shows $167 \mathrm{~kL}$ of INFARM ferrocyanide waste layered on top of $38 \mathrm{~kL}$ of solids from first-cycle $\mathrm{BiPO}_{4}$ wastes. Assuming little mixing, the PUREX cladding waste solids would be the top layer. Core analyses (Simpson et al. 1993a, 1993b) suggest that mixing of the layers occurred.

In 1970, 1.5 ML of waste was removed and replaced with 1.4 ML of PUREX cladding and B-Plant wastes; in 1975, 1.39 ML of waste was removed. In 1976, the tank was removed from service, then salt well pumped through the third quarter of 1977 to remove free liquid; the tank was inactive thereafter. The final solids volume of $240 \mathrm{~kL}$ is slightly greater $(\sim 23 \mathrm{~kL})$ than the estimated volume of ferrocyanide waste added to the tank.

\subsection{Contents of Tank C-112}

Based on Simpson et al. (1993a) and Anderson (1990), C-112 apparently received waste from six or more different processes starting with the $\mathrm{BiPO}_{4}$ process first- and second-cycle waste in 1946. Although this tank was the third in a cascade, it was not normally used in this mode. The initial waste, along with added unscavenged uranium recovery waste, was removed starting in 1955, and the tank was used for direct transfer of ferrocyanide scavenging waste. The INFARM radiocesium scavenging process was used. Concurrently, scavenging of strontium by co-precipitating with calcium phosphate and cobalt by co-precipitating with nickel sulfide was probably performed occasionally, but the records do not show the details. Records suggest (Anderson 1990) that from 1960 to 1964, the solids were about $14 \mathrm{~kL}(36 \mathrm{~cm})$ and did not change with a small amount of cladding waste added. Hot strontium semiworks waste comprised the first new major solids addition and brought the liquid level up to about $1.6 \mathrm{ML}$, including $740 \mathrm{~kL}(200 \mathrm{~cm})$ of solids. Considerable ${ }^{90} \mathrm{Sr}$ was probably added at this time.

In 1970 , about $1.3 \mathrm{ML}(270 \mathrm{~cm})$ was transferred out, leaving a heel of at least $150 \mathrm{~cm}$. This heel presumably contained most of the ferrocyanide sludge and the solids layer was estimated at $380 \mathrm{~kL}$ $(100 \mathrm{~cm})$. Also in 1970, 1.2 ML of B-plant waste was added, increasing the waste stored in C-112 by $250 \mathrm{~cm}$. A small amount of drainage from the C-301 catch tank also was added to $\mathrm{C}-112$. The layering calculated by Agnew was $61 \mathrm{~kL}$ of uranium recovery sludge, $250 \mathrm{~kL}$ of ferrocyanide sludge, 4 $\mathrm{kL}$ of unknown material, $80 \mathrm{~kL}$ of cladding waste, and an undetermined but probably small amount of hot semiworks material.

The drainable liquid was pumped out in 1975 and 1976, and may have included some of the cladding waste solids. The cladding waste had a high $\mathrm{pH}$ and may have had some contact with the underlying ferrocyanide sludge; it is improbable, however, that the solids actually mixed. Because no deliberate mixing occurred in this tank, it is quite likely that the ferrocyanide sludge remained near the bottom of the tank, layered over or partially mixed with the uranium recovery sludge.

\subsection{Sampling and Analysis Strategy for Wastes from C-112 and C-109}

The WHC sampling strategy used for these two Hanford underground storage tanks (USTs) containing ferrocyanide waste was to obtain two samples from each tank near the waste inlet and one from the opposite side of the tank using existing penetrations (risers) in the roof of the tank. Waste in C-112 was sampled first with cores 35 and 36 taken from near the inlet and core 34 taken from the opposite 
side of the tank (Simpson et al. 1993a). From C-109, cores 47 and 48 were taken from near the waste inlet, and core 49 was taken from the opposite side (Simpson et al. 1993b).

Because of the safety concerns with respect to these wastes, and the potential for layering of the wastes added to the tank, a special characterization strategy was used. In this strategy, homogenized composite solid and liquid samples and homogenized quarter segments of each core were analyzed. The labeling system for each sample was to identify the uppermost segment as 1 , with each lower segment identifier incremented by 1 . The quarter-segment labeling scheme was to identify the uppermost quarter segment as A, with each lower $12.1-\mathrm{cm}$ quarter segment identified with the succeeding letter. The same identification scheme is used in this report.

\subsection{Samples Taken from C-112 and C-109}

In early 1992, WHC obtained three core samples from Tank C-112. The cores were taken through risers on the outer perimeter of the tank. It was expected, based on historical records, that each core would consist of two 48-cm segments. Cores 34 and 36 each consisted of two partial segments; however, core 35 consisted of only one partial segment. Recoveries were: for each segment in core 34,87 and $75 \%$ of expected; for core 35,0 and $35 \%$; and for core 36,65 and $91 \%$ of expected.

In the third quarter of 1992 , WHC obtained three core samples from Tank C-109 using the pushmode core sampler truck. The cores were taken through risers on the outer perimeter of the tank. Each core was expected to contain slightly less than one full segment $(46 \mathrm{~cm})$ of waste. This effort resulted in three partial cores, 47,48 , and 49 , containing 65,30 , and $90 \%$ of expected waste, respectively. 


\subsection{Preparation of INFARM Simulants}

To evaluate, in the absence of actual waste samples, the potential reactivity hazards associated with storage of highly radioactive, ferrocyanide-bearing waste, WHC prepared several different ferrocyanide waste simulants by scavenging simulated feeds using the U-Plant, INFARM, and T-Plant flowsheets that were used in the 1950s (Jeppson and Wong 1993).

These three basic flowsheets were used to remove radiocesium from different Hanford aqueous wastes. The U-Plant flowsheet was used to decontaminate the acidic solution of uranium recovery waste from the U-Plant. The T-Plant flowsheet was used to decontaminate first-cycle $\mathrm{BiPo}_{4} \mathbf{w a s t e}$. The INFARM flowsheet was used to decontaminate supernate of neutralized uranium recovery waste.

Using three basic flowsheets to treat three different waste types, using different concentrations of the scavenging agents, and often coupling other scavenging processes to remove radiostrontium and radiocobalt resulted in ferrocyanide-bearing wastes having varied compositions. To reflect these variations, WHC prepared large batches of two INFARM flowsheet wastes, two U-Plant flowsheet wastes, and one T-Plant flowsheet waste.

As mentioned in Section 2.0, the ferrocyanide-bearing wastes deposited in these tanks resulted from using the INFARM flowsheet, which employed ferrocyanide treatment at $0.005 \mathrm{M}$ ferrocyanide and nickel. With the INFARM flowsheet, the supernate from neutralized uranium recovery waste was

scavenged, producing a solid waste containing sodium nickel ferrocyanide and an interstitial solution containing nitrate, and traces of sulfate and phosphate. WHC prepared two simulants using variations of the INFARM flowsheet coupled with 1) radiocobalt scavenging and 2) radiostrontium scavenging identified as INFARM-1 and INFARM-2, respectively; these simulants should be representative of two of the INFARM processing campaigns. The composition of the simulated feed solutions and the scavenging agent treatment level are presented in Table 3.1. The simulant INFARM-2 should be representative of ferrocyanide-bearing waste deposited in C-112 and C-109.

At the times that these INFARM ferrocyanide wastes were generated, nitrite was likely not a major constituent in the feed stream (Smith and Coppinger 1954). However, as Bell (1993) and Sprouse (1993) found, nitrite is now a major constituent. Though small amounts of nitrite are added to the tank wastes as a corrosion inhibitor, most of the large amount present in tank wastes arises from radiolysis of nitrate. To simulate its presence in the simulant, sodium nitrite was added to the simulated feed using the assumption that a quarter of the nitrate was converted to nitrite during the over 30 years of storage. The nitrite concentration used to prepare the simulants is nominally typical of nitrite concentrations found in Hanford Site radioactive wastes.

Using the compositions of the feed solutions, the measured densities of the supernates, and the measured water contents, assuming that the solids formed were sodium nickel ferrocyanide with traces of cesium, nickel sulfide, and calcium phosphate (depending on the flowsheet used), and assuming that the interstial solution had the composition of the simulated feed, we estimated compositions for the dry INFARM-1 and INFARM-2 simulated ferrocyanide wastes. Table 3.2 presents the predicted and the measured compositions on a dry basis for the top and bottom centrifuged solid fractions for these two simulants. The INFARM simulants were dried at $60^{\circ} \mathrm{C}$ for 18 hours under a vacuum (Jeppson and Wong 1993). 
The relatively good agreement between the predicted and measured compositions shown in Table 3.1 for the INFARM simulants indicates that the scavenging process behaves as expected. Based on this, the INFARM simulants should be representative of freshly prepared ferrocyanide wastes that were generated by the INFARM ferrocyanide radiocesium scavenging processes, assuming that the simulated feed is representative of the actual feed solutions.

Table 3.1. Recipes for Preparation of Simulated INFARM Flowsheet Wastes (Jeppson and Wong 1993)

\begin{tabular}{|c|c|c|}
\hline Material & Concentration, $\underline{\mathbf{M}}$ & Concentration, $\underline{\mathrm{M}}$ \\
\hline Feed Solution & INFARM-1 & INFARM-2 \\
\hline $\mathrm{NaNO}_{3}$ & 4.5 & 3.75 \\
\hline $\mathrm{NaNO}_{2}$ & 1.5 & 1.25 \\
\hline $\mathrm{Na}_{2} \mathrm{SO}_{4}$ & 0.23 & 0.17 \\
\hline $\mathrm{Na}_{3} \mathrm{PO}_{4}$ & 0.27 & 0.16 \\
\hline $\mathrm{CsNO}_{3}$ & $3.7 \times 10^{-4}$ & $2.5 \times 10^{-4}$ \\
\hline Scavenging Agents & Addition Level & Addition Level \\
\hline $\mathrm{Na}_{4} \mathrm{Fe}(\mathrm{CN})_{6}$ & 0.0075 & 0.005 \\
\hline $\mathrm{NiSO}_{4}$ & 0.01 & 0.005 \\
\hline $\mathrm{Na}_{2} \mathrm{~S}$ & 0.003 & 0 \\
\hline $\mathrm{Ca}\left(\mathrm{NO}_{3}\right)_{2}$ & 0 & 0.164 \\
\hline
\end{tabular}

Table 3.2. Comparison of Predicted and Measured Compositions of WHC-Prepared INFARM Flowsheet Waste Simulants on a Dry Basis

\begin{tabular}{|c|c|c|c|c|c|c|}
\hline Element/ Anion & $\begin{array}{c}\text { Predicted } \\
\text { INFARM-1, } \\
\text { wt } \% \text { (a) }\end{array}$ & $\begin{array}{l}\text { Measured } \\
\text { INFARM-1 } \\
\text { Top, wt \%(o) }\end{array}$ & $\begin{array}{c}\text { Measured } \\
\text { INFARM-1 } \\
\text { Bottom, wt\% (b) }\end{array}$ & $\begin{array}{c}\text { Predicted } \\
\text { INFARM-2, } \\
\text { wt\% (0) }\end{array}$ & $\begin{array}{l}\text { Measured } \\
\text { INFARM-2 } \\
\text { Top, wt \% (b) }\end{array}$ & $\begin{array}{c}\text { Measured INFARM- } \\
2 \text { Bottom, wt } \%^{(b)}\end{array}$ \\
\hline $\mathbf{N a}$ & 25 & 17 & 17 & 21 & 22 & 20 \\
\hline $\mathrm{NO}_{3}$ & 36 & 29 & 29 & 29 & 27 & 25 \\
\hline $\mathrm{NO}_{2}$ & 9.0 & 8.2 & 7.6 & 7.1 & 7.3 & 6.3 \\
\hline $\mathrm{SO}_{4}$ & 3.0 & 2.5 & 2.6 & 2.1 & 2.0 & 2.3 \\
\hline $\mathrm{PO}_{4}$ & 3.4 & 1.9 & 2.4 & 3.2 & 2.2 & 2.0 \\
\hline $\mathrm{Ca}$ & 0.0 & Not Reported & Not Reported & 0.8 & Not Reported & Not Reported \\
\hline $\mathbf{N i}$ & 4.9 & 5 & 6.8 & 6.1 & 4.1 & 4.5 \\
\hline $\mathrm{Fe}$ & 3.3 & 3.5 & 4.9 & 5.8 & 3.8 & 4 \\
\hline $\mathrm{CN}$ & 9.3 & 9.0 & 13 & 16 & 9.1 & 11 \\
\hline $\mathbf{S}$ & 0.8 & Not Reported & Not Reported & 0 & Not Reported & Not Reported \\
\hline $\mathrm{Cs}$ & 0.39 & 0.3 & 0.4 & 0.69 & 0.5 & 0.5 \\
\hline TOC & 4.3 & Not Reported & Not Reported & 7.5 & Not Reported & Not Reported \\
\hline Bound $\mathrm{H}_{2} \mathrm{O}^{(*)}$ & 4.9 & 5.8 & 5.4 & 8.6 & 5.6 & 5.9 \\
\hline
\end{tabular}

\footnotetext{
(a) Assumes $50 \mathrm{wt} \%$ water in undried sludge and interstitial solution densities of 1.33 and $1.27 \mathrm{~g} / \mathrm{mL}$ for INFARM-1 and INFARM-2 supernates, respectively.

(b) Jeppson and Simpson 1994

(c) Assumes $4.6 \mathrm{H}_{2} \mathrm{O}$ 's per mole of ferrocyanide.
} 


\subsection{Chemical and Radiochemical Properties of INFARM-2 Simulated Waste and Wastes From C-109 and C-112}

The chemical composition and radiochemical content of the waste will determine the potential chemical reactivity hazards associated with the stored Hanford ferrocyanide wastes. In addition, the location and concentration of characteristic elements and chemicals will also provide insight into how the ferrocyanide waste was distributed throughout a tank, and whether it has mixed with other wastes added to a tank. The chemical composition, in particular the ferrocyanide and nitrate/nitrite content, will determine the maximum reaction rate the mixture will reach if a reaction were to be initiated thermally or by some other unknown mechanism. Experimental studies performed at PNL (Burger and Scheele 1991; Hallen et al. 1992; Scheele et al. 1992a; Scheele et al. 1992b; Scheele et al. 1992c; Scheele et al. 1993) and by Fauske \& Associates (Jeppson and Wong 1993) have shown that mixtures of ferrocyanide and the oxidants nitrate and/or nitrite can react rapidly depending on the composition and water content. The work by Scheele et al. (1993) investigating the effects of diluents and other potential wastes constituents found that mixtures of sodium nickel ferrocyanide and sodium nitrate and/or nitrite will not explode if sufficient sodium aluminate is present.

Theoretically, the maximum rate should occur for a near-stoichiometric mixture of fuel and oxidant, because there is no excess material to absorb the heat produced by the exothermic reaction(s). Thus, all of the heat produced goes into heating the reaction mixture which, if the reaction follows Arrhenius behavior, will increase exponentially with temperature. The rate is thus dependent on the concentration of the fuel ferrocyanide, the oxidant or oxidants, diluents such as water or sodium aluminate or sodium nitrate, and other materials that can act as catalysts or initiators. Water, because of its high heat capacity and high heat of vaporization, will act as one of the strongest mitigating factors for the prevention of a self-sustaining and self-heating reaction and/or a propagating reaction.

Given that the Hanford Site ferrocyanide wastes were created in the early to late 1950 s, the chemical composition of the actual waste relative to the predicted and simulant compositions will provide insight on whether the cyanide has been consumed via chemical or radiolytic reactions. With respect to tracking the cyanide in the wastes generated by INFARM processes, nickel, iron, cyanide, and radiocesium will provide a guide for where the ferrocyanide once was located or whether it was ever where the sample was taken.

In this section we compare the measured chemical compositions of the INFARM-2 simulant (Jeppson and Wong 1993; Jeppson and Simpson 1994) and those of the core sample composite and quarter segments taken from the various locations in Tanks C-112 and C-109 (Bell 1993; Sprouse 1993), and we present and discuss radioisotope concentrations. In addition, the water solubility of the radiocesium in the samples is presented, because it should also serve as an indication whether an insoluble cesium compound such as cesium nickel ferrocyanide existed in that location.

A variety of analytical methods to measure selected chemical properties of the simulants and the wastes from C-112 and C-109. Selected elements were analyzed using inductively coupled argon plasma (ICP)/atomic emission spectroscopy (AES) (ICP/AES); uranium was measured also using laser fluorescence (LF). Ion chromatography (IC) was used to measure anion concentrations after leaching with water; total cyanide was measured using the method developed by Pool (1994). Radiochemical 
contents were measured using gamma energy analysis (GEA), alpha energy analysis (AEA), and beta particle analysis after selective separation from other beta and gamma emitters.

Given the importance of nickel as a characteristic of ferrocyanide wastes, it should be mentioned that the nickel concentrations in C-112 and C-109 samples may be biased high. The solid waste samples were analyzed for nickel using ICP/AES after the material had been fused with potassium hydroxide in a nickel crucible. M. W. Urie, Group Leader of PNL's Inorganic Chemistry Analytical Group, believes that the nickel analyses are not biased much since the solution resulting from a blank fusion contained negligible amounts of nickel relative to the amounts found in the wastes. Original plans for activities in 1994 were to reanalyze available samples using a zirconium or non-nickel crucible; however, operational problems prevented the reanalysis. It is therefore recommended that these analyses be performed to eliminate concerns about the potential high bias.

\subsection{Comparison of Chemical Compositions}

In this section we present the measured elemental and anion concentrations (mmol/g) found in the wastes from C-112 and C-109 and the INFARM-2 simulant; elemental and anion concentration in wt\% are presented in Appendices A and B for C-109 and C-112, respectively. This section will focus on nickel, iron, cyanide, nitrate, and nitrite; the tables also include other constituents for the reader's information. Nickel is characteristic of ferrocyanide wastes or of radiocobalt scavenging wastes that were produced in conjunction with ferrocyanide wastes; traces of nickel may be present in wastes from corrosion of steel equipment. Iron has more sources, including corrosion of steel pipes, vessels, and other processing equipment, the ferrocyanide scavenging processes, the uranium recovery process, and the PUREX process. Cyanide, of course, was added during the ferrocyanide scavenging campaigns and has no other known source. Cesium is another element that would provide information on the location of the ferrocyanide wastes in C-109 and C-112; although it was not measured chemically, radiocesium was measured.

\subsubsection{Comparison of INFARM-2 and C-109 Chemical Compositions}

As discussed in Section $2.0, \mathrm{C}-109$ contains about $51 \mathrm{~cm}$ of waste, with the bottom $8 \mathrm{~cm}$ from first-cycle $\mathrm{BiPO}_{4}$ process waste, the next $35 \mathrm{~cm}$ from radiocesium scavenging waste produced using the INFARM flowsheet, and the final $8 \mathrm{~cm}$ a mix of wastes from the strontium semiworks and PUREX aluminum cladding removal waste. The $\mathrm{BiPO}_{4}$ waste would be characterized by aluminum, bismuth, phosphate, uranium, and iron. The ferrocyanide waste would be characterized by nickel, iron, and cyanide and, if coupled with radiostrontium scavenging, calcium and phosphate; if coupled with radiocobalt scavenging, additional nickel. The cladding removal waste would be characterized by aluminum.

Tables 4.1 through 4.6 present comparisons of the elemental and anion concentrations found in the top and bottom centrifuge fractions of an INFARM-2 simulated ferrocyanide waste and the wastes obtained from $\mathrm{C}-109$ by cores 47,48 , and 49 . The results are reported on a dry basis using the water content determined gravimetrically by drying at $60^{\circ} \mathrm{C}$ for $24 \mathrm{~h}$ under a vacuum, presumably a house vacuum. A concentration of 0 is used to indicate those elements and anions that were not added to INFARM-2. It should be remembered that the reported nickel concentrations are based on analyses of 
Table 4.1. Comparison of Element Concentrations on a Dry Basis (as Measured by ICP) of INFARM-2 Simulant with Waste from C-109 (Core 47) (Jeppson and Simpson 1994; Sprouse 1993)

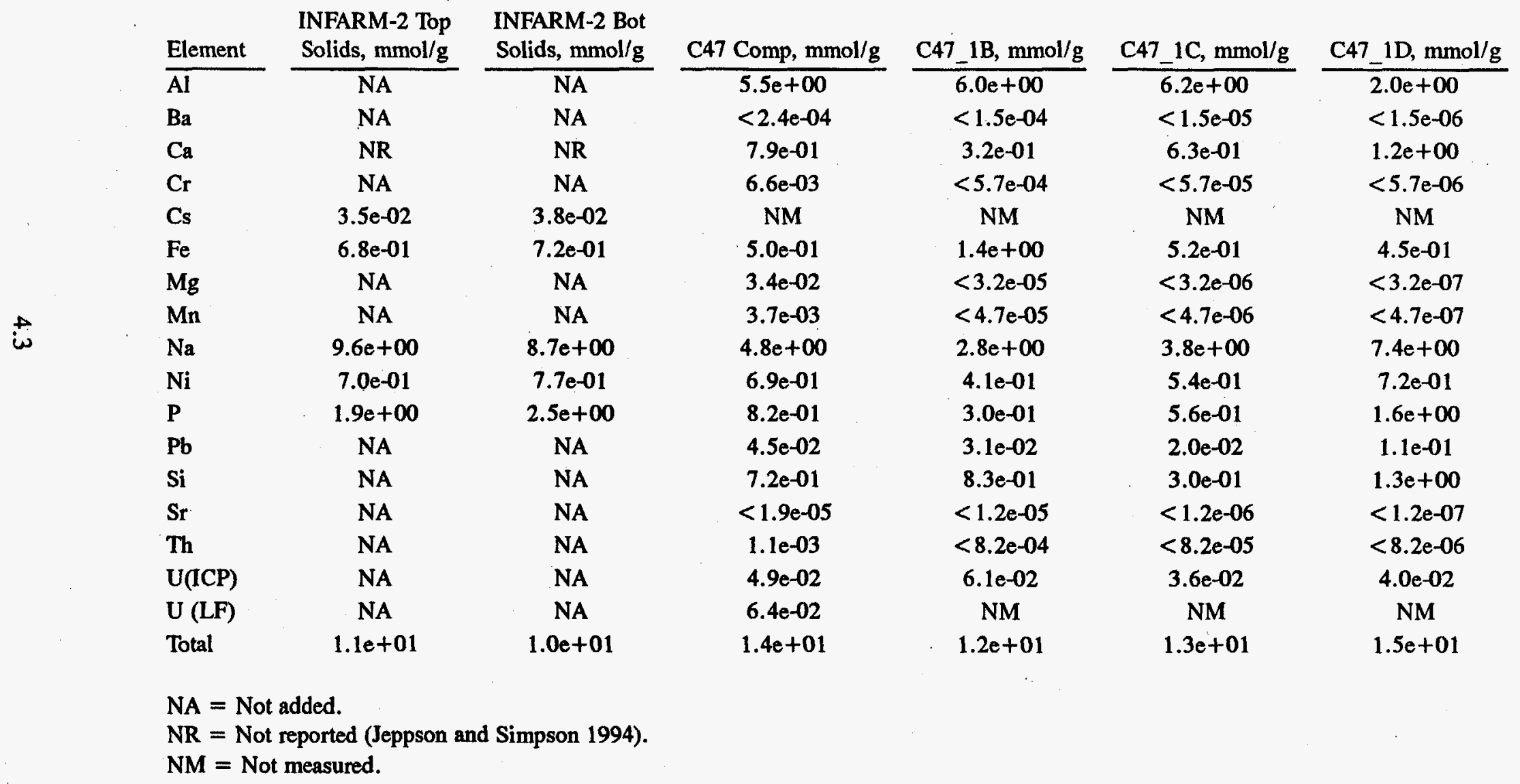


Table 4.2. Comparison of Anion Concentrations on a Dry Basis in INFARM-2 Simulants and Wastes from C-109 (Core 47) (Jeppson and Wong 1993; Sprouse 1993)

\begin{tabular}{|c|c|c|c|c|c|c|}
\hline Analyte & $\begin{array}{l}\text { INFARM-2 } \\
\text { Top, mmol/g }\end{array}$ & $\begin{array}{c}\text { INFARM-2 } \\
\text { Bot, mmol/g }\end{array}$ & $\begin{array}{c}\text { Composite, } \\
\mathrm{mmol} / \mathrm{g}\end{array}$ & $\begin{array}{l}\mathrm{C} 47 \_1 \mathrm{~B} \\
\mathrm{mmol} / \mathrm{g}\end{array}$ & $\begin{array}{l}\mathrm{C} 47 \_1 \mathrm{C} \\
\mathrm{mmol} / \mathrm{g}\end{array}$ & $\begin{array}{c}\mathrm{C} 47 \_1 \mathrm{D}, \\
\mathrm{mmol} / \mathrm{g}\end{array}$ \\
\hline$\overline{\mathrm{NO}_{3}^{-}}$ & $4.4 e+00$ & $4.0 e+00$ & $7.6 e-01$ & $5.5 e-01$ & $8.1 e-01$ & $1.0 \mathrm{e}+00$ \\
\hline $\mathrm{NO}_{2}^{-}$ & $1.6 e+00$ & $1.4 \mathrm{e}+00$ & $1.1 \mathrm{e}+00$ & $7.5 e-01$ & $1.1 e+00$ & $1.4 \mathrm{e}+00$ \\
\hline $\mathrm{PO}_{4}^{3-}$ & $2.1 \mathrm{e}-01$ & $2.4 e-01$ & $3.0 e-01$ & $9.5 e-02$ & $1.4 \mathrm{e}-01$ & $7.7 e-01$ \\
\hline $\mathrm{SO}_{4}^{2-}$ & $2.3 e-01$ & $2.1 \mathrm{e}-01$ & $9.7 \mathrm{e}-02$ & $6.6 e-02$ & $1.0 \mathrm{e}-01$ & $1.3 e+00$ \\
\hline $\mathrm{CN}^{-(a)}$ & NM & NM & $4.0 \mathrm{e}-02$ & $2.7 \mathrm{e}-02$ & $4.5 e-02$ & $5.8 \mathrm{e}-02$ \\
\hline \multicolumn{7}{|l|}{ Total } \\
\hline $\mathrm{CN}^{-(\mathrm{b})}$ & $3.5 e+00$ & $4.3 e+00$ & $2.1 \mathrm{e}-01$ & $1.2 \mathrm{e}-01$ & $1.7 \mathrm{e}-01$ & $2.2 \mathrm{e}-01$ \\
\hline $\mathrm{Cl}^{-}$ & NA & NA & $2.5 \mathrm{e}-02$ & $2.1 \mathrm{e}-02$ & $2.8 \mathrm{e}-02$ & $3.7 \mathrm{e}-02$ \\
\hline $\mathrm{F}^{-}$ & NA & NA & $2.7 \mathrm{e}-02$ & $2.0 \mathrm{e}-02$ & $2.2 \mathrm{e}-02$ & $2.6 \mathrm{e}-02$ \\
\hline TOC & NM & $\mathrm{NM}$ & $2.4 \mathrm{e}-01$ & $2.3 e-01$ & $2.3 e-01$ & $3.0 \mathrm{e}-01$ \\
\hline $\mathrm{CO}_{3}^{2-(c)}$ & NM & NM & $1.2 \mathrm{e}-01$ & $0.0 e+00$ & $0.0 e+00$ & $7.4 \mathrm{e}-02$ \\
\hline $\mathrm{HCO}_{3}^{-(c)}$ & NM & NM & $0.0 \mathrm{e}+00$ & $1.1 \mathrm{e}-01$ & $1.2 \mathrm{e}-01$ & $7.3 e-02$ \\
\hline Total & $9.9 e+00$ & $1.0 \mathrm{e}+01$ & $2.9 e+00$ & $2.0 e+00$ & $2.7 e+00$ & $5.2 e+00$ \\
\hline
\end{tabular}

(a) Water soluble cyanide as measured by IC.

(b) Cyanide content as determined using Total Cyanide Method (Pool 1994).

(c) Carbonate and bicarbonate measured as total inorganic carbon. The distribution between the two based on $\mathrm{pH}$.

solutions obtained after fusing the sample in a nickel crucible, which may bias the reports high; it should also be remembered that a blank fusion in a nickel crucible contained insignificant concentrations of nickel.

Table 4.1 for core 47 from C-109 shows that the major elemental constituents in this waste sample are aluminum, calcium, iron, sodium, nickel, phosphorus, and silicon. The high concentration of aluminum throughout the subsegment samples indicates that the aluminum cladding waste was mixed with the ferrocyanide wastes that should be present in subsegments $1 \mathrm{C}, 1 \mathrm{~B}$, and part of $1 \mathrm{D}$. The high calcium and phosphorus concentrations could be due to radiostrontium scavenging; the phosphorus could be from the bismuth phosphate waste present in the tank, or a combination of the two, as the highest phosphorus concentration is found in the bottom segment, which is where the bismuth phosphate waste should be located based on historical records. Bismuth would be an indicator for bismuth phosphate waste, but the samples were not analyzed for bismuth.

The similarities between the elemental composition of the core 47 composite sample and the INFARM-2 samples indicate that the waste as predicted by history was principally ferrocyanide waste. This comparison also indicates that other waste types are present in C-109 both from the presence of elements not expected in ferrocyanide wastes and the lower-than-predicted concentrations of iron and nickel. 
Table 4.3. Comparison of Element Concentrations on a Dry Basis (as Measured by ICP) of INFARM-2 Simulant with Waste from Core 48 Taken from C-109 (Jeppson and Simpson 1994; Sprouse 1993)

\begin{tabular}{|c|c|c|c|c|c|}
\hline Element & $\begin{array}{l}\text { INFARM-2 Top } \\
\text { Solids, } \mathrm{mmol} / \mathrm{g}\end{array}$ & $\begin{array}{l}\text { INFARM-2 Bot } \\
\text { Solids, } \mathrm{mmol} / \mathrm{g}\end{array}$ & $\begin{array}{c}\text { C48_Comp, } \\
\mathrm{mmol} / \mathrm{g}\end{array}$ & $\begin{array}{c}\mathrm{C} 48 \_1 \mathrm{C} \\
\mathrm{mmol} / \mathrm{g}\end{array}$ & $\begin{array}{c}\text { C48_1D, } \\
\mathrm{mmol} / \mathrm{g}\end{array}$ \\
\hline$\overline{\mathrm{Al}}$ & $\overline{\mathrm{NA}}$ & $\overline{\mathrm{NA}}$ & $4.1 e-01$ & $3.8 \mathrm{e}-01$ & $6.0 e-01$ \\
\hline $\mathrm{Ba}$ & NA & NA & $<1.5 \mathrm{e}-04$ & $<1.2 \mathrm{e}-04$ & $<1.2 \mathrm{e}-05$ \\
\hline $\mathrm{Ca}$ & NR & NR & $5.6 \mathrm{e}-01$ & $1.0 \mathrm{e}+00$ & $6.9 e-01$ \\
\hline $\mathrm{Cr}$ & NA & NA & $<5.6 \mathrm{e}-04$ & $<4.6 \mathrm{e}-04$ & $<4.6 \mathrm{e}-05$ \\
\hline Cs & $3.5 e-02$ & $3.8 \mathrm{e}-02$ & NM & $\mathbf{N M}$ & NM \\
\hline $\mathrm{Fe}$ & $6.8 \mathrm{e}-01$ & $7.2 e-01$ & $5.1 e-01$ & $5.0 e-01$ & $6.2 e-01$ \\
\hline Mg & NA & NA & $<3.2 \mathrm{e}-05$ & $<2.6 e-05$ & $<2.6 \mathrm{e}-06$ \\
\hline $\mathrm{Mn}$ & NA & NA & $<4.7 \mathrm{e}-05$ & $<3.9 \mathrm{e}-05$ & $<3.9 \mathrm{e}-06$ \\
\hline $\mathrm{Na}$ & $9.6 e+00$ & $8.7 e+00$ & $5.5 e+00$ & $7.0 \mathrm{e}+00$ & $7.3 e+00$ \\
\hline $\mathrm{Ni}$ & $7.0 \mathrm{e}-01$ & $7.7 e-01$ & $7.2 \mathrm{e}-01$ & $1.1 \mathrm{e}+00$ & $6.7 e-01$ \\
\hline $\mathbf{P}$ & $1.9 e+00$ & $2.5 e+00$ & $8.3 e-01$ & $1.1 e+00$ & $1.1 e+00$ \\
\hline $\mathrm{Pb}$ & NA & NA & $4.3 e-03$ & $3.7 e-03$ & $5.5 e-03$ \\
\hline $\mathrm{Si}$ & NA & NA & $1.0 \mathrm{e}-01$ & $1.4 \mathrm{e}-01$ & $1.3 e-01$ \\
\hline $\mathrm{Sr}$ & NA & NA & $<1.2 \mathrm{e}-05$ & $<9.7 e-06$ & $<9.7 \mathrm{e}-07$ \\
\hline $\mathrm{Th}$ & NA & NA & $<8.2 \mathrm{e}-04$ & $<6.7 \mathrm{e}-04$ & $<6.7 e-05$ \\
\hline U (ICP) & NA & NA & $1.3 \mathrm{e}-01$ & $9.8 e-02$ & $1.0 e-01$ \\
\hline U (LF) & NA & NA & $1.5 \mathrm{e}-01$ & NM & NM \\
\hline Total & $1.1 e+01$ & $1.0 \mathrm{e}+01$ & $8.8 e+00$ & $1.1 e+01$ & $1.1 e+01$ \\
\hline
\end{tabular}

NA $=$ Not added

NR $=$ Not reported (Jeppson and Simpson).

$\mathrm{NM}=$ Not measured.

The concentrations of nickel and iron in the subsegments of core 47 indicate a distribution different than predicted based on history. The bottom segment has the highest concentration of nickel, which is a defining characteristic of the ferrocyanide waste; the amount is very near the level in the simulant. Based on history, the bottom segment should be about one-third by volume ferrocyanide waste. The iron concentration is highest in subsegment $1 \mathrm{~B}$, which should be ferrocyanide waste; the concentration is roughly twice that in the simulant. If the composite were prepared from equal quantities of waste from the subsegments, the concentration should be $0.8 \mathrm{mmol} / \mathrm{g}$, which is slightly higher than measured in the composite; this difference suggests nonhomogeneous samples or a need to re-analyze the sample.

Table 4.2 compares the anion concentrations found in INFARM-2 simulant, and in the core 47 composite and its individual subsegments obtained from C-109. Comparison of the anion concentrations in the core 47 composite with those found in the simulant shows significantly less nitrate and nitrite in the actual waste with the nitrate-to-nitrite ratio reversed; the phosphate concentration is comparable; the total cyanide concentration is about $5 \%$ of that in the simulant. 
Table 4.4. Comparison of Anion Concentrations on a Dry Basis in INFARM-2 Simulants and Wastes from C-109 (Core 48) (Jeppson and Wong 1993; Sprouse 1993)

\begin{tabular}{|c|c|c|c|c|c|}
\hline Analyte & $\begin{array}{c}\text { INFARM-2 Top, } \\
\mathrm{mmol} / \mathrm{g}\end{array}$ & $\begin{array}{l}\text { INFARM-2 Bot, } \\
\text { mmol/g }\end{array}$ & Composite, $\mathrm{mmol} / \mathrm{g}$ & $\mathrm{C} 48 \_1 \mathrm{C}, \mathrm{mmol} / \mathrm{g}$ & $\mathrm{C} 48 \_1 \mathrm{D}, \mathrm{mmol} / \mathrm{g}$ \\
\hline $\mathrm{NO}_{3}^{-}$ & $4.4 e+00$ & $4.0 \mathrm{e}+00$ & $1.8 \mathrm{e}+00$ & $1.9 \mathrm{e}+00$ & $1.8 \mathrm{e}+\infty$ \\
\hline $\mathrm{NO}_{2}^{-}$ & $1.6 \mathrm{e}+00$ & $1.4 e+00$ & $2.3 e+00$ & $2.3 e+00$ & $2.2 \mathrm{e}+\infty$ \\
\hline $\mathrm{PO}_{4}^{2-2}$ & $2.1 \mathrm{e}-01$ & $2.4 \mathrm{e}-01$ & $6.6 e-01$ & $3.6 \mathrm{e}-01$ & $7.8 \mathrm{e}-01$ \\
\hline $\mathrm{SO}_{4}^{2-}$ & $2.3 e-01$ & $2.1 e-01$ & $2.3 e-01$ & $2.4 \mathrm{e}-01$ & $2.2 e-01$ \\
\hline $\mathrm{CN}^{-(2)}$ & NM & NM & $1.2 \mathrm{e}-01$ & $1.2 \mathrm{e}-01$ & $1.1 e-01$ \\
\hline Total $\mathrm{CN}^{-(\mathrm{b})}$ & $3.5 e+00$ & $4.3 e+00$ & $5.5 e-01$ & $4.3 e-01$ & $3.3 e-01$ \\
\hline $\mathrm{Cl}^{-}$ & NA & NA & $5.3 e-02$ & $5.7 e-02$ & $5.8 \mathrm{e}-02$ \\
\hline $\mathrm{F}^{-}$ & NA & NA & $1.6 \mathrm{e}-01$ & $5.6 \mathrm{e}-02$ & $8.2 \mathrm{e}-02$ \\
\hline TOC & NM & NM & $6.1 e-01$ & $6.5 e-01$ & $6.0 e-01$ \\
\hline $\mathrm{CO}_{3}^{2-(c)}$ & NM & NM & $1.1 \mathrm{e}-01$ & $0.0 \mathrm{e}+00$ & $2.6 \mathrm{e}-01$ \\
\hline $\mathrm{HCO}_{3}^{-(c)}$ & NM & NM & $1.1 \mathrm{e}-01$ & $3.0 \mathrm{e}-01$ & $0.0 e+\infty 0$ \\
\hline Total & $9.9 e+00$ & $1.0 e+01$ & $6.6 e+00$ & $6.4 e+\infty 0$ & $6.4 e+\infty 0$ \\
\hline
\end{tabular}

(a) Water soluble cyanide as measured by IC.

(b) Cyanide content as determined using Total Cyanide Method (Pool 1994).

(c) Carbonate and bicarbonate measured as total inorganic carbon. The distribution between the two based on pH.

Table 4.5. Comparison of Element Concentrations on a Dry Basis (as Measured by ICP) of INFARM-2 Simulant with Waste from Core 49 Taken from C-109 (Jeppson and Simpson 1994; Sprouse 1993)

\begin{tabular}{|c|c|c|c|c|c|c|}
\hline Element & $\begin{array}{l}\text { INFARM-2 Top } \\
\text { Solids, } \mathrm{mmol} / \mathrm{g}\end{array}$ & $\begin{array}{l}\text { INFARM-2 Bot } \\
\text { Solids, } \mathrm{mmol} / \mathrm{g}\end{array}$ & $\begin{array}{c}\text { C49_Comp, } \\
\mathrm{mmol} / \mathrm{g}\end{array}$ & $\begin{array}{l}\mathrm{C} 49 \_1 \mathrm{~B} \\
\mathrm{mmol} / \mathrm{g}\end{array}$ & $\begin{array}{l}\mathrm{C} 49_{-1 \mathrm{C}} \\
\mathrm{mmol} / \mathrm{g}\end{array}$ & $\begin{array}{l}\mathrm{C} 49 \_1 \mathrm{D} \\
\mathrm{mmol} / \mathrm{g}\end{array}$ \\
\hline$\overline{\mathrm{AI}}$ & $\overline{\text { NA }}$ & $\overline{\text { NA }}$ & $5.9 e+00$ & $8.5 e+00$ & $5.0 \mathrm{e}+00$ & $4.3 e+\infty 0$ \\
\hline $\mathrm{Ba}$ & NA & NA & $<1.5 e-04$ & $<1.2 \mathrm{e}-04$ & $<1.2 \mathrm{e}-05$ & $<1.20-06$ \\
\hline $\mathrm{Ca}$ & NR & NR & $4.7 e-01$ & $1.3 \mathrm{e}-01$ & $6.50-01$ & $9.3 e-01$ \\
\hline $\mathrm{Cr}$ & NA & NA & $<5.6 \mathrm{e}-04$ & $<4.6 e-04$ & $<4.6 e-05$ & $<4.60-06$ \\
\hline Cs & $3.5 e-02$ & $3.8 \mathrm{e}-02$ & NM & $\mathbf{N M}$ & $\mathbf{N M}$ & NM \\
\hline $\mathrm{Fe}$ & $6.8 \mathrm{e}-01$ & $7.2 \mathrm{e}-01$ & $2.1 \mathrm{e}-01$ & $3.5 e-01$ & $1.2 e-01$ & $4.6 e-01$ \\
\hline $\mathbf{M g}$ & NA & NA & $<3.2 \mathrm{e}-05$ & $<2.6 e-05$ & $<2.60-06$ & $<2.6 \mathrm{e}-07$ \\
\hline $\mathrm{Mn}$ & NA & NA & $<4.7 e-05$ & $<3.9 e-05$ & $<3.9 e-06$ & $<3.90-07$ \\
\hline $\mathrm{Na}$ & $9.6 e+\infty$ & $8.7 e+00$ & $4.2 e+00$ & $2.3 e+\infty$ & $3.8 e+00$ & $6.6 e+00$ \\
\hline $\mathrm{Ni}$ & $7.0 e-01$ & $7.7 e-01$ & $5.00-01$ & $2.30-01$ & $7.6 e-01$ & $8.6 e-01$ \\
\hline $\mathbf{P}$ & $1.9 e+\infty$ & $2.5 e+00$ & $6.0 e-01$ & $1.6 e-01$ & $5.20-01$ & $1.1 e+\infty$ \\
\hline $\mathrm{Pb}$ & NA & NA & $5.0 \mathrm{e}-03$ & $1.2 \mathrm{e}-02$ & $2.5 e-03$ & $5.80-03$ \\
\hline $\mathbf{S i}$ & NA & NA & $1.0 \mathrm{e}-01$ & $1.3 e-01$ & $4.4 e-02$ & $9.9 e-02$ \\
\hline $\mathbf{S} \mathbf{r}$ & NA & NA & $<1.2 \mathrm{e}-05$ & $<9.7 \mathrm{e}-06$ & $<9.7 e-07$ & $<9.7 e-08$ \\
\hline Th & NA & NA & $<8.2 \mathrm{e}-04$ & $<6.7 e-04$ & $<6.7 e-05$ & $<6.7 e-06$ \\
\hline U(ICP) & NA & NA & $2.5 \mathrm{e}-02$ & $4.10-02$ & $7.6 e-03$ & $8.60-02$ \\
\hline $\mathrm{U}(\mathrm{LF})$ & NA & NA & $4.0 e-02$ & NM & NM & $\mathbf{N M}$ \\
\hline Total & $1.1 e+01$ & $1.0 e+01$ & $1.2 e+01$ & $1.2 e+01$ & $1.1 \mathrm{e}+01$ & $1.4 e+01$ \\
\hline
\end{tabular}

NA $=$ Not added.

NR = Not reported (Jeppson and Simpson 1994).

$\mathrm{NM}=$ Not measured. 
Table 4.6. Comparison of Anion Concentrations on a Dry Basis in INFARM-2 Simulants and Wastes from C-109 (Core 49) (Jeppson and Wong 1993; Sprouse 1993)

\begin{tabular}{|c|c|c|c|c|c|c|}
\hline Analyte & $\begin{array}{c}\text { INFARM-2 Top, } \\
\mathrm{mmol} / \mathrm{g}\end{array}$ & $\begin{array}{l}\text { INFARM-2 Bot, } \\
\mathrm{mmol} / \mathrm{g}\end{array}$ & $\begin{array}{c}\text { Composite, } \\
\mathrm{mmol} / \mathrm{g}\end{array}$ & $\begin{array}{l}\text { C49_1B, } \\
\text { mmol/g }\end{array}$ & $\begin{array}{l}\mathrm{C} 49 \text { 1C, } \\
\mathrm{mmol} / \mathrm{g}\end{array}$ & $\begin{array}{l}\mathrm{C} 49 \_1 \mathrm{D}, \\
\mathrm{mmol} / \mathrm{g}\end{array}$ \\
\hline$\overline{\mathrm{NO}_{3}^{-}}$ & $4.4 e+00$ & $4.0 \mathrm{e}+00$ & $8.00-01$ & $5.2 \mathrm{e}-01$ & $1.1 e+00$ & $1.1 \mathrm{e}+00$ \\
\hline $\mathrm{NO}_{2}^{-}$ & $1.6 e+00$ & $1.4 e+00$ & $1.2 \mathrm{e}+00$ & $7.2 \mathrm{e}-01$ & $1.6 e+00$ & $1.6 e+\infty$ \\
\hline $\mathrm{PO}_{4}^{3-}$ & $2.1 \mathrm{e}-01$ & $2.4 \mathrm{e}-01$ & $1.9 \mathrm{e}-01$ & $8.0 \mathrm{e}-02$ & $1.5 \mathrm{e}-01$ & $4.4 \mathrm{e}-01$ \\
\hline $\mathrm{SO}_{4}^{2-}$ & $2.3 e-01$ & $2.1 \mathrm{e}-01$. & $9.5 e-02$ & $6.1 \mathrm{e}-02$ & $1.4 \mathrm{e}-01$ & $1.3 e-01$ \\
\hline $\mathrm{CN}^{-(a)}$ & NM & NM & $2.9 e-02$ & $1.8 \mathrm{e}-02$ & $4.1 \mathrm{e}-02$ & $4.6 e-02$ \\
\hline Total $\mathrm{CN}^{-(\mathrm{b})}$ & $3.5 e+00$ & $4.3 e+00$ & $2.2 \mathrm{e}-01$ & $1.3 \mathrm{e}-01$ & $3.1 e-01$ & $2.1 \mathrm{e}-01$ \\
\hline $\mathrm{Cl}^{-}$ & NA & NA & $3.1 e-02$ & $1.8 e-02$ & $3.7 e-02$ & $3.7 e-02$ \\
\hline $\mathrm{F}^{-}$ & NA & NA & $2.9 e-02$ & $2.0 \mathrm{e}-02$ & $2.6 \mathrm{e}-02$ & $8.7 e-02$ \\
\hline TOC & NM & NM & $2.7 e-01$ & $1.9 \mathrm{e}-01$ & $3.0 \mathrm{e}-01$ & $3.6 e-01$ \\
\hline $\mathrm{CO}_{3}^{2-(0)}$ & NM & NM & $0.0 \mathrm{e}+00$ & $4.0 \mathrm{e}-02$ & $8.9 e-02$ & $1.9 \mathrm{e}-01$ \\
\hline $\mathrm{HCO}_{3}^{-(\mathrm{c})}$ & NM & NM & $1.0 e-01$ & $4.0 e-02$ & $8.8 e-02$ & $0.0 \mathrm{e}+\infty$ \\
\hline Total & $9.9 e+00$ & $1.0 \mathrm{e}+01$ & $2.9 e+00$ & $1.8 \mathrm{e}+00$ & $3.8 \mathrm{e}+00$ & $4.3 e+00$ \\
\hline
\end{tabular}

(a) Water soluble cyanide as measured by IC.

(b) Cyanide content as determined using Total Cyanide Method (Pool 1994).

(c) Carbonate and bicarbonate measured as total inorganic carbon. The distribution between the two based on pH.

Comparison of the anion concentrations in the subsegments of core 47, and a similar comparison in core 48 (Table 4.4), yields little insight into the location of ferrocyanide waste in the tank, because most of the cyanide, which is the anion characteristic of ferrocyanide waste, appears to have largely disappeared in the core 47 and core 48 waste. The higher relative phosphate concentration in the bottom subsegment of these cores indicates that this layer contains bismuth phosphate waste as predicted by historical records. The nearly equal distribution of cyanide throughout the waste layers indicates that either the waste types have been mixed or the cyanide has migrated. A potential mechanism for migration which would be consistent with Lilga's research $(1992 ; 1993)$ would be decomposition of the precipitated sodium nickel ferrocyanide into nickel hydrous oxide and the soluble, and thus more mobile, sodium ferrocyanide.

Comparison of the element concentrations in the simulant with those found in the composite sample from core 48 (Table 4.3), indicates that the waste obtained by this sampling is also principally ferrocyanide waste. Comparison of core 48 results with core 47 results indicates significant differences in compositions. The two locations have similar concentrations of iron in the two layers; however, the aluminum concentrations are much lower in core 48 and the nickel is a factor of two higher in the 1C layer but equivalent in the bottom layer. The high relative phosphorus concentration in the bottom layer, indicates that the bottom layer contains bismuth phosphate waste.

Core 49 has yet again a different composition than found in cores 47 and 48 , which is not surprising given that core 49 was taken on the opposite side of the tank from the inlet. The waste in core 49 has comparable aluminum concentrations to those found in core 47 , but the core 49 composite has less iron and nickel than the core 47 composite. This finding suggests significant inhomogeneity within C109 as a function of location. 
Table 4.5 compares the measured INFARM-2 element concentrations with those found in the waste obtained from $\mathrm{C}-109$ by core 49 . Core 49 was taken on the far side of $\mathrm{C}-109$ opposite the waste inlet. Comparison of the simulant with the composite yields mixed conclusions. The iron concentration suggests that this waste has been significantly diluted with other waste types, most likely aluminum cladding waste based on the high aluminum concentration. However, the nickel concentration does not confirm a high dilution.

Comparison of the simulant with the core 49 subsegments also yields mixed conclusions regarding the nature of the waste layers. The iron concentration is typically less than in the simulant, indicating significant dilution of the layers; the nickel concentrations indicate a concentration of ferrocyanide waste in the bottom two subsegments. The high phosphorus concentration in the bottom layer suggests that the bottom layer contains substantial bismuth phosphate waste; determination of bismuth concentrations would be necessary to confirm this conclusion.

The cyanide concentrations in the simulant and the waste in core 49 (Table 4.6) indicates that much of the cyanide has disappeared. The distribution of total cyanide throughout the waste layers suggests mixing of the different waste types or migration of the cyanide. Subsegment 1C, which based on historical records should be ferrocyanide waste, has the highest cyanide concentration.

In summary, with respect to waste stored in C-109, the INFARM-2 simulant is fairly representative of the nickel and iron concentrations, particularly of the waste obtained near the inlet, given that some dilution by other wastes have occurred. The simulant is not as representative of the waste obtained by core 49, as greater variability in layer compositions exists and the nickel and iron results provide conflicting conclusions. The INFARM-2 simulant contains about 20 times as much cyanide as the actual wastes, providing an upper bound for the cyanide composition. With respect to the relative nitrate to nitrate concentrations, the relative concentrations are reversed in the actual waste compared to the simulant. In all samples there is sufficient nitrate and/or oxidant to react with all the cyanide present.

\subsubsection{Chemical Composition of Waste from C-112}

As discussed in Section 2.0, C-112 contains about $80 \mathrm{~cm}$ of waste, with the bottom $13 \mathrm{~cm}$ from unscavenged uranium recovery waste, the next $52 \mathrm{~cm}$ from radiocesium scavenging waste produced using the INFARM flowsheet, the next $1 \mathrm{~cm}$ of an unknown waste type, and the final $17 \mathrm{~cm}$ PUREX aluminum cladding removal waste and a small amount of waste from the strontium semiworks (Agnew 1993). The uranium recovery waste would be characterized by phosphate, sulfate, and iron. The ferrocyanide waste would be characterized by nickel, iron, and cyanide and if coupled with radiostrontium scavenging, calcium and phosphate; if coupled with radiocobalt scavenging, additional nickel. The cladding removal waste would be characterized by aluminum.

Tables 4.7 to 4.12 present comparisons of the elemental and anion concentrations found in the top and bottom centrifuge fractions of INFARM-2 simulated ferrocyanide waste and the wastes obtained from $\mathrm{C}-112$ by cores 34,35 , and 36 . The results are reported on a dry basis using the water content determined gravimetrically by drying at $60^{\circ} \mathrm{C}$ for $24 \mathrm{~h}$ under a vacuum, presumably a house vacuum. The reported nickel concentrations are potentially biased high as the nickel content was measured by analyzing solutions obtained after fusing a sample in a nickel crucible; the blank fusion in a nickel crucible contained insignificant concentrations of nickel relative to those measured in the waste. 
Table 4.7. Comparison Element Concentrations on a Dry Basis in INFARM-2 Simulants and Waste from Core 34, C-112 (Jeppson and Simpson 1994; Bell 1993)

$$
\text { INFARM-2 Top INFARM-2 Bot }
$$$$
\text { Element }
$$

Solids, $\mathrm{mmol} / \mathrm{g}$

C34 Comp, $\mathrm{mmol} / \mathrm{g}$

C34_1D,

C34_2B,

C34_2C,

C34_2D,

$\overline{\mathrm{Al}}$

Solids, mm

$<1.8 \mathrm{e}-04$

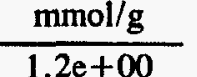

$\mathrm{mmol} / \mathrm{g}$

$\mathrm{mmol} / \mathrm{g}$ $\mathrm{mmol} / \mathrm{g}$

$\mathrm{Ca} \quad \mathrm{NR}$

$\mathrm{Cr} \quad \mathrm{NA}$

Cs $\quad 3.5 e-02$

$\mathrm{Fe} \quad 6.8 \mathrm{e}-01$

Mg NA

NA

$9.6 \mathrm{e}+00$

NA

NR

$1.2 \mathrm{e}+00$

$<3.0 \mathrm{e}-04$

$2.6 e+0$

$1.3 \mathrm{e}+00$

$<3.0 \mathrm{e}-04$

$9 e+00$

$1.3 \mathrm{e}+00$

NA

$3.8 \mathrm{e}-02$

$<6.8 \mathrm{e}-04$

$<1.1 \mathrm{e}-03$

$1.2 \mathrm{e}+00$

$<3.0 \mathrm{e}-04$

NM

NM

$<1.1 \mathrm{e}-03$

$1.3 \mathrm{e}+00$

$1.6 \mathrm{e}+00$

$6.6 \mathrm{e}-01$

$2.8 \mathrm{e}-01$

NM

$<1.1 \mathrm{e}-03$

$<1.1 \mathrm{e}-03$

NA

$<3.9 \mathrm{e}-05$

$<6.3 \mathrm{e}-05$

$<9.3 \mathrm{e}-05$

$5.6 \mathrm{e}-01$

NM

NM

NA $\quad<5.7 \mathrm{e}-05$

$<6.3 e-05$

$<9.3 e-05$

$6.3 \mathrm{e}-01$

3.8e-01

$8.1 \mathrm{e}+00$

$7.2 \mathrm{e}+00$

$8.2 \mathrm{e}+00$

$<6.3 \mathrm{e}-05$

$<9.3 \mathrm{e}-05$

$<6.3 \mathrm{e}-05$

$8.2 \mathrm{e}-01$

$7.0 \mathrm{e}-01$

8.0e-01

$9.2 \mathrm{e}+00$

$<9.3 e-05$

$7.7 \mathrm{e}-01$

$1.1 e+00$

$7.5 \mathrm{e}-01$

$7.6 \mathrm{e}-01$

$9.0 \mathrm{e}-01$

$1.9 \mathrm{e}+00$

NA

1.1e-01

$1.1 \mathrm{e}-01$

$3.7 \mathrm{e}-02$

$8.5 \mathrm{e}-01$

$1.3 \mathrm{e}+00$

NA

NA

9.1e-01

8.1e-01

$2.4 \mathrm{e}-01$

4.1e-02

$1.2 \mathrm{e}-02$

$<1.4 \mathrm{e}-05$

$<2.3 \mathrm{e}-05$

$<1.6 \mathrm{e}-03$

$6.6 \mathrm{e}-03$

$2.7 e-01$

$1.1 \mathrm{e}-01$

NA $\quad<9.9 \mathrm{e}-04$

9.8e-02

2.2e-02

7.4e-03

$3.6 \mathrm{e}-03$

NA

$1.2 \mathrm{e}-01$

NM

2.6e-02

$<1.6 \mathrm{e}-03$

$<1.6 \mathrm{e}-03$

NA

NA

$1.5 e+01$

$1.2 \mathrm{e}+01$

NM

5.0e-02

Total

1.1e+01

$1.4 e+01$

$1.6 e+01$

$\mathrm{NM}$

NA $=$ Not added.

NR = Not reported (Jeppson and Simpson 1994).

$\mathrm{NM}=$ Not measured. 
Table 4.8. Comparison of Anion Concentrations on a Dry Basis in INFARM-2 Simulant and in Waste from C-112 Core 34 (Jeppson and Wong 1993; Bell 1993)

\begin{tabular}{|c|c|c|c|c|c|c|c|}
\hline Analyte & $\begin{array}{c}\text { INFARM-2 } \\
\text { Top, mmol/g }\end{array}$ & $\begin{array}{c}\text { INFARM-2 } \\
\text { Bot, } \mathrm{mmol} / \mathrm{g}\end{array}$ & $\begin{array}{c}\text { Composite, } \\
\mathrm{mmol} / \mathrm{g}\end{array}$ & $\begin{array}{l}\text { C34_1D, } \\
\mathrm{mmol} / \mathrm{g}\end{array}$ & $\begin{array}{l}\mathrm{C} 34 \_2 B \\
\mathrm{mmol} / \mathrm{g}\end{array}$ & $\begin{array}{l}\mathrm{C} 34 \_2 \mathrm{C} \\
\mathrm{mmol} / \mathrm{g}\end{array}$ & $\begin{array}{l}\text { C34_2D, } \\
\mathrm{mmol} / \mathrm{g}\end{array}$ \\
\hline$\overline{\mathrm{NO}_{3}^{-}}$ & $4.4 e+00$ & $4.0 e+\infty 0$ & $2.1 \mathrm{e}+00$ & $2.3 e+00$ & $2.4 \mathrm{e}+00$ & $2.5 e+00$ & $2.0 \mathrm{e}+00$ \\
\hline $\mathrm{NO}_{2}^{-}$ & $1.6 e+00$ & $1.4 \mathrm{e}+\infty 0$ & $2.2 e+00$ & $2.4 \mathrm{e}+00$ & $2.5 e+00$ & $2.5 e+00$ & $2.1 \mathrm{e}+00$ \\
\hline $\mathrm{PO}_{4}^{3-}$ & $2.1 \mathrm{e}-01$ & $2.4 \mathrm{e}-01$ & $3.2 \mathrm{e}-01$ & $2.2 e-01$ & $2.7 \mathrm{e}-01$ & $2.9 \mathrm{e}-01$ & $3.8 \mathrm{e}-01$ \\
\hline $\mathrm{SO}_{4}^{2-}$ & $2.3 e-01$ & $2.1 \mathrm{e}-01$ & $2.6 \mathrm{e}-01$ & $2.7 e-01$ & $2.9 \mathrm{e}-01$ & $2.9 e-01$ & $2.4 \mathrm{e}-01$ \\
\hline $\mathrm{CN}^{-(a)}$ & NM & NM & $1.3 \mathrm{e}-01$ & $1.3 e-01$ & $1.3 \mathrm{e}-01$ & $1.3 e-01$ & $9.6 \mathrm{e}-02$ \\
\hline Total $\mathrm{CN}^{-(b)}$ & $3.5 e+00$ & $4.3 e+00$ & $3.7 e-01$ & $2.0 e-01$ & $1.7 e-01$ & $3.2 \mathrm{e}-01$ & $2.9 \mathrm{e}-01$ \\
\hline $\mathrm{Cl}^{-}$ & NA & NA & $5.9 \mathrm{e}-02$ & $5.6 \mathrm{e}-02$ & $6.0 \mathrm{e}-02$ & $6.1 e-02$ & $5.0 \mathrm{e}-02$ \\
\hline $\mathrm{F}^{-}$ & NA & NA & $8.5 e-02$ & $9.6 \mathrm{e}-02$ & $1.0 \mathrm{e}-01$ & $1.1 \mathrm{e}-01$ & $1.0 \mathrm{e}-01$ \\
\hline TOC & NM & NM & $4.2 \mathrm{e}-01$ & $7.4 e-01$ & $5.3 \mathrm{e}-01$ & $6.2 \mathrm{e}-01$ & $6.9 \mathrm{e}-01$ \\
\hline $\mathrm{CO}_{3}^{2-(0)}$ & NM & NM & $1.2 \mathrm{e}-01$ & $0.0 \mathrm{e}+00$ & $0.0 e+\infty 0$ & $0.0 \mathrm{e}+00$ & $0.0 \mathrm{e}+00$ \\
\hline $\mathrm{HCO}_{3}^{-(o)}$ & NM & NM & $1.1 \mathrm{e}-01$ & $2.3 e-01$ & $1.9 \mathrm{e}-01$ & $2.0 \mathrm{e}-01$ & $2.3 e-01$ \\
\hline Total & $9.9 e+00$ & $1.0 e+01$ & $6.2 e+00$ & $6.5 e+00$ & $6.5 e+00$ & $6.9 e+00$ & $6.0 \mathrm{e}+00$ \\
\hline
\end{tabular}

(a) Water soluble cyanide as measured by IC.

(b) Cyanide content as determined using Total Cyanide Method (Pool 1994).

(c) Carbonate and bicarbonate measured as total inorganic carbon. The distribution between the two based on $\mathrm{pH}$. 
Table 4.9. Comparison of Element Concentrations on a Dry Basis in INFARM-2 and Waste from Core 35, C-112 (Jeppson and Simpson 1994; Bell 1993)

\begin{tabular}{lccc} 
Element & INFARM-2 Top Solids, mmol/g & INFARM-2 Bot Solids, mmol/g & C35_Comp, mmol/g \\
\cline { 2 - 3 } $\mathrm{Al}$ & $\mathrm{NA}$ & $\mathrm{NA}$ & $2.5 \mathrm{e}+00$ \\
$\mathrm{Ba}$ & $\mathrm{NA}$ & $\mathrm{NA}$ & $<3.2 \mathrm{e}-04$ \\
$\mathrm{Ca}$ & $\mathrm{NR}$ & $\mathrm{NR}$ & $5.7 \mathrm{e}-01$ \\
$\mathrm{Cr}$ & $\mathrm{NA}$ & $\mathrm{NA}$ & $<1.2 \mathrm{e}-03$ \\
$\mathrm{Cs}$ & $3.5 \mathrm{e}-02$ & $3.8 \mathrm{e}-02$ & $\mathrm{NM}$ \\
$\mathrm{Fe}$ & $6.8 \mathrm{e}-01$ & $7.2 \mathrm{e}-01$ & $8.8 \mathrm{e}-01$ \\
$\mathrm{Mg}$ & $\mathrm{NA}$ & $\mathrm{NA}$ & $<6.8 \mathrm{e}-05$ \\
$\mathrm{Mn}$ & $\mathrm{NA}$ & $\mathrm{NA}$ & $<1.0 \mathrm{e}-04$ \\
$\mathrm{Na}$ & $9.6 \mathrm{e}+00$ & $8.7 \mathrm{e}+00$ & $5.4 \mathrm{e}+00$ \\
$\mathrm{Ni}$ & $7.0 \mathrm{e}-01$ & $7.7 \mathrm{e}-01$ & $5.1 \mathrm{e}-01$ \\
$\mathrm{P}$ & $1.9 \mathrm{e}+00$ & $2.5 \mathrm{e}+00$ & $1.0 \mathrm{e}+00$ \\
$\mathrm{~Pb}$ & $\mathrm{NA}$ & $\mathrm{NA}$ & $<2.2 \mathrm{e}-03$ \\
$\mathrm{Si}$ & $\mathrm{NA}$ & $\mathrm{NA}$ & $8.5 \mathrm{e}-01$ \\
$\mathrm{Sr}$ & $\mathrm{NA}$ & $\mathrm{NA}$ & $<2.5 \mathrm{e}-05$ \\
$\mathrm{Th}$ & $\mathrm{NA}$ & $\mathrm{NA}$ & $<1.7 \mathrm{e}-03$ \\
$\mathrm{U}(\mathrm{ICP})$ & $\mathrm{NA}$ & $\mathrm{NA}$ & $5.7 \mathrm{e}-01$ \\
$\mathrm{U}(\mathrm{LF})$ & $\mathrm{NA}$ & $\mathrm{NA}$ & $2.8 \mathrm{e}-01$ \\
$\mathrm{Total}$ & $1.1 \mathrm{e}+01$ & $1.0 \mathrm{e}+01$ & $1.2 \mathrm{e}+01$ \\
$\mathrm{NA}=$ Not added. & & & \\
$\mathrm{NR}=$ Not reported (Jeppson and Simpson 1994). & & \\
$\mathrm{NM}=$ Not measured. & & & \\
& & &
\end{tabular}

Table 4.10. Comparison of Anion Concentrations on a Dry Basis in INFARM-2 Simulant and in Waste from C-112 Core 35 (Jeppson and Wong 1993; Bell 1993)

\begin{tabular}{|c|c|c|c|}
\hline Analyte & INFARM-2 Top, $\mathrm{mmol} / \mathrm{g}$ & INFARM-2 Bot, mmol/g & C35_Composite, $\mathrm{mmol} / \mathrm{g}$ \\
\hline $\mathrm{NO}_{3}^{-}$ & $4.4 e+00$ & $4.0 e+00$ & $1.1 \mathrm{e}+00$ \\
\hline $\mathrm{NO}_{2}^{-}$ & $1.6 \mathrm{e}+00$ & $1.4 \mathrm{e}+00$ & $1.1 \mathrm{e}-00$ \\
\hline $\mathrm{PO}_{4}^{3-}$ & 2.1e-01 & $2.4 \mathrm{e}-01$ & $2.8 \mathrm{e}-01$ \\
\hline $\mathrm{SO}_{4}^{2-}$ & $2.3 e-01$ & $2.10-01$ & $9.00-02$ \\
\hline $\mathrm{CN}^{-(\mathrm{a})}$ & $N_{M}^{(b)}$ & NM & $4.7 e-02$ \\
\hline Total CN_(b) & $3.5 e+00$ & $4.3 e+00$ & NM \\
\hline $\mathrm{Cl}^{-}$ & NA & NA & $3.6 \mathrm{e}-02$ \\
\hline $\mathrm{F}^{-}$ & NA & NA & $2.4 e-02$ \\
\hline TOC & NM & NM & $3.2 \mathrm{e}-01$ \\
\hline $\mathrm{CO}_{3}^{2-(c)}$ & NM & NM & $0.0 \mathrm{e}+00$ \\
\hline $\mathrm{HCO}_{3}^{-(\mathrm{c})}$ & NM & NM & $9.2 \mathrm{e}-02$ \\
\hline Total & $9.9 e+00$ & $1.0 e+01$ & $3.0 e+00$ \\
\hline
\end{tabular}
(a) Water soluble cyanide as measured by IC.
(b) Cyanide content as determined using Total Cyanide Method (Pool 1994).
(c) Carbonate and bicarbonate measured as total inorganic carbon. The distribution between the two based on $\mathrm{pH}$.


Table 4.11. Comparison of Element Concentrations on a Dry Basis in INFARM-2 and Waste from Core 36, C-112 (Jeppson and Simpson 1994; Bell 1993)

\begin{tabular}{|c|c|c|c|c|c|c|c|c|c|}
\hline Element & $\begin{array}{l}\text { INFARM-2 Top } \\
\text { Solids, } \mathrm{mmol} / \mathrm{g}\end{array}$ & $\begin{array}{l}\text { INFARM-2 Bot } \\
\text { Solids, } \mathrm{mmol} / \mathrm{g}\end{array}$ & $\begin{array}{c}\text { C36_Comp, } \\
\mathrm{mmol} / \mathrm{g}\end{array}$ & $\begin{array}{c}\mathrm{C} 36 \_1 \mathrm{C} \\
\mathrm{mmol} / \mathrm{g}\end{array}$ & $\begin{array}{l}\text { C36_1D, } \\
\mathrm{mmol} / \mathrm{g}\end{array}$ & $\begin{array}{c}\mathrm{C} 36 \_2 \mathrm{~A}, \\
\mathrm{mmol} / \mathrm{g}\end{array}$ & $\begin{array}{c}\mathrm{C} 36 \_2 \mathrm{~B} \\
\mathrm{mmol} / \mathrm{g}\end{array}$ & $\begin{array}{c}\mathrm{C} 36 \_2 \mathrm{C} \\
\mathrm{mmol} / \mathrm{g}\end{array}$ & $\begin{array}{c}\mathrm{C} 36 \_2 \mathrm{D} \\
\mathrm{mmol} / \mathrm{g}\end{array}$ \\
\hline$\overline{\mathrm{Al}}$ & NA & NA & $4.3 \mathrm{e}-01$ & $1.1 \mathrm{e}+00$ & $3.5 \mathrm{e}-01$ & $5.4 \mathrm{e}-01$ & $1.9 \mathrm{e}-01$ & $1.9 \mathrm{e}-01$ & $2.2 \mathrm{e}-01$ \\
\hline $\mathrm{Ba}$ & NA & $\mathrm{NA}$ & $<1.3 \mathrm{e}-04$ & $1.8 \mathrm{e}-03$ & $<2.6 \mathrm{e}-04$ & $9.1 \mathrm{e}-04$ & $<1.2 \mathrm{e}-04$ & $<1.2 \mathrm{e}-04$ & $<1.2 \mathrm{e}-04$ \\
\hline $\mathrm{Ca}$ & NR & NR & $9.3 \mathrm{e}-01$ & $1.4 e+00$ & $1.7 e+00$ & $7.2 \mathrm{e}-01$ & $3.8 \mathrm{e}-01$ & $3.8 \mathrm{e}-01$ & $2.1 \mathrm{e}-01$ \\
\hline $\mathrm{Cr}$ & NA & NA & $<4.8 \mathrm{e}-04$ & $7.2 \mathrm{e}-03$ & $<9.8 \mathrm{e}-04$ & $6.6 \mathrm{e}-03$ & $<4.5 \mathrm{e}-04$ & $<4.5 \mathrm{e}-04$ & $<4.3 \mathrm{e}-04$ \\
\hline Cs & $3.5 \mathrm{e}-02$ & $3.8 \mathrm{e}-02$ & NM & NM & NM & NM & NM & NM & NM \\
\hline $\mathrm{Fe}$ & $6.8 \mathrm{e}-01$ & $7.2 \mathrm{e}-01$ & $8.5 e-01$ & $1.3 e+00$ & $3.2 \mathrm{e}-01$ & $6.4 \mathrm{e}-01$ & $2.7 \mathrm{e}-01$ & $2.7 e-01$ & $7.5 \mathrm{e}-01$ \\
\hline Mg & NA & NA & $<2.8 \mathrm{e}-05$ & $4.6 \mathrm{e}-02$ & $<5.5 \mathrm{e}-05$ & $2.4 \mathrm{e}-02$ & $<2.6 \mathrm{e}-05$ & $<2.6 \mathrm{e}-05$ & $<2.5 \mathrm{e}-05$ \\
\hline Mn & NA & NA & $<4.1 \mathrm{e}-05$ & $1.2 \mathrm{e}-02$ & $<8.2 \mathrm{e}-05$ & $6.2 \mathrm{e}-03$ & $<3.8 \mathrm{e}-05$ & $<3.8 \mathrm{e}-05$ & $<3.6 \mathrm{e}-05$ \\
\hline $\mathrm{Na}$ & $9.6 e+00$ & $8.7 e+00$ & $9.6 e+00$ & $6.9 e+00$ & $8.5 e+00$ & $3.5 e+00$ & $6.7 e+00$ & $6.7 e+00$ & $1.3 e+01$ \\
\hline $\mathrm{Ni}$ & 7.0e-01 & $7.7 e-01$ & $4.0 \mathrm{e}-01$ & $7.3 e-01$ & $9.3 e-01$ & $3.7 \mathrm{e}-01$ & $1.4 \mathrm{e}-01$ & $1.4 \mathrm{e}-01$ & $4.7 \mathrm{e}-02$ \\
\hline $\mathbf{P}$ & $1.9 e+00$ & $2.5 e+00$ & $2.2 \mathrm{e}+00$ & $1.2 \mathrm{e}+00$ & $1.5 e+00$ & $6.2 \mathrm{e}-01$ & $1.4 \mathrm{e}+00$ & $1.4 \mathrm{e}+00$ & $3.0 \mathrm{e}+00$ \\
\hline $\mathrm{Pb}$ & NA & NA & $9.2 \mathrm{e}-01$ & $2.7 \mathrm{e}-02$ & $<1.8 \mathrm{e}-03$ & $1.4 \mathrm{e}-02$ & $<8.3 \mathrm{e}-04$ & $<8.3 \mathrm{e}-04$ & $<8.0 \mathrm{e}-04$ \\
\hline $\mathbf{S i}$ & NA & NA & $1.0 \mathrm{e}+00$ & $1.1 \mathrm{e}+00$ & $6.6 e-02$ & $5.6 \mathrm{e}-01$ & $7.7 \mathrm{e}-02$ & $7.7 \mathrm{e}-02$ & $8.5 \mathrm{e}-02$ \\
\hline Sr & NA & NA & $<1.0 \mathrm{e}-05$ & $3.2 \mathrm{e}-03$ & $3.2 \mathrm{e}-03$ & $1.6 \mathrm{e}-03$ & $3.2 \mathrm{e}-03$ & $3.2 \mathrm{e}-03$ & $9.8 \mathrm{e}-03$ \\
\hline Th & NA & NA & $<7.1 \mathrm{e}-04$ & $<1.4 \mathrm{e}-03$ & $<1.4 \mathrm{e}-03$ & $<1.4 \mathrm{e}-03$ & $<6.6 \mathrm{e}-04$ & $<6.6 \mathrm{e}-04$ & $<6.3 \mathrm{e}-04$ \\
\hline U (ICP) & NA & NA & $8.0 \mathrm{e}-01$ & $2.3 e-02$ & $3.1 \mathrm{e}-02$ & $1.2 \mathrm{e}-02$ & $1.2 e+00$ & $1.2 \mathrm{e}+00$ & $1.3 e+00$ \\
\hline $\mathrm{U}(\mathrm{LF})$ & NA & NA & $7.2 \mathrm{e}-01$ & NM & NM & NM & NM & NM & NM \\
\hline Total & $1.1 e+01$ & $1.0 e+01$ & $1.7 e+01$ & $1.4 e+01$ & $7.1 \mathrm{e}+00$ & $7.1 e+00$ & $1.0 e+01$ & $1.0 e+01$ & $1.8 \mathrm{e}+01$ \\
\hline
\end{tabular}

$\mathrm{NA}=$ Not added

NR $=$ Not reported (Jeppson and Simpson 1994).

$\mathrm{NM}=$ Not measured. 
Table 4.12. Comparison of Anion Concentrations on a Dry Basis in INFARM-2 Simulant and in Waste from C-112 Core 36 (Jeppson and Wong 1993; Bell 1993)

INFARM-2 INFARM-2 C36 Composite, C36 1C $\quad$ C36 1D $\quad$ C36 2A, C36 2B, C36 2C,

\begin{tabular}{|c|c|c|c|c|c|c|c|c|c|}
\hline Analyte & $\begin{array}{l}\text { INFARM-2 } \\
\text { Top, } \mathrm{mmol} / \mathrm{g}\end{array}$ & $\begin{array}{l}\text { INFARM-2 } \\
\text { Bot, } \mathrm{mmol} / \mathrm{g}\end{array}$ & $\begin{array}{c}\text { C36_Composite, } \\
\mathrm{mmol} / \mathrm{g}\end{array}$ & $\begin{array}{l}\mathrm{C} 36 \_1 \mathrm{C} \\
\mathrm{mmol} / \mathrm{g}\end{array}$ & $\begin{array}{l}\text { C36_1D, } \\
\mathrm{mmol} / \mathrm{g}\end{array}$ & $\begin{array}{c}\text { C36_2A, } \\
\mathrm{mmol} / \mathrm{g}\end{array}$ & $\begin{array}{l}\mathrm{C} 36 \_2 \mathrm{~B} \\
\mathrm{mmol} / \mathrm{g}\end{array}$ & $\begin{array}{l}\mathrm{C} 36 \_2 \mathrm{C} \\
\mathrm{mmol} / \mathrm{g}\end{array}$ & $\begin{array}{l}\text { C36_2D, } \\
\mathrm{mmol} / \mathrm{g}\end{array}$ \\
\hline$\overline{\mathrm{NO}_{3}^{-}}$ & $4.4 e+00$ & $4.0 \mathrm{e}+00$ & $2.1 \mathrm{e}+00$ & $\overline{2.0 e+00}$ & $\overline{2.6 e+00}$ & $2.5 e+00$ & $\overline{1.2 \mathrm{e}+00}$ & $\overline{2.1 e+00}$ & $1.9 e+00$ \\
\hline $\mathrm{NO}_{2}^{-}$ & $1.6 \mathrm{e}+00$ & $1.4 e+00$ & $2.1 \mathrm{e}+00$ & $2.0 \mathrm{e}+00$ & $2.6 e+00$ & $2.5 e+00$ & $1.1 \mathrm{e}+00$ & $1.9 e+\infty$ & $1.7 \mathrm{e}+00$ \\
\hline $\mathrm{PO}_{4}^{3-}$ & $2.1 \mathrm{e}-01$ & $2.4 \mathrm{e}-01$ & $9.5 e-01$ & $3.4 \mathrm{e}-01$ & $4.5 \mathrm{e}-01$ & $5.6 \mathrm{e}-01$ & $3.6 \mathrm{e}-01$ & $1.2 \mathrm{e}+00$ & $1.3 e+00$ \\
\hline $\mathrm{SO}_{4}^{2-}$ & $2.3 \mathrm{e}-01$ & $2.1 e-01$ & $2.6 \mathrm{e}-01$ & $2.5 \mathrm{e}-01$ & $3.2 \mathrm{e}-01$ & $3.0 \mathrm{e}-01$ & $1.4 \mathrm{e}-01$ & $2.5 e-02$ & $2.2 \mathrm{e}-01$ \\
\hline $\mathrm{CN}^{-(a)}$ & NM & NM & $9.1 \mathrm{e}-02$ & $8.3 e-02$ & $1.1 \mathrm{e}-02$ & $1.1 \mathrm{e}-02$ & $4.6 \mathrm{e}-02$ & $8.5 e-02$ & $7.9 \mathrm{e}-02$ \\
\hline \multicolumn{10}{|l|}{ Total $^{(\mathfrak{b})}$} \\
\hline $\mathrm{CN}^{-}$ & $3.5 e+00$ & $4.3 e+\infty 0$ & $2.7 e-01$ & NM & $2.8 \mathrm{e}-01$ & $3.5 e-01$ & $2.9 e-01$ & $1.5 \mathrm{e}-01$ & $2.2 \mathrm{e}-01$ \\
\hline $\mathrm{Cl}^{-}$ & NA & NA & $5.4 \mathrm{e}-02$ & $5.0 \mathrm{e}-02$ & $6.7 e-02$ & $5.9 e-02$ & $2.9 e-02$ & $1.5 \mathrm{e}-01$ & $4.5 e-02$ \\
\hline $\mathrm{F}^{-}$ & NA & NA & $4.3 e-02$ & $4.6 \mathrm{e}-02$ & $6.3 e-02$ & $6.1 \mathrm{e}-02$ & $3.6 \mathrm{e}-02$ & $5.1 \mathrm{e}-02$ & $1.4 \mathrm{e}-01$ \\
\hline TOC & NM & NM & $4.7 e-01$ & $1.3 \mathrm{e}-01$ & $9.7 e-01$ & $7.6 \mathrm{e}-01$ & $3.8 \mathrm{e}-01$ & $5.8 \mathrm{e}-01$ & $4.4 e-01$ \\
\hline $\mathrm{CO}_{3}^{2-(0)}$ & NM & NM & $0.0 \mathrm{e}+00$ & $0.0 \mathrm{e}+00$ & $0.0 \mathrm{e}+00$ & $0.0 e+00$ & $0.0 \mathrm{e}+00$ & $0.0 \mathrm{e}+\infty 0$ & $0.0 \mathrm{e}+00$ \\
\hline $\mathrm{HCO}_{3}^{-(c)}$ & NM & NM & $1.2 e-01$ & $1.3 e-01$ & $2.1 \mathrm{e}-01$ & $2.1 \mathrm{e}-01$ & $6.9 e-02$ & $1.5 \mathrm{e}-01$ & $1.1 \mathrm{e}-01$ \\
\hline Total & $9.9 e+00$ & $1.0 e+01$ & $6.3 e+00$ & $6.2 e+00$ & $7.3 e+00$ & $3.1 \mathrm{e}+00$ & $3.6 e+00$ & $6.5 e+00$ & $6.1 \mathrm{e}+00$ \\
\hline
\end{tabular}

(a) Water soluble cyanide as measured by IC.

(b) Cyanide content as determined using Total Cyanide Method (Pool 1994).

(c) Carbonate and bicarbonate measured as total inorganic carbon. The distribution between the two based on pH. 
Table 4.7 for core 34 from $\mathrm{C}-112$ shows that the major elemental constituents in this waste sample are aluminum, calcium, iron, sodium, nickel, lead, phosphorus, and silicon. The high concentration of aluminum throughout the subsegment samples indicates that the aluminum cladding waste was well mixed with the ferrocyanide wastes and the uranium recovery wastes on the bottom. The high calcium and phosphorus could be due to radiostrontium scavenging, or the phosphorus could be from the uranium recovery waste present in the tank, or a combination of the two, because the highest phosphorus concentration is found in the bottom segment, which is consistent with historical records.

The similarities between the compositions of the INFARM-2 simulant and the core 34 composite indicate that the wastes obtained by core 34 is largely ferrocyanide wastes. This conclusion is supported by the similarities between the iron and nickel concentrations.

The subsegment results presented in Table 4.7 suggests that subsegments $2 \mathrm{~B}$ and $2 \mathrm{C}$ are largely ferrocyanide wastes based on the iron and nickel concentrations. The nickel concentrations are higher than would be predicted assuming that the ferrocyanide precipitate was disodium nickel ferrocyanide with an iron to nickel molar ratio of $1: 1$. The high nickel bias might be the explanation, but is considered unlikely by the analysts.

The comparison of the anion concentrations in the simulant and the samples from core 34 presented in Table 4.8 indicate that most of the predicted ferrocyanide has disappeared. There is somewhat less nitrate and nitrite present than would be expected based on the simulant composition and the molar ratio of nitrate to nitrite is near $1: 1$, as opposed to $3: 1$ in the simulant. The higher nitrite concentration could lead to a more reactive waste if sufficient fuel were present.

The distribution of cyanide throughout the waste layers obtained by core 34 indicates that either the wastes have been mixed or that the cyanide has migrated throughout the waste. A mechanism whereby migration could occur would be if the decomposition of sodium nickel ferrocyanide proceeds via the mechanism suggested by Lilga (1992), which shows that high pHs cause sodium nickel ferrocyanide to decompose forming nickel oxide and soluble ferrocyanide; these would be destroyed by hydrolysis or could migrate.

Core 35 was a partial core consisting of only one subsegment, 2D, obtained from the lower depths of the waste near the waste inlet to C-112. Inspection of Table 4.9 shows that the elemental composition of this waste sample is similar to that of the INFARM-2 simulants. The lower concentrations of iron and nickel in the core 35 waste relative to the simulants and the presence of aluminum suggests that this waste has been mixed with cladding waste. The presence of calcium and phosphorus in this waste suggests that radiostrontium scavenging was frequently performed in conjunction with radiocesium scavenging. The calcium concentration of $0.57 \mathrm{mmol} / \mathrm{g}$ is sufficient only to form $0.2 \mathrm{mmol} / \mathrm{g}$ of calcium phosphate or to tie up $40 \%$ of the phosphorus in the waste, indicating that uranium recovery waste may be present in this waste fraction.

Comparison of the elemental concentrations in core 35 with core 34 subsegment 2D indicates substantial differences between the two subsegments acquired from similar depths. The aluminum and iron concentrations in core 35 are roughly twice that observed in core 34 subsegment $2 \mathrm{D}$. In contrast, the calcium and nickel concentrations are a factor of 2 to 3 greater in core 34_2D waste than in core 35 waste. The uranium concentration is a factor of 10 greater in core 35 than in core 34 2D, indicating the presence of some bismuth phosphate waste. 
In terms of anion concentrations, the nitrate and nitrite concentrations are lower in Core 35 than in the simulant. The nitrate to nitrite ratio is, as with core 34 , about $1: 1$, differing from the $3: 1$ in the simulant. Total cyanide was not measured for this waste sample.

The comparison in Table 4.11 of the elemental compositions found in the composite sample of waste obtained by core 36 and the INFARM-2 simulant finds few similarities between the two. The iron concentration of $0.85 \mathrm{mmol} / \mathrm{g}$ is greater than in the simulant but the nickel concentration of $0.4 \mathrm{mmol} / \mathrm{g}$ is less than that predicted by the simulant and less than that required to form disodium nickel ferrocyanide; one possible explanation is the presence of a waste type high in iron, such as the B-Plant waste added to $\mathrm{C}-112$ at one time.

Comparison shown in Table 4.11 of the elemental concentrations in the subsegments of core 36 with the INFARM-2 finds, in general, few similarities between the wastes in the subsegments and the simulant. The uppermost subsegment $1 \mathrm{C}$, that based on history and assuming layering of added wastes within and across the tank, should be comprised of about $50 \%$ aluminum cladding waste, $10 \%$ an unknown waste, and $40 \%$ ferrocyanide waste. The elemental composition of $1 \mathrm{C}$ is not consistent with this distribution assuming that INFARM-2 is representative of the ferrocyanide waste added to this layer of waste in $\mathrm{C}-112$. The nickel concentration is near that of the undiluted simulant, yet the aluminum concentration is high, indicating the presence of cladding waste. The iron is $90 \%$ higher in $2 \mathrm{C}$ than in the simulant, suggesting the presence of a high iron-bearing waste. The nickel concentration in 1D suggests a ferrocyanide waste with a higher than expected ferrocyanide concentration based on the INFARM-2 simulant, yet there is only about one-third of the necessary iron to form disodium nickel ferrocyanide. In the remaining waste subsegments, there is an excess of iron relative to nickel. The three lowest segments have significant uranium concentrations of about $1.2 \mathrm{mmol} / \mathrm{g}$, indicating substantial mixing of the ferrocyanide waste predicted to be present in these layers with a uraniumbearing waste such as first-cycle waste from the $\mathrm{BiPO}_{4}$ process. The subsegment analyses indicate substantial mixing of the wastes added to $\mathrm{C}-112$ in the region near the inlet.

Comparison of core 36_2D with core 35, which based on their proximity to each other and the inlet should be similar, shows somewhat similar compositions. The iron and nickel contents are similar but the core 35 sample contains 10 times the aluminum found in the core 36 sample. The uranium content is markedly different, with about 25 times more in the core 36 sample. Based on the nickel content, these contain ferrocyanide wastes.

The wastes in cores 34 and 36 also differ markedly in elemental compositions. Core 34 subsegment samples have high aluminum concentrations and the core 36 samples, in general, do not, with the exception of 1C. The iron and nickel concentrations differ by subsegment, with no consistent relative concentration. The uranium concentration also is markedly different, with low concentrations found in core 34 samples and high concentrations found in the lower three subsegments of core 36 . These two samples indicate substantial horizontal inhomogeneity in C-112.

The anion concentrations found in core 36 samples, shown in Table 4.12, in general, differ from those observed in the INFARM-2 simulant. The combined nitrate and nitrite concentration in the core 36 waste is two-thirds of that in the simulant. In addition, the nitrate-to-nitrite ratio of $1: 1$ differs from the simulant's 3:1 ratio. The cyanide concentrations in the core 36 wastes are 4 to $9 \%$ of that found in the simulant, indicating that the cyanide has disappeared. Likely mechanisms for this disappearance are hydrolysis (Lilga 1992; 1993) and radiolytic oxidation. 
In summary, with respect to the waste stored in C-112, the INFARM-2 simulant approximates the composition of the average waste in $\mathrm{C}-112$ given that some physical or chemical mixing has occurred during the years of active use. This indicates that, as the historical records show, the waste in C-112 is largely ferrocyanide waste. It is evident from the elemental distributions that the tank is not homogeneous either vertical or horizontally. Unfortunately, one of the two cores obtained near the inlet was only a subsegment and exhibited differences between the other core obtained near the inlet at the same depth.

\subsection{Radiochemical Content}

It is not possible to compare radionuclide content of a radioactive waste with a nonradioactive simulated waste; however, some of the radiochemical results provide some interesting insights into the chemistry of the ferrocyanide wastes and the distribution of wastes in C-109 and C-112. In particular, the water-leach results suggest that ferrocyanide is present at a sufficiently high level to prevent solubilization of the cesium. The distributions of ${ }^{137} \mathrm{Cs}$ and ${ }^{90} \mathrm{Sr}$ in the different core samples from $\mathrm{C}-109$ and C-112 suggest that the waste stored in these tanks are not homogeneous vertically or across the tank; it should be noted that the partial recoveries of waste for each core sample limit the ability to compare concentrations at different locations both vertically and horizontally. The following discussion does not take into account sampling errors and correct assignment of waste acquisition location or analytical errors.

Tables 4.13 and 4.14 present the concentration of ${ }^{137} \mathrm{Cs}$ found in the waste samples taken from C-109 and C-112, respectively, plus the amount of ${ }^{137} \mathrm{Cs}$ leached from these samples by treating $1 \mathrm{~g}$ of material with $100 \mathrm{~mL}$ of room-temperature water. Inspection of these tables shows that only a very small amount, less than $1 \%$, of the normally very soluble cesium is leached with water, indicating that an insoluble cesium-containing compound still exists or that solubilization of cesium is critically slow. Although $\mathrm{Na}_{2} \mathrm{NiFe}(\mathrm{CN})_{6}$ is apparently decomposed with time, at high $\mathrm{pH}, \mathrm{Cs}_{2} \mathrm{NiFe}(\mathrm{CN})_{6}$ is much more stable and possibly could still be present (Lilga 1992; 1993). The greater stability of the cesium nickel ferrocyanide could explain the low solubility of the cesium in the water leach. Alternatively, an insoluble silicate may be responsible. It is worth noting that the total cesium, ${ }^{133} \mathrm{Cs}$, ${ }^{135} \mathrm{Cs}$, and ${ }^{137} \mathrm{Cs}$, might be about 3.2 times the ${ }^{137} \mathrm{Cs}$ measured; ${ }^{134} \mathrm{Cs}$ should have decayed to background levels during the over 30 years of storage.

The water-leach results presented in Tables 4.13 and 4.14 for cores 47,48 , and 49 for C-109, and cores 34 and 35 for C-112 cannot be used to assess whether ferrocyanide has distributed itself throughout the different waste types within C-109. Because the process of compositing would mix any alkali nickel ferrocyanide with cesium in the other wastes, it would be expected, given the lower solubility and greater stability of the cesium nickel ferrocyanide relative to sodium nickel ferrocyanide, that the cesium would exchange for sodium, creating an insoluble cesium compound.

The results for core 36 can be used to assess whether ferrocyanide distributed itself throughout the waste in $\mathrm{C}-112$. Assuming that an insoluble ferrocyanide is responsible for the low solubility of the cesium observed for water leaches of the subsegments from core 36 , ferrocyanide has distributed itself throughout the different waste types added to C-112. The bottom subsegment should be uranium recovery waste, the next four subsegments should be ferrocyanide waste, and the last subsegment on top of that should be cladding waste plus an unknown. It would be expected that any cesium in the 
Table 4.13 Water Solubility of ${ }^{137} \mathrm{Cs}$ in Waste from C-109 (Sprouse 1993)

\begin{tabular}{lccc} 
Sample & {$\left[{ }^{137} \mathrm{Cs}\right], \mu \mathrm{Ci} / \mathrm{g}$} & & $\begin{array}{c}\%{ }^{137} \mathrm{Cs} \text { Water Leached } \\
\left(100 \mathrm{~mL} \mathrm{H}_{2} \mathrm{O} / \mathrm{g}\right)\end{array}$ \\
\cline { 1 - 1 } Core 47 Composite & 870 & 1.1 \\
Core 48 Composite & 1000 & 0.9 \\
Core 49 Composite & 560 & 0.9
\end{tabular}

Table 4.14. Water Solubility of ${ }^{137} \mathrm{Cs}$ in Waste from C-112 (Bell 1993)

\begin{tabular}{|c|c|c|}
\hline Sample & {$\left[{ }^{137} \mathrm{Cs}\right], \mu \mathrm{Ci} / \mathrm{g}$} & $\begin{array}{c}\text { \% }{ }^{137} \mathrm{Cs} \text { Water Leached } \\
\left(100 \mathrm{~mL} \mathrm{H}_{2} \mathrm{O} / \mathrm{g}\right)\end{array}$ \\
\hline Core 34 Composite & 750 & 0.8 \\
\hline Core 35 Composite. & 790 & 0.7 \\
\hline Core $36 \_1 C$ & 410 & 0.5 \\
\hline Core $36 \_1 \mathrm{D}$ & 1200 & 0.4 \\
\hline Core $36 \_2 A$ & 880 & 1.4 \\
\hline Core $36 \_2 B$ & 530 & 1.4 \\
\hline Core $36 \_2 C$ & 100 & 4.0 \\
\hline Core 36 1D & 35 & 2.9 \\
\hline
\end{tabular}

bottom subsegment would be soluble with no mixing or migration of waste, which is contrary to what is observed. The next four subsegments should have low cesium solubilities, as they do. The last subsegment should have soluble cesium, which is not what was found. Thus the results indicate that the ferrocyanide has migrated throughout the waste or the wastes have been mixed.

Results recently reported by Lumetta, Rapko, and Colton (1994) indicate that other low-solubility cesium materials exist in Hanford Tanks. Lumetta et al. investigated washing sludges from 241-B-110 with water, and washing sludges from $241-\mathrm{B}-201, \mathrm{C}-109, \mathrm{C}-112$, and $241-\mathrm{U}-110$ with $0.1 \mathrm{M} \mathrm{NaOH}$ at wash-to-sludge ratios ranging from 3 to $23 \mathrm{~mL} / \mathrm{g}$ sludge; they found limited solubilization of ${ }^{137} \mathrm{Cs}$. For $241-\mathrm{B}-110$, they removed $50 \%$ of the radiocesium; however, for the remainder they only removed $10 \%$ or less of the radiocesium by washing. This suggests that limited cesium solubility does not imply a low-solubility cesium ferrocyanide, although for C-109 and C-112 with cyanide still present in the waste, the assumption is reasonable. It is interesting to note that treating C-109 and C-112 sludge with $3 \mathrm{M} \mathrm{NaOH}$ at $100^{\circ} \mathrm{C}$ for $5 \mathrm{~h}$ dissolved all of the radiocesium; this result is consistent with the hypothesis that treatment of hydroxide decomposes an alkali nickel ferrocyanide (Lilga 1992; 1993).

Tables 4.15 and 4.16 present the radionuclide concentrations found in C-109 and C-112, respectively. The radionuclide concentrations provide some limited information on the distribution of materials within the tank. 
Inspection of Table $4: 15$ reveals similar concentrations of ${ }^{137} \mathrm{Cs}$ in the composites of cores 47 $(870 \mu \mathrm{Ci} / \mathrm{g}), 48(1000 \mu \mathrm{Ci} / \mathrm{g})$, and $49(560 \mu \mathrm{Ci} / \mathrm{g})$. The two samples obtained by core 48 were obtained near the bottom of the tank where the highest ${ }^{137} \mathrm{Cs}$ concentrations exist, thus skewing the composite to higher concentrations. Based on the results for core 49 and partial core 48 , it appears that the waste on the opposite side of the tank, away from the inlet, is slightly lower than near the inlet.

In terms of the distribution of ${ }^{137} \mathrm{Cs}$ within $\mathrm{C}-109$, the highest concentrations are near the bottom of the tank, about $1000 \mu \mathrm{Ci} / \mathrm{g}$, with the concentration declining as the top of the waste is approached. Comparison of core 47 and core 49 by segments obtained at the same levels indicates that the cesium concentrations are higher near the inlet.

The other major radionuclide in the $\mathrm{C}-109$ waste is ${ }^{90} \mathrm{Sr}$, which does not exhibit the same distribution profile as the cesium. The concentration declines with increasing depth; the highest concentration is at the top, which is consistent with the addition of waste from strontium semiworks after the ferrocyanide wastes. The distribution of strontium suggests layering within the waste in C-109 and a lack of physical mixing.

Inspection of Table 4.16 reveals that the composites from the three cores from $\mathrm{C}-112$ contain about the same amount of radiocesium but differing amounts of radiostrontium. Cores 34 and 35 contain about the same amount of ${ }^{90} \mathrm{Sr}$, but the core 36 composite contains about one-third of the concentration of the other two cores; based on location, the ${ }^{90} \mathrm{Sr}$ concentration should be more similar for cores 35 and 36 given their proximity to the inlet and each other.

The vertical distributions of ${ }^{137} \mathrm{Cs}$ are fairly constant in core 34 but vary substantially within core 36 . It would be expected based on history that the bottom subsegment should contain less radiocesium than the four subsegments above it, as is the case for core 36 but not for core 34 . It would be expected that the uppermost subsegment would contain less radiocesium than the ferrocyanide layers; again this is the case for core 36 but not for core 34 . This finding suggests that the waste might have formed layers near the inlet but somehow mixed on the opposite side of the tank.

The vertical distributions of ${ }^{90} \mathrm{Sr}$ are fairly constant in core 34 but vary substantially within core 36 . The concentration of strontium in ferrocyanide wastes is difficult to predict but would be expected to be low, just as the strontium concentration in the high $\mathrm{pH}$ supernate from neutralized uranium recovery wastes that were scavenged should be fairly low. Thus, the distribution observed for core 36 is fairly consistent with historical predictions: high strontium content in the bottom subsegment; higher in the next, which should contain some uranium recovery waste; lower in the next three; and higher again for the last subsegment, which should contain waste from the strontium semiworks.

In summary, 1) the water-leach results from all the cores suggest that sufficient ferrocyanide remains to prevent the solubilization of the normally soluble cesium; 2) the leach results from core 36 indicate that ferrocyanide has distributed itself throughout the waste in $\mathrm{C}-112 ; 3$ ) the strontium distributions in C-109 indicate that little physical mixing occurred during years of storage; 4) distributions of strontium in C-112 suggest that, near the tank inlet, little physical mixing occurred, but on the opposite side of the tank physical mixing of the waste occurred; and 5) there is sufficient variability in the data from core samples from the same layers in the tanks to suggest that there are significant inhomogeneities within the tanks. 
Table 4.15. Radionuclide Content of Waste (As-Received) from C-109 (Sprouse 1993)

\begin{tabular}{|c|c|c|c|c|c|c|c|c|c|c|c|c|}
\hline Radionuclide & $\begin{array}{l}\text { C-109 Comp } \\
\text { Super, } \mu \mathrm{Ci} / \mathrm{g}\end{array}$ & $\frac{\mathrm{C}-47 \text { Comp. }}{\mu \mathrm{Ci} / \mathrm{g}}$ & $\frac{\mathrm{C} 47-1 \mathrm{~B}}{\mu \mathrm{C} \mathrm{i} / \mathrm{g}}$ & $\frac{\mathrm{C} 47-1 \mathrm{C}}{\mu \mathrm{C} / \mathrm{g}}$ & $\frac{\mathrm{C} 47-1 \mathrm{D}}{\mu \mathrm{Ci} / \mathrm{s}}$ & $\frac{\mathrm{C}-48-\text { Comp }}{\mu \mathrm{Ci} / \mathrm{g}}$ & $\frac{\mathrm{C}-48-1 \mathrm{C}_{2}}{\mu \mathrm{Ci} / \mathrm{g}}$ & $\frac{\mathrm{C}-48-1 \mathrm{D}}{\mu \mathrm{C} / \mathrm{g}}$ & $\frac{\mathrm{C}-49 \mathrm{Comp}}{\mu \mathrm{Ci} / \mathrm{g}}$ & $\frac{\mathrm{C} 49-1 \mathrm{~B}_{2}}{\mu \mathrm{Ci} / \mathrm{g}}$ & $\frac{\mathrm{C}^{2} 9-1 \mathrm{C} \mathrm{C}_{2}}{\mu \mathrm{C}_{\mathrm{i}} / \mathrm{g}}$ & $\frac{\mathrm{C} 49-1 \mathrm{D},}{\mu \mathrm{C} / \mathrm{g}}$ \\
\hline${ }^{60} \mathrm{Co}$ & $1.5 e-03$ & $<2.4 e-02$ & $<2.8 \mathrm{e}-02$ & $<2.4 \mathrm{e}-02$ & $<2.0 \mathrm{e}-02$ & $<2.6 e-02$ & $<1.5 \mathrm{e}-02$ & $<1.6 \mathrm{e}-02$ & $<1.4 \mathrm{e}-02$ & $<1.3 \mathrm{e}-02$ & $<6.3 \mathrm{e}-03$ & $<1.1 \mathrm{e}-02$ \\
\hline${ }^{137} \mathrm{Cs}$ & $5.6 \mathrm{e}+02$ & $8.74 e+02$ & $3.3 e+02$ & $7.0 e+02$ & $9.5 e+02$ & $1.0 \mathrm{e}+03$ & $1.2 \mathrm{e}+03$ & $1.2 e+03$ & $5.6 e+02$ & $1.2 \mathrm{e}+02$ & $3.5 e+02$ & $7.0 \mathrm{e}+02$ \\
\hline${ }^{14} \mathrm{Eu}$ & $<0.3 \mathrm{e}-03$ & $<2.4 \mathrm{e}-01$ & $8.8 \mathrm{e}-01$ & $<1.3 \mathrm{e}-01$ & $<1.1 \mathrm{e}-01$ & $<7.2 \mathrm{e}-2$ & $<7.6 \mathrm{e}-02$ & $<9.5 \mathrm{e}-02$ & $3.6 \mathrm{e}-01$ & $7.8 \mathrm{e}-01$ & $<3.8 \mathrm{e}-02$ & $<6.2 \mathrm{e}-02$ \\
\hline${ }^{135} \mathrm{Eu}$ & $2.4 \mathrm{e}-02$ & $<0.8 \mathrm{e}-02$ & $1.2 \mathrm{e}+00$ & $<8.6 \mathrm{e}-01$ & $<9.7 \mathrm{e}-01$ & $<1.2 \mathrm{e} 0$ & $<1.1 \mathrm{e00}$ & $<1.2 \mathrm{e} 00$ & $<5.2 \mathrm{e}-01$ & $9.3 \mathrm{e}-01$ & $<2.5 \mathrm{e}-01$ & $<4.9 \mathrm{e}-01$ \\
\hline${ }^{241} \mathrm{Am}$ & $<1.4 \mathrm{e}-03$ & $<0.4 \mathrm{e}-02$ & $7.5 e-01$ & $<4.8 \mathrm{e}-01$ & $<5.5 \mathrm{e}-01$ & $<7.1 \mathrm{e}-01$ & $<5.9 \mathrm{e}-01$ & $<6.3 \mathrm{e}-01$ & $<3.5 \mathrm{e}-01$ & $5.2 \mathrm{e}-01$ & $<1.4 \mathrm{e}-01$ & $<2.6 \mathrm{e}-01$ \\
\hline Total Alpha & $<0.5 \mathrm{e}-04$ & $9.9 \mathrm{e}-01$ & NR & NR & NR & $6.5 e-02$ & $\mathrm{NR}$ & NR & $1.3 \mathrm{e}-01$ & NR & NR & NR \\
\hline${ }^{239} \mathrm{Pu}+{ }^{241} \mathrm{Pu}$ & NR & $8.8 \mathrm{e}-01$ & NR & NR & NR & $6.8 \mathrm{e}-02$ & NR & NR & $7.90 \mathrm{e}-0$ & NR & NR & NR \\
\hline${ }^{221} \mathrm{Am}$ & NR & $3.2 \mathrm{e}-01$ & NR & NR & NR & $1.0 \mathrm{e}-02$ & NR & NR & $1.3 \mathrm{e}-01$ & NR & NR & NR \\
\hline Total Bela & $5.4 e+00$ & $2.8 e+03$ & NR & NR & NR & $1.3 e+03$ & NR & NR & $2.3 e+03$ & NR & NR & NR \\
\hline${ }^{90} \mathrm{~S} \mathbf{r}$ & $1.1 \mathrm{e}-02$ & $1.2 \mathrm{e}+03$ & $4.6 e+03$ & $4.7 e+02$ & $2.2 e+02$ & $1.9 e+02$ & $1.5 e+02$ & $1.2 e+02$ & $9.3 e+02$ & $2.4 e+03$ & $2.0 e+02$ & $1.9 \mathrm{e}+02$ \\
\hline${ }^{90} \mathrm{Tc}$ & $1.6 \mathrm{e}-01$ & $1.1 \mathrm{e}-01$ & NR & NR & NR & $1.2 \mathrm{e}-01$ & NR & NR & $9.4 \mathrm{e}-02$ & NR & NR & NR \\
\hline${ }^{11} \mathrm{C}$ & $2.4 \mathrm{e}-03$ & $6.3 \mathrm{e}-06$ & NR & NR & NR & $1.8 \mathrm{e}-05$ & NR & NR & $3.6 \mathrm{e}-05$ & NR & NR & NR \\
\hline${ }^{3} \mathrm{H}$ & $3.3 \mathrm{e}-03$ & $8.5 \mathrm{e}-03$ & NR & NR & NR & $6.4 \mathrm{e}-03$ & NR & NR & $6.4 \mathrm{e}-03$ & NR & NR & NR \\
\hline${ }^{79} \mathrm{Se}$ & NR & $<8.0 \mathrm{e} .05$ & NR & NR & NR & $6.0 \mathrm{e}-05$ & NR & NR & $5.0 \mathrm{e}-05$ & NR & NR & NR \\
\hline
\end{tabular}


Table 4.16. Radionuclide Content of W

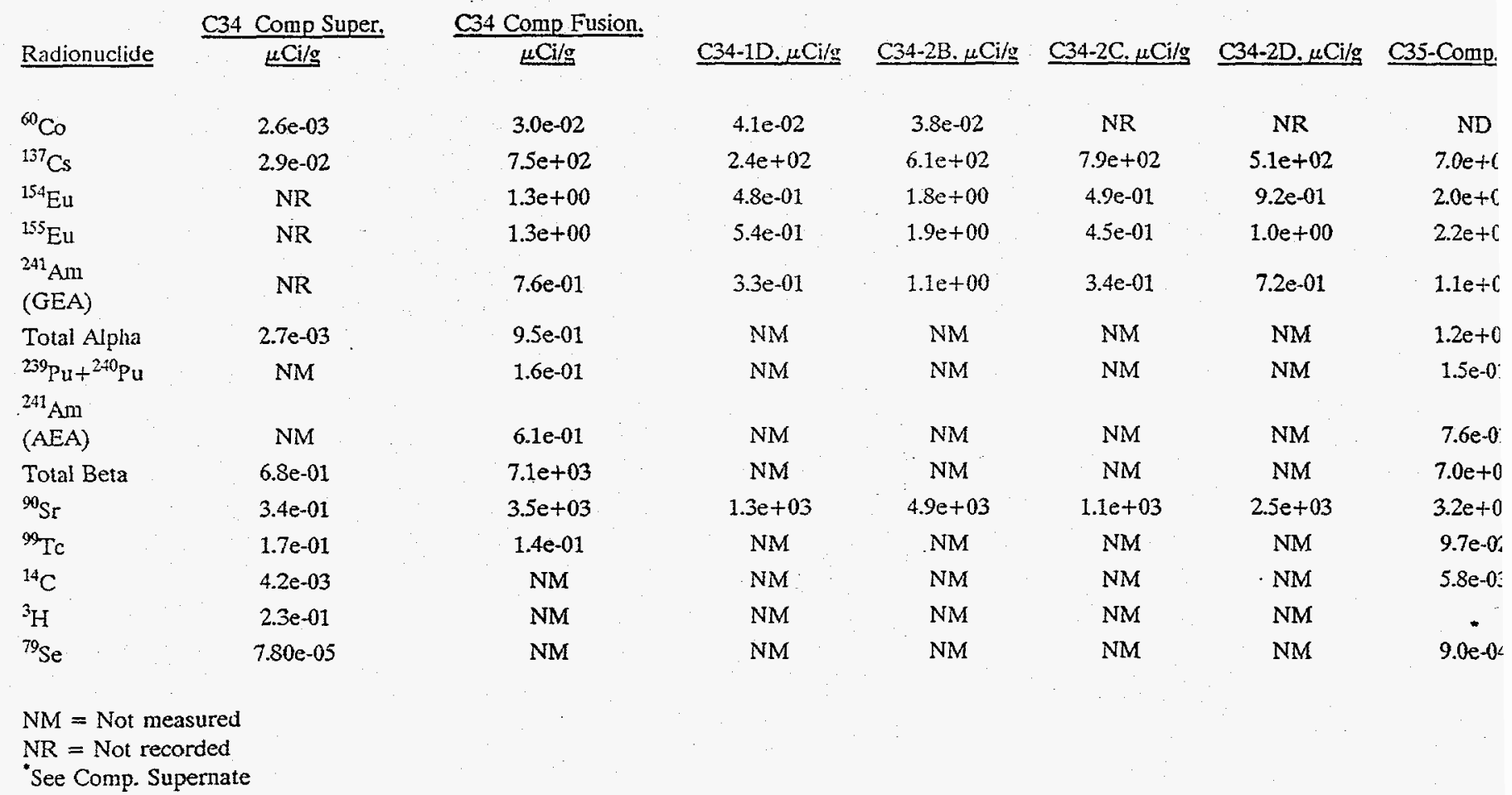


ste (As-Received) from C-112 (Bell, 1993)

\begin{tabular}{|c|c|c|c|c|c|c|c|}
\hline$\frac{235 \text { Comp Super. }}{\mu \mathrm{Ci} / \mathrm{g}}$ & C36 Comp. $\mu \mathrm{Ci} / \mathrm{g}$ & $\mathrm{C} 36-1 \mathrm{C}, \mu \mathrm{Ci} / \mathrm{g}$ & C36-1D. $\mu \mathrm{Ci} / g$ & $\underline{\mathrm{C} 36-2 \mathrm{~A}, \mu \mathrm{Ci} / \mathrm{g}}$ & C36-2B. $\mu \mathrm{Ci} / \mathrm{g}$ & $\mathrm{C} 36-2 \mathrm{C}, \mu \mathrm{Ci} / \mathrm{g}$ & C36-2D, $\mu \mathrm{Ci} / \mathrm{g}$ \\
\hline $3.0 \mathrm{e}-03$ & NR & $2.3 e-02$ & NR & N R & $8.2 \mathrm{e}-03$ & $8.0 \mathrm{e}-03$ & $7.4 \mathrm{e}-03$ \\
\hline $7.4 \mathrm{e}-03$ & $7.9 \mathrm{e} \div 02$ & $4.1 e+02$ & $1.2 e+03$ & $8.8 e+02$ & $5.3 e+02$ & $1.0 \mathrm{e}+02$ & $3.5 e+01$ \\
\hline ND & $1.6 \mathrm{e}-01$ & $4.9 \mathrm{e}-01$ & NR & NR & NR & $3.4 \mathrm{e}-02$ & $3.2 \mathrm{e}-02$ \\
\hline ND & NR & 4.4e- 01 & NR & NR & NR & NR & $3.5 \mathrm{e}-02$ \\
\hline $\mathrm{ND}$ & NR & $2.9 e-01$ & $2.7 \mathrm{e}-01$ & NR & NR & $4.8 \mathrm{e}-02$ & $2.5 \mathrm{e}-02$ \\
\hline $8.2 e-04$ & $1.6 \mathrm{e}-01$ & NM & NM & NM & $\mathrm{NM}$ & NM & NM \\
\hline NR & $5.9 \mathrm{e}-02$ & NM & NM & NM & $\mathrm{NM}$ & NM & NM \\
\hline NR & $6.1 \mathrm{e}-02$ & NM & NM & NM & $\mathrm{NM}$ & NM & NM \\
\hline $4.8 \mathrm{e}-01$ & $1.7 e+03$ & NM & NM & NM & $\mathrm{NM}$ & NM & NM \\
\hline $2.3 e-01$ & $5.1 e+02$ & $4.0 \mathrm{e}+02$ & $1.5 e+01$ & $2.0 e+01$ & $7.0 e+01$ & $1.4 e+02$ & $2.0 \mathrm{e}+02$ \\
\hline $8.4 \mathrm{e}-02$ & $1.1 \mathrm{e}-01$ & NR & NR & NR & NR & NR & NR \\
\hline $1.3 e-03$ & $<$ Blank & NM & NM & NM & NM & NM & NM \\
\hline $2.1 \mathrm{e}-03$ & NR & NM & NM & $\mathrm{NM}$ & NM & NM & NM \\
\hline $2.1 \mathrm{e}-04$ & $3.9 \mathrm{e}-04$ & NR & NR & NR & NR & NR & NR \\
\hline
\end{tabular}




\subsection{Physical Properties of Actual and INFARM Simulants}

Several physical properties are important to those interested in developing models for the behavior of ferrocyanide wastes; for example, density, particle size, rheological properties, and thermal behavior. This section presents and compares the measured densities, particle sizes, rheological properties, and thermal behaviors of simulated INFARM wastes and wastes from Tanks C-109 and C-112.

The initial characterization effort for the simulated wastes (Jeppson and Wong 1993) did not determine the settling or rheological behavior of the simulated wastes; therefore, PNL obtained additional top and bottom INFARM-1 simulant samples from T. M. Hohl of WHC. Selected properties such as density were measured for each of the as-received materials, after these two samples were blended, and the 1:1 and 3:1 water-to-waste volume dilutions prepared from the blended INFARM-1 simulant.

\subsection{Density, Water Content, and Other Bulk Physical Properties}

This section compares available measured densities, water contents, and pHs of simulated INFARM wastes with waste samples and, in some cases, water dilutions of actual waste samples obtained from C-109 and C-112.

As shown in Table 5.1, the measured bulk densities of the as-received wastes from C-109 and C-112 vary from 1.2 to $2.0 \mathrm{~g} / \mathrm{mL}$ depending on sampling location. The densities of the INFARM-1 and INFARM-2 simulants fell within this range. Based on process history, the ferro-cyanide wastes in C-109 and C-112 should be similar to INFARM-2, which had a density of $1.4 \mathrm{~g} / \mathrm{mL}$ after being centrifuged for the equivalent of $30 \mathrm{~g}-\mathrm{a}$. INFARM-2 had a higher density than that measured for the waste samples obtained from C-109 $(1.2$ to $1.3 \mathrm{~g} / \mathrm{mL})$. The bulk densities measured for the waste samples from $\mathrm{C}-112$ were $1.6,2.0$, and $1.2 \mathrm{~g} / \mathrm{mL}$ for cores 34,35 , and 36 , respectively; these densities were, in general, higher than INFARM-2's density. Based on the results in Table 5.1, the INFARM-2 simulant's density is not representative of wastes from C-109 or C-112. This conclusion could be expected given that the drainable liquid has been removed from the wastes stored in C-109 and $\mathrm{C}-112$ and that compaction forces experienced by the actual wastes and the simulant were different.

With respect to water content as presented in Table 5.2, INFARM-2 is not representative of the waste obtained in cores 47 or 49 , but is representative of the waste obtained by core 48 . This is likely due to the fact that $\mathrm{C}-109$ has been interim stabilized, with most of its pumpable water removed. It is interesting to note that cores 47 and 49 , based on the gravimetric analyses, have very similar water contents as a function of depth, yet were taken on opposite sides of the tank; core 48, which was taken about $3.5 \mathrm{~m}$ from core 47 , differs dramatically from both core 47 waste and core 49 waste.

Based on the results for the three cores presented in Table 5.2, INFARM-2, with its water content of about $50 \mathrm{wt} \%$, is moderately representative of the interim stabilized waste present in C-109, because two of three cores had water contents ranging from 20 to $40 \mathrm{wt} \%$. However, with respect to water content, it is representative of the waste in core 49 taken from the tank opposite the inlet. 
Table 5.1. Comparison of Densities of Simulated INFARM Wastes and Core 47 from C-109 and Core 36 from C-112 (Bell 1993; Sprouse 1993; Simpson et al. 1993a, 1993b; Jeppson and Wong 1993)

Density, $\mathrm{g} / \mathrm{mL}$

\begin{tabular}{|c|c|c|c|c|}
\hline Sample & Bulk & Solids, Centrifuged & Solids, Settled & Supernate \\
\hline INFARM-1 $^{(\mathrm{a})}$ & & 1.5 & 1.3 & 1.3 \\
\hline 1:1 Dilution & $1.2^{(\mathrm{b})}$ & $1.3^{(b)}$ & NM & $1.1^{(b)}$ \\
\hline 3:1 Dilution & $1.1^{(b)}$ & $1.2^{(\mathrm{b})}$ & NM & $1.1^{(\mathfrak{b})}$ \\
\hline INFARM-2 $^{(\mathfrak{a})}$ & & 1.4 & 1.3 & 1.3 \\
\hline \multicolumn{5}{|l|}{ C-109 Core 47} \\
\hline As-Received & 1.2 & NM & NM & NM \\
\hline 1:1 Dilution & NM & NM & NM & NM \\
\hline 3:1 Dilution & 1.1 & 1.4 & NM & 1.0 \\
\hline C-109 Core 48 & 1.3 & NM & NM & NM \\
\hline C-109 Core 49 & 1.2 & NM & NM & NM \\
\hline C-112 Core 34 & $1.5,1.6$ & NM & NM & NM \\
\hline C-112 Core 35 & 2.0 & NM & NM & NM \\
\hline \multicolumn{5}{|l|}{ C-112 Core 36} \\
\hline As-Received & $1.2,1.2$ & NM & NM & NM \\
\hline 1:1 Dilution & NM & NM & NM & NM \\
\hline 3:1 Dilution & 1.1 & 1.3 & NM & 1.0 \\
\hline
\end{tabular}

(a) The simulants as characterized had been centrifuged for the equivalent of $30 \mathrm{~g}-\mathrm{a}$.

(b) Measurements recently performed by PNL for this report. 
Table 5.2. Comparison of Water Contents and pHs of Simulated INFARM-2 Waste and Waste Samples from C-109 (Bell 1993; Sprouse 1993; Simpson et al. 1993a, 1993b; Jeppson and Wong 1993)

\begin{tabular}{|c|c|c|c|}
\hline \multirow[b]{2}{*}{ Sample } & \multicolumn{2}{|c|}{ Water, Wt\% } & \multirow[b]{2}{*}{$\mathrm{pH}$} \\
\hline & Gravimetric & $\mathrm{TGA}^{(\mathrm{a})}$ & \\
\hline \multicolumn{4}{|l|}{ INFARM-2 } \\
\hline Top & 52 & NM & $9.1^{(b)}$ \\
\hline Bottom & 50 & & \\
\hline \multicolumn{4}{|l|}{ C-109 } \\
\hline Core 47 1B & 19.3 & 31.4 & 8.82 \\
\hline Core $471 \mathrm{C}$ & 28.4 & 39.3 & 9.65 \\
\hline Core 47 1D & 39.4 & 28.2 & 10.21 \\
\hline Composite & 21.5 & 33.4 & 10.75 \\
\hline Core 48 1C & 52.8 & NM & 9.69 \\
\hline Core 48 1D & 51.6 & 48.1 & 10.99 \\
\hline Composite & 57.7 & NM & 10.08 \\
\hline Core 49 1B & 19.6 & 34.1 & 10.22 \\
\hline Core $491 \mathrm{C}$ & 38.3 & 46.6 & 10.53 \\
\hline Core 49 1D & 39.6 & 40.0 & 10.95 \\
\hline Composite & 27.8 & 46.1 & 9.37 \\
\hline
\end{tabular}

(a) Mass loss as measured by thermogravimetric analysis (TGA) before $100^{\circ} \mathrm{C}$ assumed to be due to water loss.

(b) $\mathrm{pH}$ of solution before addition of ferrocyanide and nickel.

With respect to the water contents observed in C-112, the INFARM-2 simulant, with its $50 \mathrm{wt} \%$ water content, is roughly representative of the water contents observed for cores 34 and 36 (water contents ranging from 45 to $60 \mathrm{wt} \%$ ). The $35 \mathrm{wt} \%$ water content in core 35 is lower than observed in the other two cores and that in INFARM-2. Tank C-112 has been interim stabilized yet has a higher water content than the waste in C-109.

With respect to $\mathrm{pH}$, the INFARM-2 simulant was prepared using an initial $\mathrm{pH}$ of 9.1 while the pHs observed for the wastes in $\mathrm{C}-109$ and $\mathrm{C}-112$ ranged from 8.8 to 10.5 (Tables 5.2 and 5.3). Thus the $\mathrm{pH}$ for INFARM-2 is roughly representative of the $\mathrm{pH}$ found in the two actual wastes. A large variability would be expected for the actual wastes depending on the pHs of the other wastes added to 
Table 5.3 Comparison of Water Contents and pHs of Simulated INFARM-2 Waste and Waste Samples from C-112 (Bell 1993; Sprouse 1993; Simpson et al. 1993a, 1993b; Jeppson and Wong 1993)

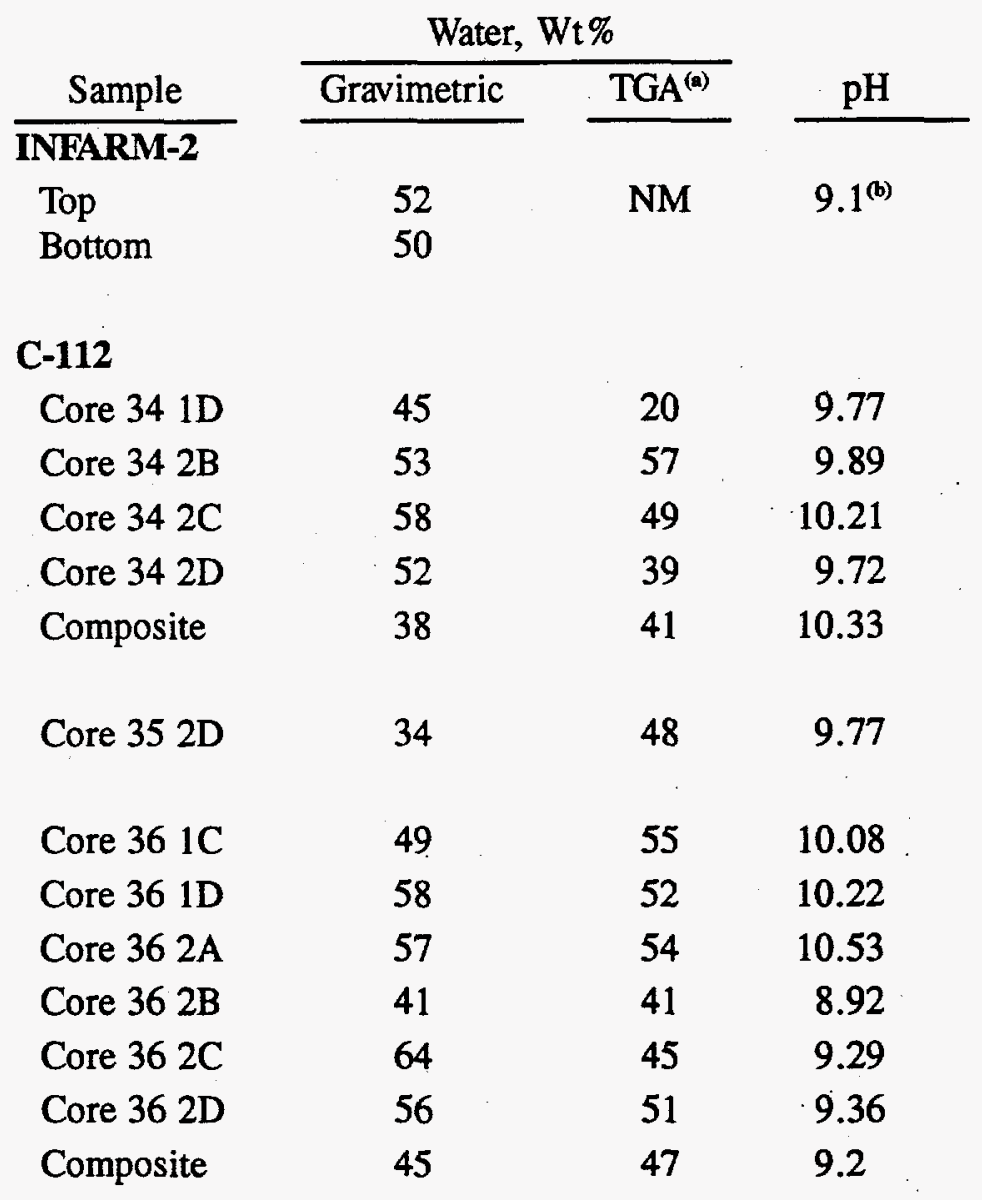

(a) Mass loss as measured by thermogravimetric analysis (TGA) before $100^{\circ} \mathrm{C}$ assumed to be due to water loss.

(b) $\mathrm{pH}$ of solution before addition of ferrocyanide and nickel.

the tanks, the mixing that occurred in the tank, the mobility of the aqueous in the waste, and on exposure of the waste to air with the attendant absorption of carbon dioxide by the hydroxide in the waste.

There is no definite $\mathrm{pH}$ trend as a function of depth within each tank. Inspection of the results for core 36 in Table 5.3 indicates that the $\mathrm{pH}$ decreases with depth; however, inspection of the $\mathrm{pH}$ analyses for core 34 does not reveal the same trend. The pHs differ even at the same depths, suggesting inhomogeneity across the tank. 
In summary, in terms of density, the INFARM-2 simulant density is higher than those of wastes stored in C-109; however, the wastes in C-112 have densities that are both greater and less than INFARM-2's. The densities of the 3:1 volume dilutions of the C-109 and C-112 wastes were the same as that of the 3:1 dilution of INFARM-1 simulant. In terms of water content, the INFARM-2 simulant contained more water than two of the core samples from C-109 and nearly the same as the other; the simulant, in general, had a similar water content as found in the $\mathrm{C}-112$ core samples. In terms of $\mathrm{pH}$, the actual waste samples tended to have somewhat higher pHs than the simulant.

\subsection{Particle Size Distribution}

The mean and median summary statistics for the particle size distribution by number of particles having particular size and by volume occupied by particles of a particular size are presented in Tables 5.4 and 5.5 for the INFARM-2 simulant and C-109 samples and for INFARM-2 and C-112 samples, respectively. Figures 5.1 through 5.7 present the particle size distributions by number and volume for INFARM-2 simulant, composite core samples of waste from cores 47,48 , and 49 taken from C-109, and composite core samples of waste from cores 34,35 and 36 taken from $\mathrm{C}-112$, respectively.

Based on the summary statistics presented in Table 5.4, the solids are, in general, $<2 \mu \mathrm{m}$ by number and $<40 \mu \mathrm{m}$ by volume. By number, the INFARM-2 simulant and waste in core 48 from C109 are nearly identical;however, the particle sizes in waste samples from cores 47 and 49 are slightly greater than in INFARM-2. The median and mean by number for the INFARM-2 top are respectively,

Table 5.4. Mean and Median Particle Size Summary Statistics for Solids in INFARM-2 and Wastes from C-109 (Bell 1993; Sprouse 1993; Simpson et al. 1993b; Jeppson and Wong 1993)

\begin{tabular}{|c|c|c|c|c|}
\hline \multirow[b]{2}{*}{ Sample } & \multicolumn{2}{|c|}{ By Number } & \multicolumn{2}{|c|}{ By Volume } \\
\hline & Median, $\mu \mathrm{m}$ & Mean, $\mu \mathrm{m}$ & Median, $\mu \mathrm{m}$ & Mean, $\mu \mathrm{m}$ \\
\hline Core 47 & 0.85 & 1.14 & 38.72 & 37.56 \\
\hline Core 48 & 0.77 & 0.80 & 2.97 & 5.73 \\
\hline Core 49 & 0.90 & 1.38 & 24.08 & 24.47 \\
\hline INFARM-2 Top & 0.76 & 0.71 & 14.3 & 17.16 \\
\hline INFARM-2 Bottom & 0.76 & 0.79 & 16.1 & 17.99 \\
\hline
\end{tabular}

Table 5.5. Mean and Median Particle Size Summary Statistics for Solids in INFARM-2 Simulant and Waste Samples from C-112 (Bell 1993; Sprouse 1993; Simpson et al. 1993a; Jeppson and Wong 1993)

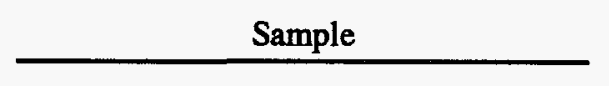

Core 34, Subsegment 2D, Initial

Core 34, Subsegment 2D, Duplicate

Core 36

INFARM-2 Top

INFARM-2 Bottom

\begin{tabular}{|c|c|}
\hline \multicolumn{2}{|c|}{ By Number } \\
\hline Median, $\mu \mathrm{m}$ & Mean, $\mu \mathrm{m}$ \\
\hline 0.76 & 0.83 \\
\hline 0.83 & 0.94 \\
\hline 0.84 & 0.95 \\
\hline 0.76 & 0.71 \\
\hline 0.76 & 0.79 \\
\hline
\end{tabular}

\begin{tabular}{|c|c|}
\hline \multicolumn{2}{|c|}{ By Volume } \\
\hline Median, $\mu \mathrm{m}$ & Mean, $\mu \mathrm{m}$ \\
\hline 6.05 & 8.68 \\
\hline 6.32 & 9.60 \\
\hline 33.26 & 33.77 \\
\hline 14.3 & 17.16 \\
\hline 16.8 & 17.99 \\
\hline
\end{tabular}


0.76 and $0.71 \mu \mathrm{m}$; for the INFARM-2 bottom, 0.76 and $0.79 \mu \mathrm{m}$; and for core $48,0.77$ and $0.8 \mu \mathrm{m}$. For core 47 , the median and mean by number are 0.85 and 1.14, which are greater than INFARM-2's solids. For core 49 , the median and mean by number are 0.9 and $1.38 \mu \mathrm{m}$, again greater than measured for INFARM-2.

INFARM-2 is not as representative of wastes in C-109 by volume occupied by particles of a particular size as it is by number. By volume, INFARM-2 has median and mean diameters of 16.1 and 18 $\mu \mathrm{m}$, respectively, compared to 39 and $38 \mu \mathrm{m}$ for core 47,3 and $6 \mu \mathrm{m}$ for core 48 , and 24 and $25 \mu \mathrm{m}$ for core 49.

The mean and median particle size summary statistics for $\mathrm{C}-112$, presented in Table 5.5, show that, by number, the solids in INFARM-2 closely resemble those in the three cores from C-112. The mean and median particle sizes by number for each core from $\mathrm{C}-112$ are $<1 \mu \mathrm{m}$, which is comparable to the solids in INFARM-2.

The summary statistics for the by-volume particle size distributions indicate that the volume occupied by particles having a particular size in the solids obtained from C-112 differ from those in INFARM-2. The solids in cores 34 and 36 were smaller by a factor of one-half than those in INFARM-2; however, the solids in core 35 were larger by about a factor of 2 than the INFARM-2 mean and median statistics.

Inspection of Figures 5.2, 5.3, and 5.4 shows that, in general, at least $90 \%$ of the particles in these samples from C-109 had diameters less than $3 \mu \mathrm{m}$. By number, the INFARM-2 simulant had smaller particles than the waste samples from cores 47 and 49 from C-109; however, the simulant had a similar number distribution as the waste from core 48 . The significance of this difference is difficult to assess, because the wastes in cores 47 and 49 taken from C-109 (Figures 5.2 and 5.4) have similar size distributions by number but differ somewhat from that measured for core 48 (Figure 5.3). The variability within the tank is different from that expected based on sampling location. Cores 47 and 48 were taken from areas in the tank near the inlet (Simpson et al. 1993b) and would therefore be expected to be more similar to each other rather than to the waste from core 49 , which was on the opposite side of the tank from the inlet.

Comparison of the particle size distributions by volume presented in Figures 5.1, 5.2, 5.3, and 5.4 indicate that the larger particles in the waste samples obtained from C-109 occupy a larger fraction of the waste volume than the larger particles in the simulant INFARM-2 with the exception of the solids obtained by core 48 . The volume distributions in the simulant and the composite core 48 sample are the most similar, with about 40 and $60 \%$ respectively, occupied by solids having a diameter $<2 \mu \mathrm{m}$. As observed for the distribution by number, the solids distribution by volume for cores 47 and 49 are roughly similar to each other and dissimilar to the solids found in core 48 . In terms of the particle size distribution by volume, the INFARM-2 simulant is not very representative of the waste samples from C-109.

The particle size distributions of solids in INFARM-2 simulant and in the waste samples from C-112 are similar by number; however, the volume distributions differ. Comparison of Figure 5.1 with Figures $5.5,5.6$, and 5.7 shows a similar size distribution by number within the simulant and the solids in $\mathrm{C}-112$, with $>95 \%$ of particles having diameters $<2 \mu \mathrm{m}$. The distributions by volume differ, with the 1 - and $2-\mu \mathrm{m}$ particles occupying about $40 \%$ of the simulant's solids volume, whereas the solids in wastes from $\mathrm{C}-112$ have a larger fraction of their volume occupied by particles having diameters ranging up to $85 \mu \mathrm{m}$, with the largest volume fraction occupied $<8 \%$. In terms of the 

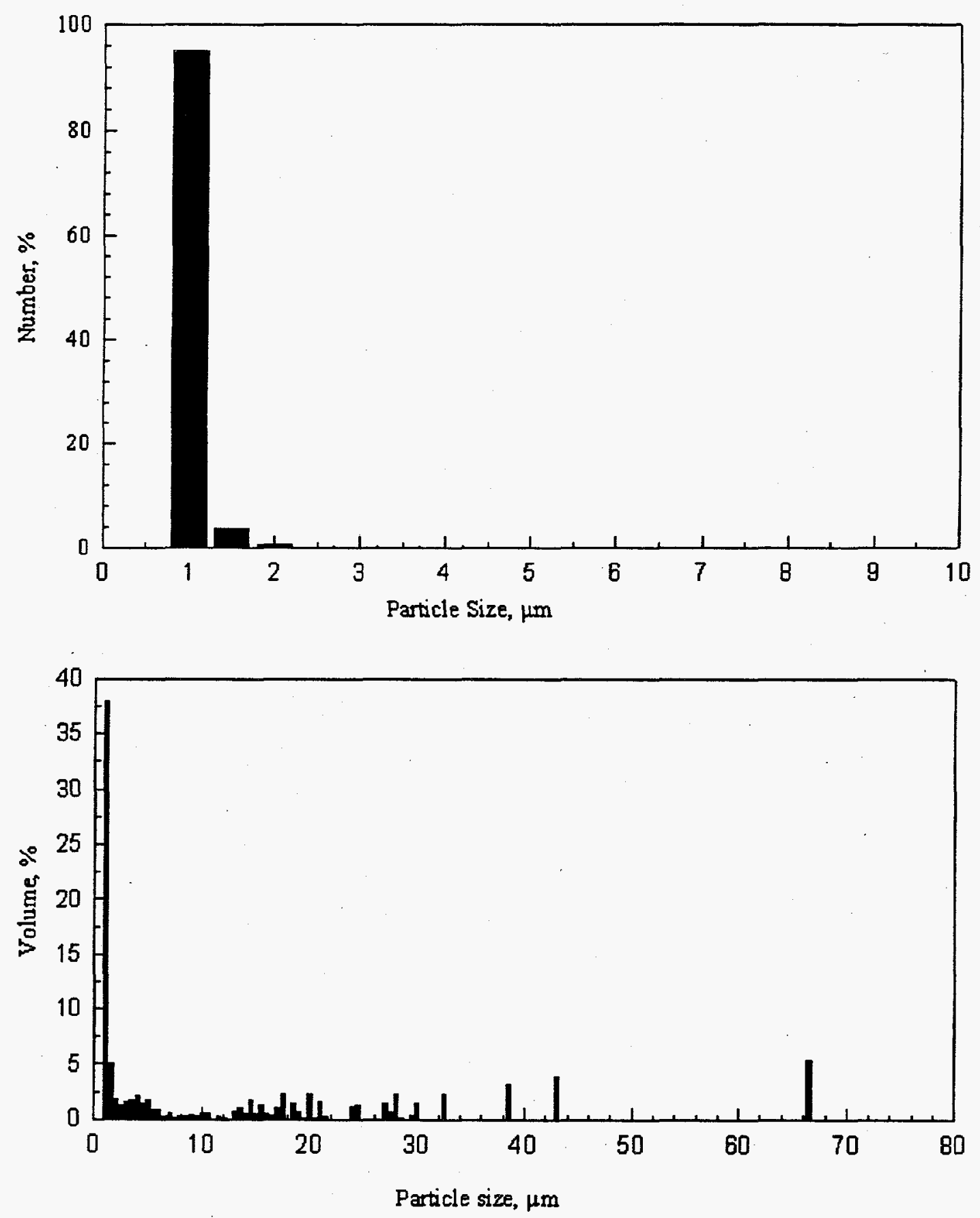

Figure 5.1. Particle Size Distributions, by Number and Volume, of the Simulated Ferrocyanide Waste INFARM-2 (Rev 25A). 

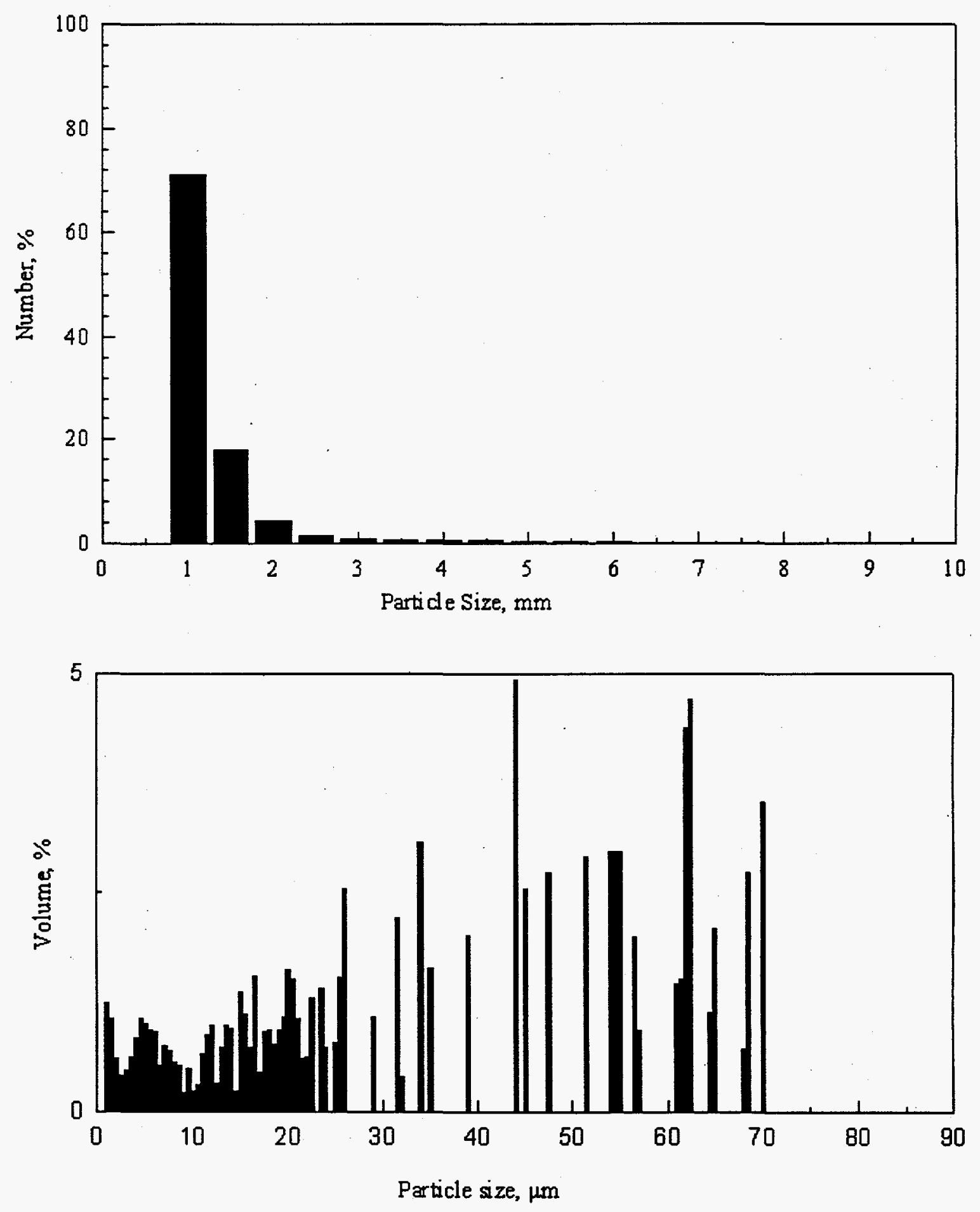

Figure 5.2. Particle Size Distributions, by Number and Volume, of Waste from Tank 241-C-109 (Core 47) 

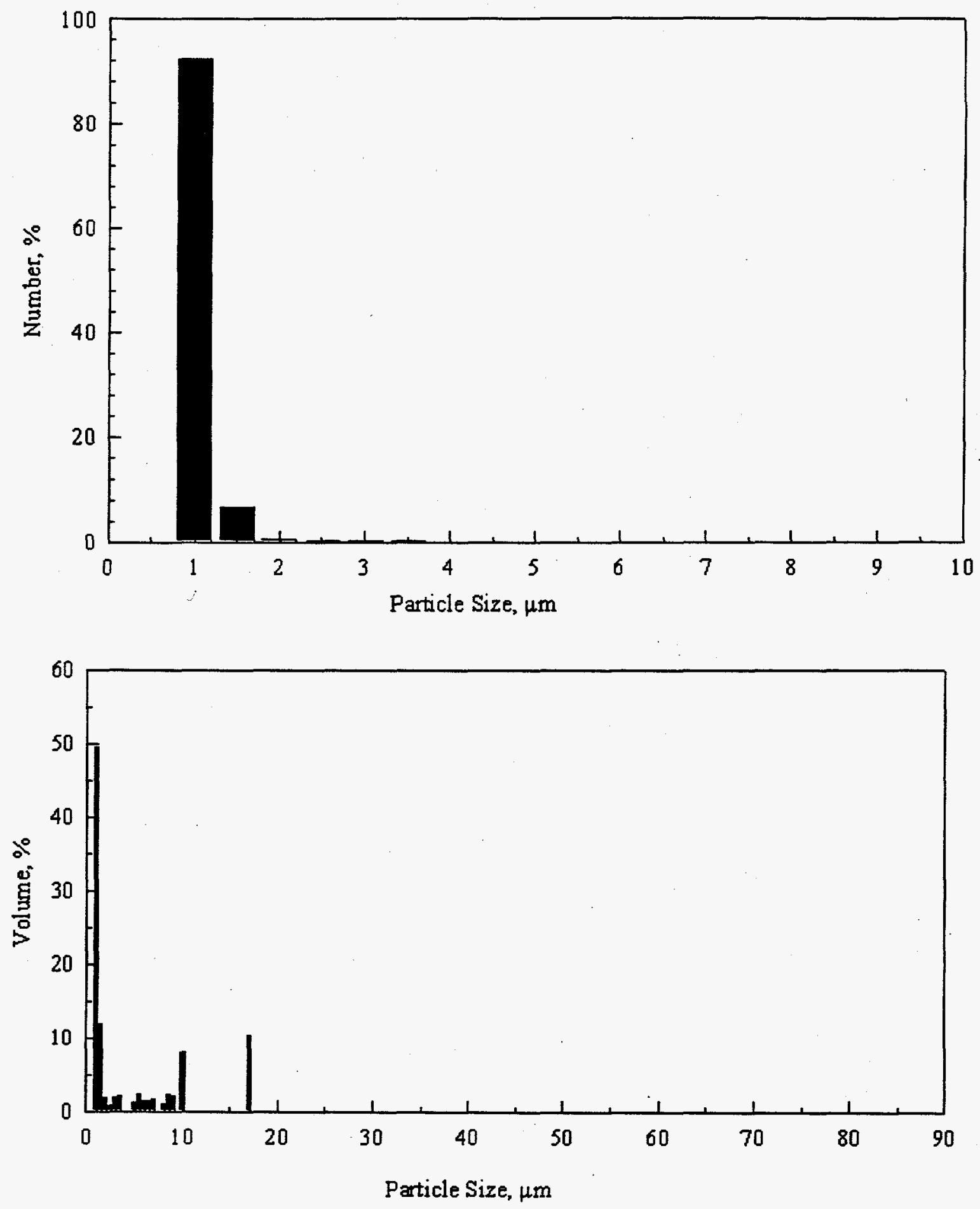

Figure 5.3. Particle Distribution, by Number and Volume, of Waste from Tank 241-C-109 (Core 48). 

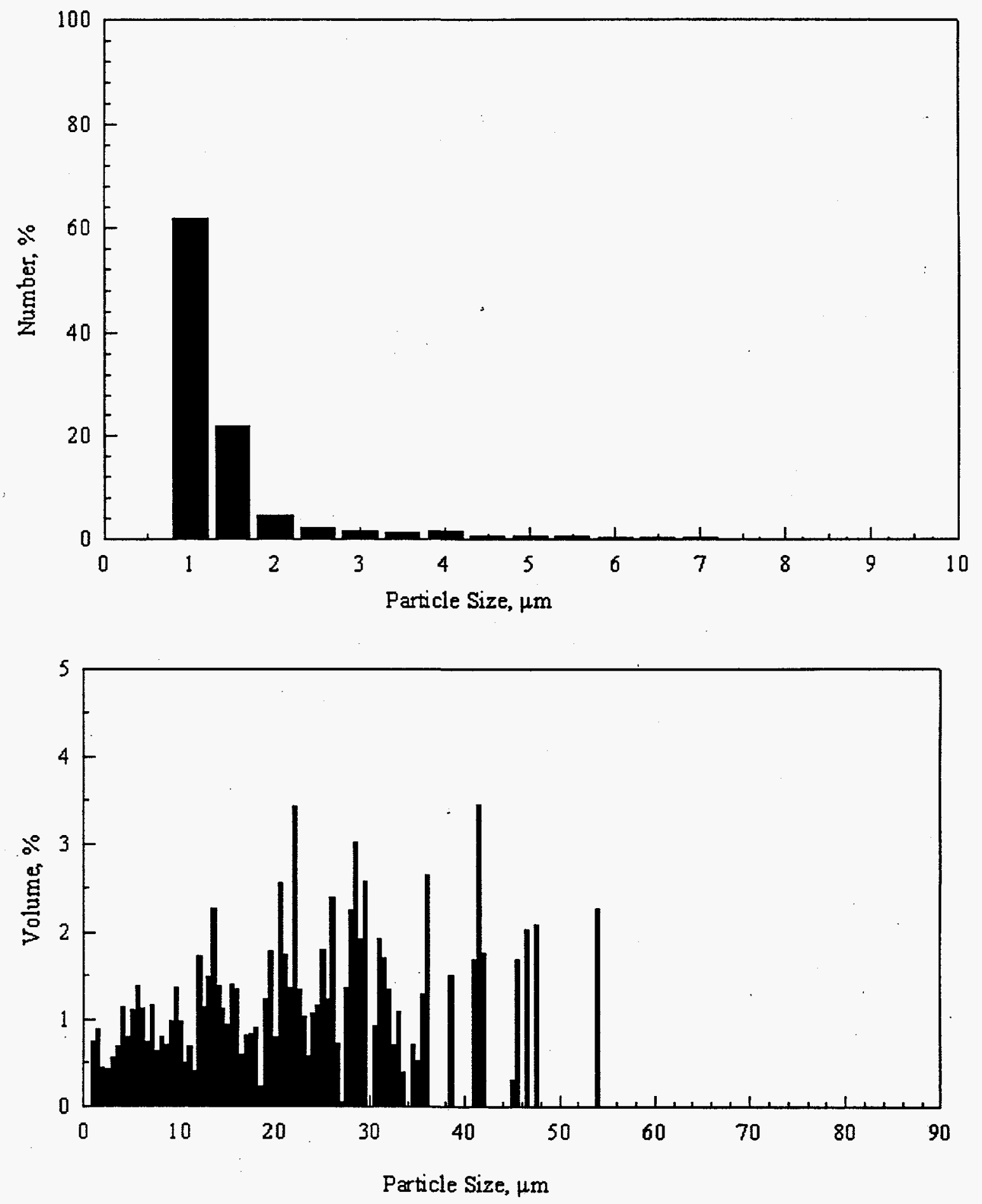

Figure 5.4. Particle Size Distribution, by Number and Volume, of Waste Obtained from Tank 241-C-109 (Core 49). 

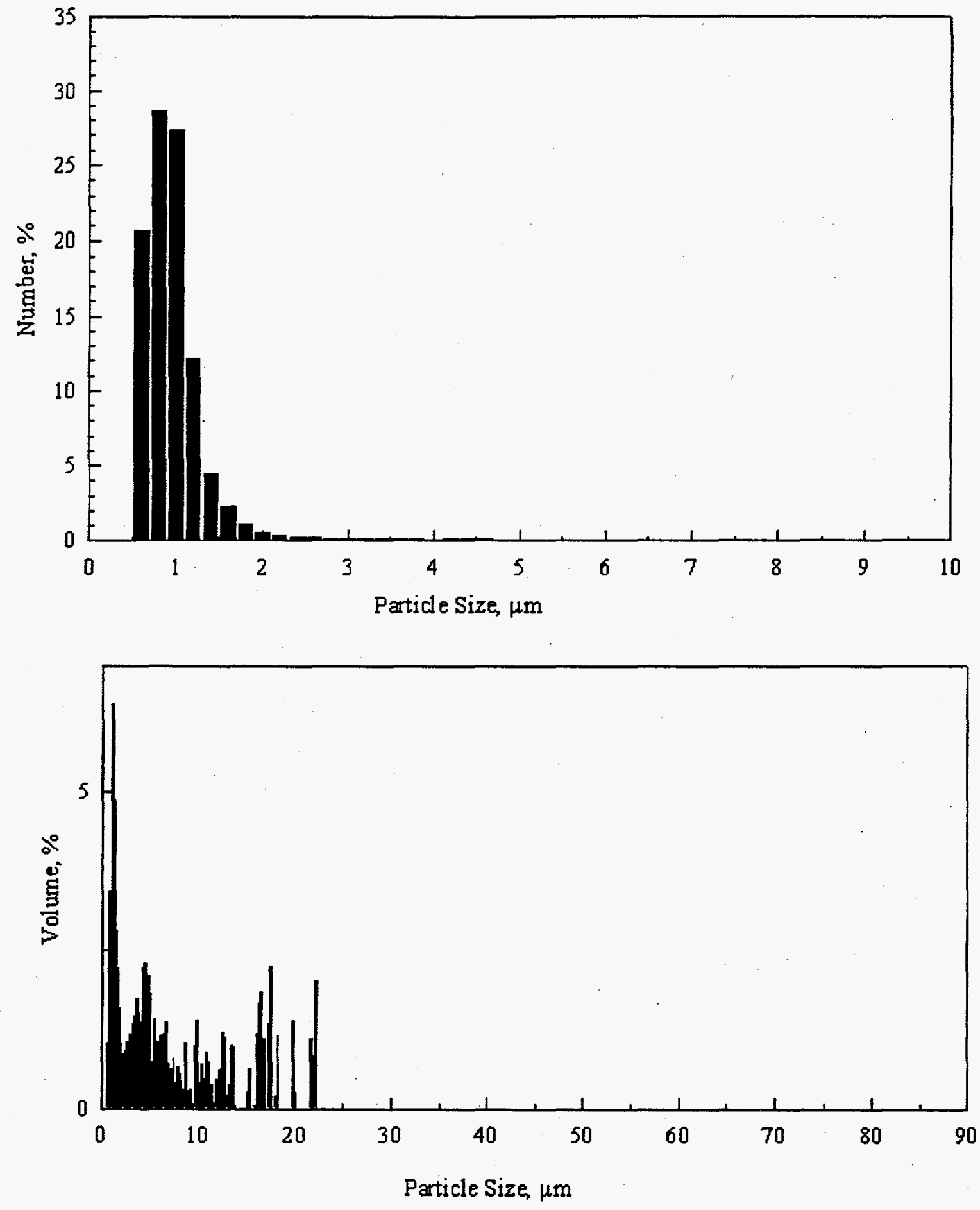

Figure 5.5. Particle Size Distribution, by Number and Volume, of Waste from the Tank 241-C-112 (Core 34). 

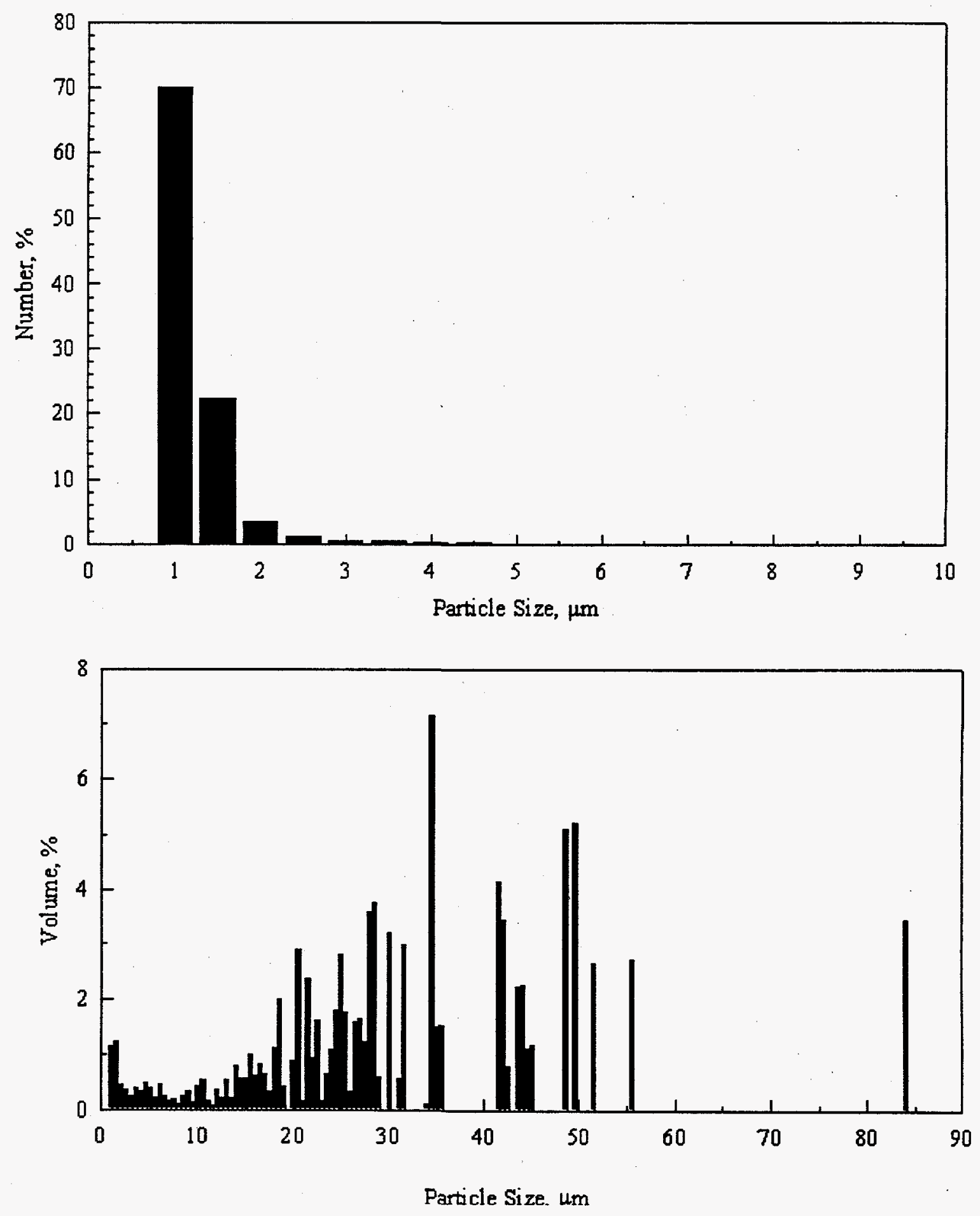

Figure 5.6. Particle Size Distribution of Waste from Tank 241-C-112 (Core 35) 

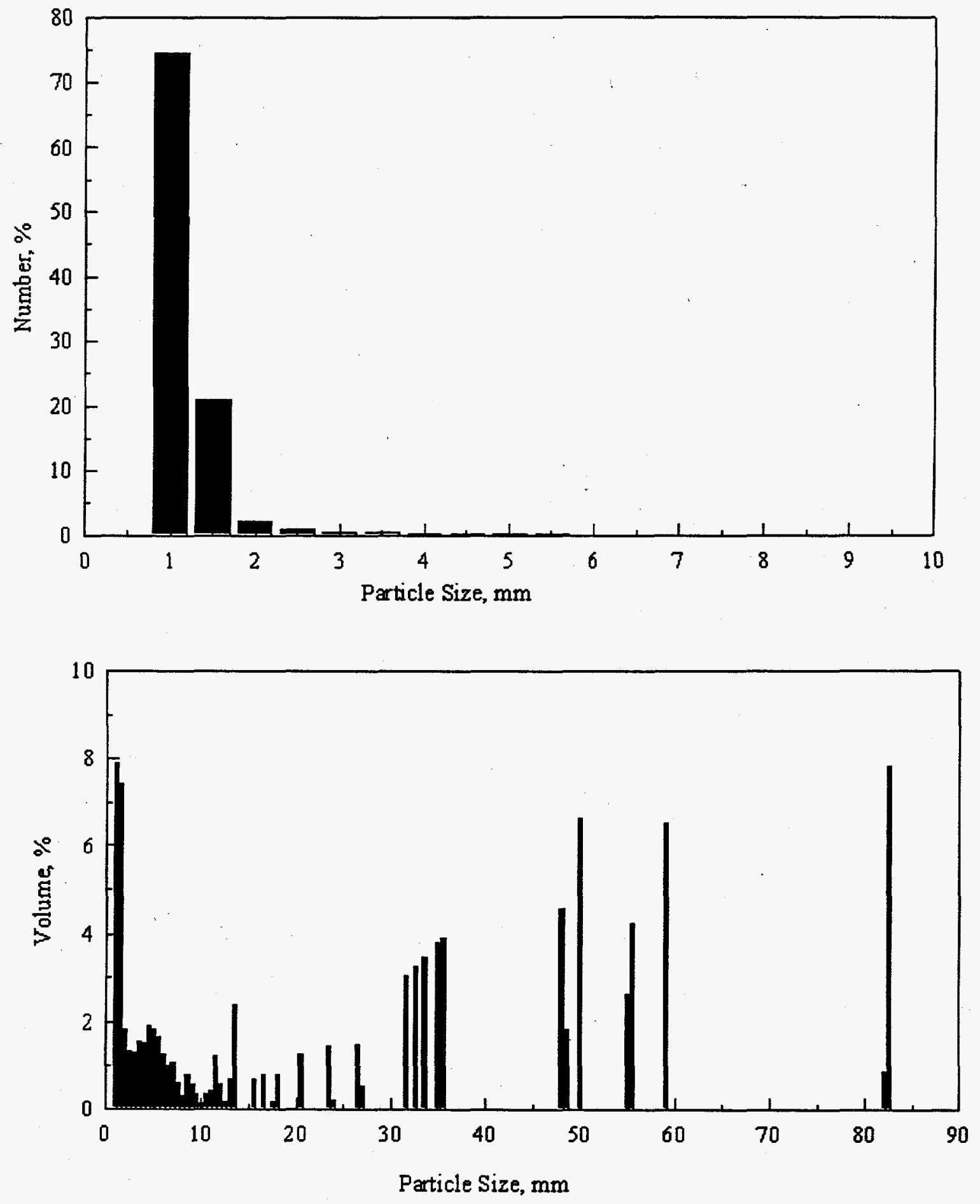

Figure 5.7 Particle Size Distribution, by Number, of Waste from Tank 241-C-112 (Core 36) 
representative-news of the INFARM-2 simulant to the C-112 waste samples, the simulant is representative in terms of number of particles, having a particular diameter; however, in terms of volume fraction occupied, the simulant is not representative.

In summary, the INFARM-2 simulant's solids were, in general, smaller than those found in the waste samples taken from $\mathrm{C}-109$ and $\mathrm{C}-112$. The distribution by number of particles having a particular size in the simulant was similar though not identical to the actual wastes; the distribution was closer to the waste from C-112 than to the waste from C-109, with the exception of waste from core 48 . In terms of volume occupied by those solids, the simulant's solids volume was occupied by very small particles having diameters of 1 and $2 \mu \mathrm{m}$ while the wastes from C-109 and C-112 distributed their solids volume across a larger range within a small range $(<8 \mathrm{vol} \%)$.

\subsection{Settling Behavior}

The settling behavior of the as-received INFARM-1 simulated ferrocyanide waste and the as-received wastes from C-109 and C-112 were the same; however, the solids settling behavior in 1:1 and 3:1 water-to-waste dilutions of INFARM-1 and the same dilutions of wastes from cores 47 and 36 taken from C-109 and C-112, respectively, differed dramatically. The as-received materials did not settle, nor did the solids in the two dilutions of the simulant during three days of sitting. In contrast, the solids in the dilutions from the actual wastes as shown in Figures 5.8 and 5.9 did settle. After about $55 \mathrm{~h}$, the solids in C-109 core $471: 1$ and $3: 1$ dilutions settled to $88 \mathrm{vol} \%$ and 41 vol\%, respectively, and the solids in the two dilutions of waste from C- 112 core 36 settled to 77 and 74 vol\%, respectively.

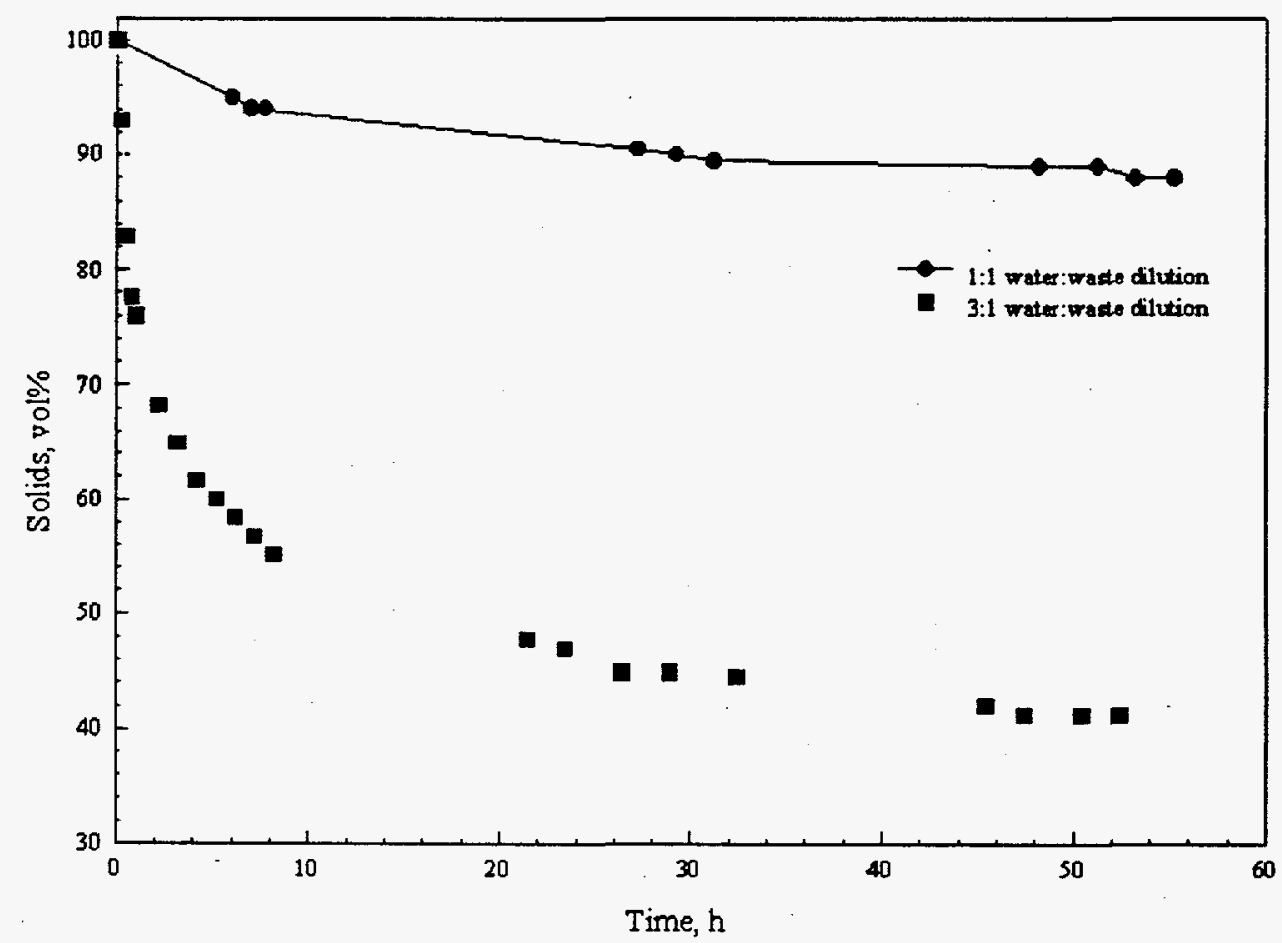

Figure 5.8. Settling Behavior of Solids in 1:1 and 3:1 Water-to-Waste Dilutions of Waste from Tank 241-C-109 (Core 47). 


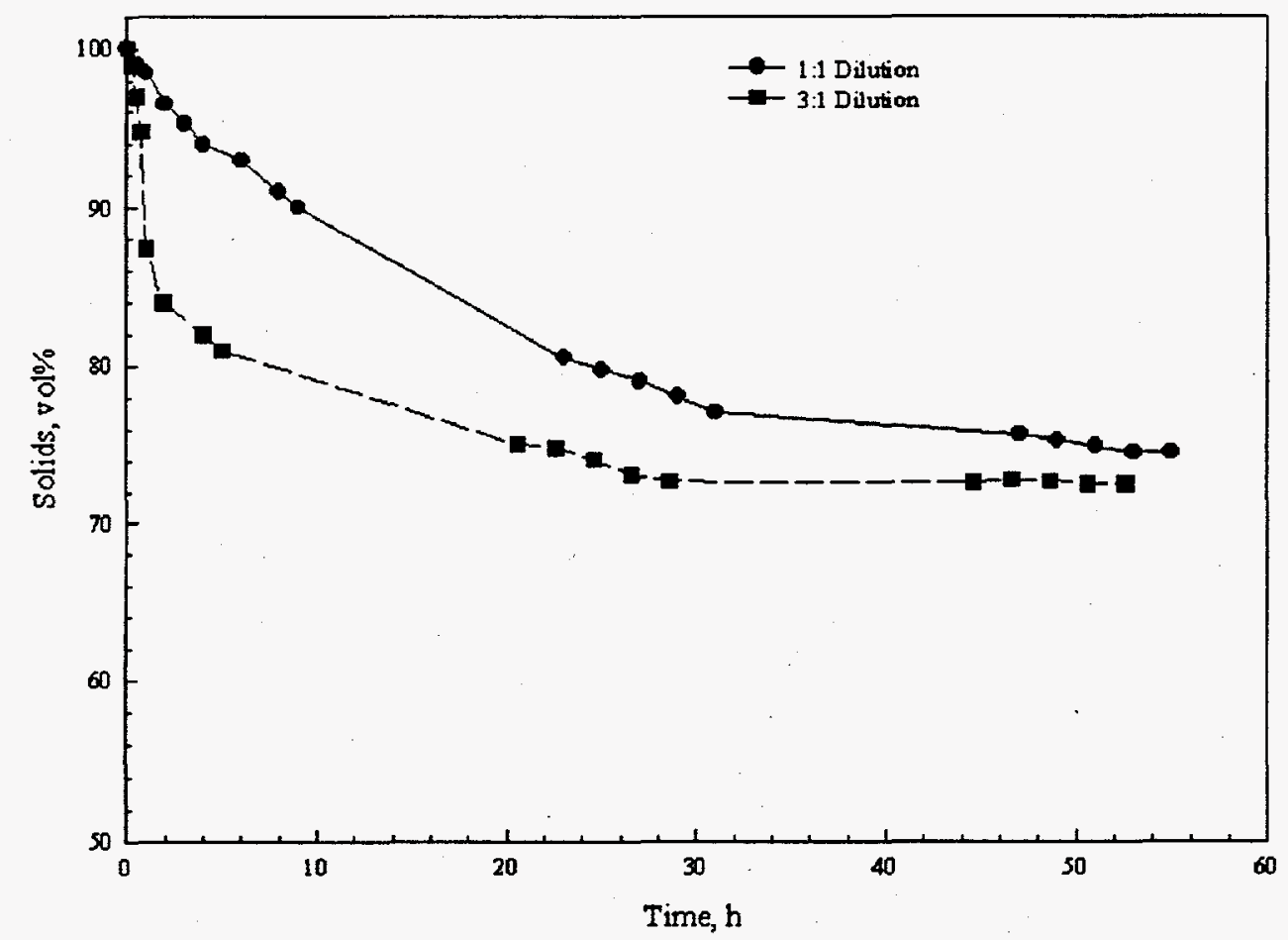

Figure 5.9. Settling Behavior of Solids in 1:1 and 3:1 Water:Waste Dilutions of Waste from Tank 241-C-112 (Core 36).

This difference in settling behavior indicates that the simulated INFARM-1 waste, as delivered to PNL from WHC, in terms of settling behavior is not representative of wastes as taken from C-109 and C-112. The lack of settling by the INFARM simulant when diluted suggests absorption of water and the formation of a gel.

\subsection{Comparison of Rheological Properties}

The flow or rheological behavior of ferrocyanide wastes is important both in terms of retrieval and the safety evaluation of "hot spot" formation and behavior. Current plans for disposal of Hanford wastes will require retrieval or removal of the ferrocyanide wastes from the high-level-waste USTs; thus the flow and rheological properties are necessary to design the removal and transport systems for these wastes. "Hot spot" formation, or the concentration of the heat-producing radionuclides in a localized area with subsequent heating of a ferrocyanide-rich region, has been suggested or proposed as one potential mechanism that could lead to exothermic reactions between cyano species in the ferrocyanide wastes and nitrate and/or nitrite.

Fauske and Cash (1993) postulate that the formation of hot spots will be dependent on the rheological or flow properties of the ferrocyanide wastes. If the waste exhibits non-Newtonian, homogeneous particle-liquid flow, they postulate that hot spots will not form due to the formation of an expanding gas bubble. In experimental studies Epstein et al. (1994) found that when nitrogen is introduced into a 
column of simulated INFARM waste, or simulated ferrocyanide sludge is heated above the boiling point of water, bubble formation occurs; this finding indicates that the simulant exhibits the nonNewtonian, homogeneous particle-liquid flow that would preclude hot spot formation, as postulated by Fauske and Cash.

This section presents the measured flow and rheological properties and empirical models for simulated INFARM-1 waste, wastes from C-109 (core 47) and C-112, and 1:1 and 3:1 water dilutions (by volume) of INFARM-1, core 47, and core 36 wastes. The properties measured include shear strength, shear stress versus shear rate, and apparent viscosity versus shear rate.

The results for the INFARM-1 simulant were recently obtained by PNL and have not been previously reported. As the simulated wastes were produced, the preparers noted differences between the top and bottom fractions of the simulant after being centrifuged for the equivalent of $30 \mathrm{~g}$-a, so they divided the centrifuged material into two fractions, top and bottom. The shear strengths for both INFARM-1 top and bottom were measured. After the shear strength measurements were complete, the two samples were combined, and the dilutions prepared and characterized.

Table 5.6 presents the measured shear strengths of INFARM-1 simulant and composited core samples of C-109 and C-112 wastes. The shear strengths of the two actual waste samples are similar $\left(17,300\right.$ and 16,000 dyne/ $\left.\mathrm{cm}^{2}\right)$; however, they differ substantially from those of the two INFARM-1 samples $\left(1,580\right.$ and 40,500 dyne/ $\left.\mathrm{cm}^{2}\right)$. Note the significant difference between the two INFARM-1 samples. The INFARM-1 simulant shear strength is not representative of cores 47 and 36 waste samples.

Table 5.7 presents the apparent viscosities of diluted INFARM-1 waste, diluted core 47 from C-109 waste, and core 36 and diluted C-112 waste at selected shear rates and at 30 and/or $90-95^{\circ} \mathrm{C}$. Figures $5.8,5.9,5.10$, and 5.11 present shear stress and apparent viscosity as a function of shear rate. We were unable to measure the shear stress as a function of shear rate for the blended INFARM-1 sample, because it could not be poured. Core 47 from C-109 was not analyzed. The 1:1 dilutions of the C-109 and C-112 wastes dried too quickly during analysis at $95^{\circ}$ to obtain accurate results (Sprouse 1993).

Table 5.6. Shear Strengths of INFARM-1 Simulant and Wastes from C-109 (Sprouse 1993) and C-112 (Bell 1993)

$\begin{array}{lr}\text { Sample } & \text { Shear Strength, dyne/cm } \\ \text { INFARM-1 Top } & 1,580 \\ \text { INFARM-1 Bottom } & 40,500 \\ \text { C-109 (Core 47) } & 17,300 \\ \text { C-112 (Core 36) } & 16,000\end{array}$


Table 5.7. Apparent Viscosities of Diluted INFARM-1 Simulant and Wastes and Diluted Wastes from C-109 (Sprouse 1993) and C-112 (Bell 1993)

\begin{tabular}{|c|c|c|c|}
\hline Sample & $\begin{array}{c}\text { Temperature, } \\
\cdot \mathrm{C} \\
\end{array}$ & Shear Rate, $\mathrm{s}^{-1}$ & $\begin{array}{c}\text { Apparent Viscosity, cP } \\
\text { (Run 1, Run 2) }\end{array}$ \\
\hline \multirow{4}{*}{$\begin{array}{l}\text { INFARM-1, 1:1 } \\
\text { Water Dilution }\end{array}$} & 30 & 140 & 585,575 \\
\hline & & 470 & 202,195 \\
\hline & 90 & 140 & 640,760 \\
\hline & & 470 & 270,300 \\
\hline \multirow{4}{*}{$\begin{array}{l}\text { INFARM-1, 3:1 } \\
\text { Water Dilution }\end{array}$} & 30 & 140 & 40,40 \\
\hline & & 470 & 16,16 \\
\hline & 90 & 140 & 30,20 \\
\hline & & 470 & 10,7 \\
\hline \multirow{2}{*}{$\begin{array}{l}\text { C-109 (Core } 47) \text {, } \\
\text { 1:1 Water Dilution }\end{array}$} & 30 & 140 & 320,350 \\
\hline & & 470 & $128, \mathrm{NM}$ \\
\hline \multirow{2}{*}{$\begin{array}{l}\text { C-109 (Core 47), } \\
\text { 3:1 Water Dilution }\end{array}$} & 30 & 140 & $<2,<2$ \\
\hline & & 470 & $<2,<2$ \\
\hline C-112 (Core 36$)$ & 30 & 140 & 900,1200 \\
\hline $\begin{array}{l}\text { C-112 (Core } 36), \\
1: 1 \text { Water Dilution }\end{array}$ & 30 & 140 & 85,75 \\
\hline \multirow{2}{*}{$\begin{array}{l}\text { C-112 (Core 36), } \\
\text { 1:1 Water Dilution }\end{array}$} & 95 & 140 & 50,40 \\
\hline & & 470 & 17,19 \\
\hline
\end{tabular}

With respect to apparent viscosity, based on the results in Table 5.8 and Figures 5.10 to 5.13 , the INFARM-1 simulant and its water dilutions do not appear to be quantitatively representative of the wastes from C-109 and C-112. For example, the INFARM-1 $1: 1$ dilution at $30^{\circ} \mathrm{C}$ and a shear rate of $140 \mathrm{~s}^{-1}$ has an apparent viscosity of $580 \mathrm{cP}$ while the $1: 1$ dilutions of the $\mathrm{C}-109$ and $\mathrm{C}-112$ wastes have apparent viscosities of $335 \mathrm{cP}$ and $80 \mathrm{cP}$. The 3:1 water-to-waste dilutions of the wastes from $\mathrm{C}-109$ had viscosities of $<2 \mathrm{cP}$, which is near the detection limit of the instrument; the viscosity of the $3: 1$ water dilution of the C-112 sample was not measured.

As shown in Figures 5.10 to 5.13 and as reported by Bell (1993), all of the materials exhibited yieldpseudoplastic behavior, with the exception of the 3:1 dilution of the C-109 waste sample, which exhibited near-Newtonian behavior as best can be surmised using data near the detection limit of the viscometer. Yield-pseudoplastic behavior implies that a force of sufficient strength must be applied to cause the material to move. Qualitatively, the INFARM-1 simulant is representative of the wastes from C-109 (core 47) and C-112 (core 36) and their dilutions, with the possible exception of the 3:1 dilution of the $\mathrm{C}-109$ sample. 

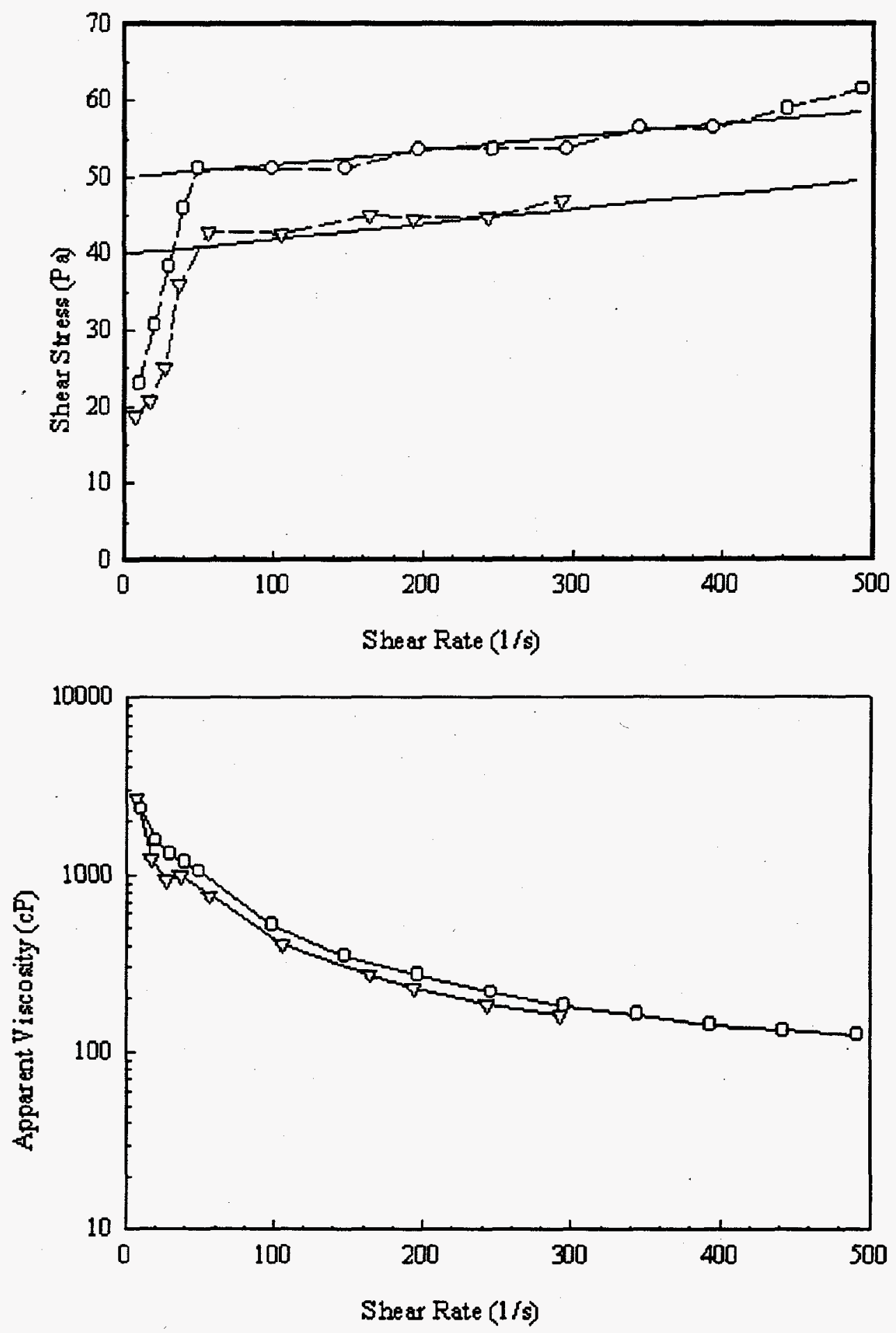

Figure 5.10. Rheological Behavior of 1:1 Water-to-Waste Dilution of Waste from Tank 241-C-109 at $30^{\circ} \mathrm{C}$. Plots are for shear stress as a function of shear rate and apparent viscosity as a function of shear rate. 

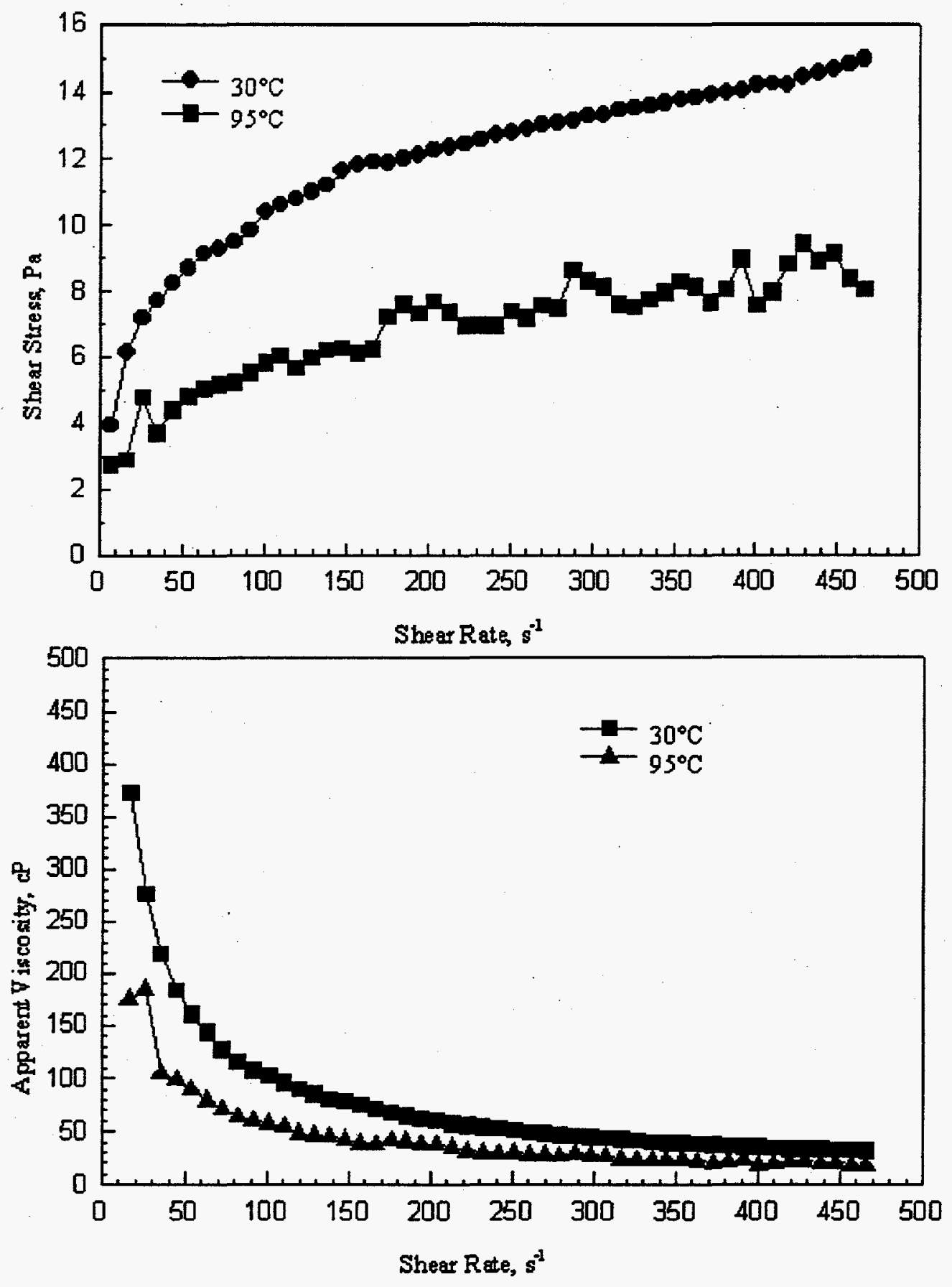

Figure 5.11. Rheological Behavior of a 1:1 Water-to-Waste Dilution of Waste from Tank 241-C-112 (Core 36 ) at 30 and $95^{\circ} \mathrm{C}$. 
Table 5.8. Power-Law Model Parameters $\left(S_{\tau}=\alpha+B \gamma^{n}\right)$ for INFARM-1 Simulant and Wastes from C-109 (Core 47) and C-112 (Core 36) where $S_{r}$ is Shear Stress, $\alpha$ is Yield Stress, B is the Consistency Factor, $\gamma$ is the Shear Rate $\left(0\right.$ to $\left.468 \mathrm{~s}^{-1}\right)$ and $n$ is the Flow Behavior Index

\begin{tabular}{|c|c|c|c|c|}
\hline Sample & Temperature, ${ }^{\circ} \mathrm{C}$ & $\alpha, \operatorname{Pa}(\operatorname{Run} 1, \operatorname{Run} 2)$ & B, Pa-s (Run 1, Run 2) & n, (Run 1, Run 2) \\
\hline $\begin{array}{l}\text { INFARM-1 } \\
\text { 1:1 Dilution }\end{array}$ & 30 & 49,50 & $7.8,9.9$ & $0.29,0.23$ \\
\hline $\begin{array}{l}\text { C-109 1:1 } \\
\text { Dilution }\end{array}$ & 30 & 50,40 & $0.017,0.019$ & 1,1 \\
\hline $\begin{array}{l}\text { C-112 1:1 } \\
\text { Dilution }\end{array}$ & 30 & $6.8,5.8$ & $0.28,0.30$ & $0.58,0.53$ \\
\hline $\begin{array}{l}\text { INFARM 3:1 } \\
\text { Dilution }\end{array}$ & 30 & $3.6,4.9$ & $0.081,0.0056$ & $1,0.88$ \\
\hline $\begin{array}{l}\text { INFARM-1 } \\
\text { 1:1 Dilution }\end{array}$ & 90 & 72,81 & $0.24,0.38$ & $0.88,0.84$ \\
\hline $\begin{array}{l}\text { C-112 1:1 } \\
\text { Dilution }\end{array}$ & 95 & $3.6,4$ & $0.079,0.10$ & $0.68,0.65$ \\
\hline $\begin{array}{l}\text { INFARM-1 } \\
\text { 3:1 Dilution }\end{array}$ & 90 & $4.5,2.4$ & $0.00001,0.0019$ & 1,1 \\
\hline
\end{tabular}

The shear stress versus shear rate was fit to a yield power-law model (equation 5.1) assuming yieldpseudoplastic behavior. Table 5.8 presents the results of these fits. Comparison of the values for each of the fit coefficients other than the yield stress is believed to have little value. These models can be used to predict the rheological properties of a material accurately, but minor changes in measured values can change the fit parameters dramatically.

$$
S_{r}=\alpha+\beta \gamma^{n}
$$

where $S$ is shear stress, $\alpha$ is yield stress, $\beta$ is the consistency factor, $\gamma$ is the shear rate, and $n$ is the flow behavior index

In general, the yield stress or $\alpha$ for INFARM-1 1:1 dilution is dissimilar to all the samples with the exception of the C-109 1:1 dilution at $30^{\circ} \mathrm{C}$. With this one exception, the INFARM-1 simulant is not representative of the actual waste behavior in terms of the force required to begin moving the diluted waste.

In summary: Qualitatively, the diluted INFARM-1 simulant exhibits the same yield-pseudoplastic rheological behavior as the corresponding ferrocyanide wastes from C-109 and C-112 with the exception of the 3:1 dilution of the C-109 waste, which exhibits Newtonian flow characteristics. Quantitatively, the INFARM-1 simulant rheological behavior is not representative of the rheological behavior of the wastes from $\mathrm{C}-109$ and $\mathrm{C}-112$. 

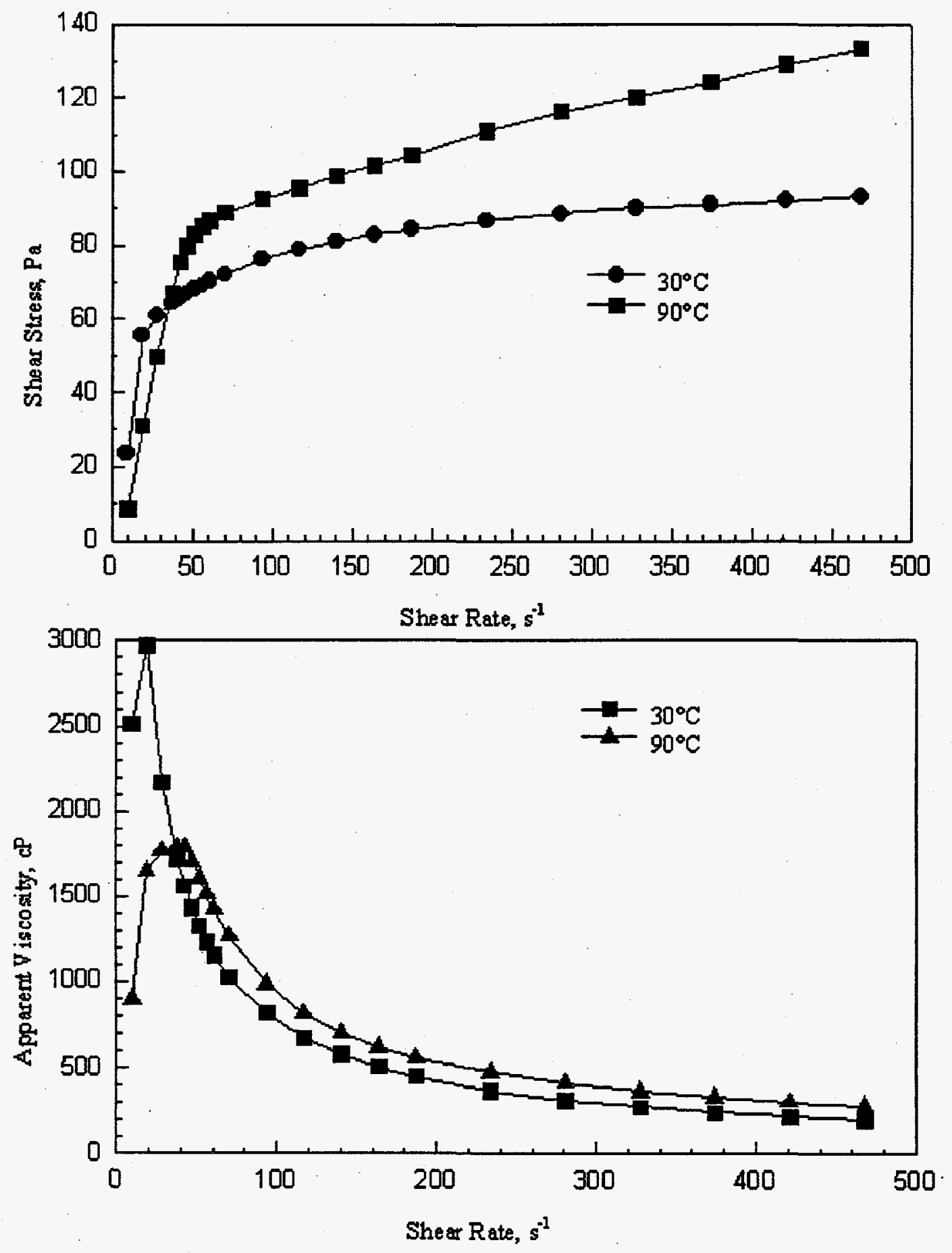

Figure 5.12. Rheological Behavior of a 1:1 Water-to-Simulated INFARM-1 Waste Dilution at 30 and $90^{\circ} \mathrm{C}$. 

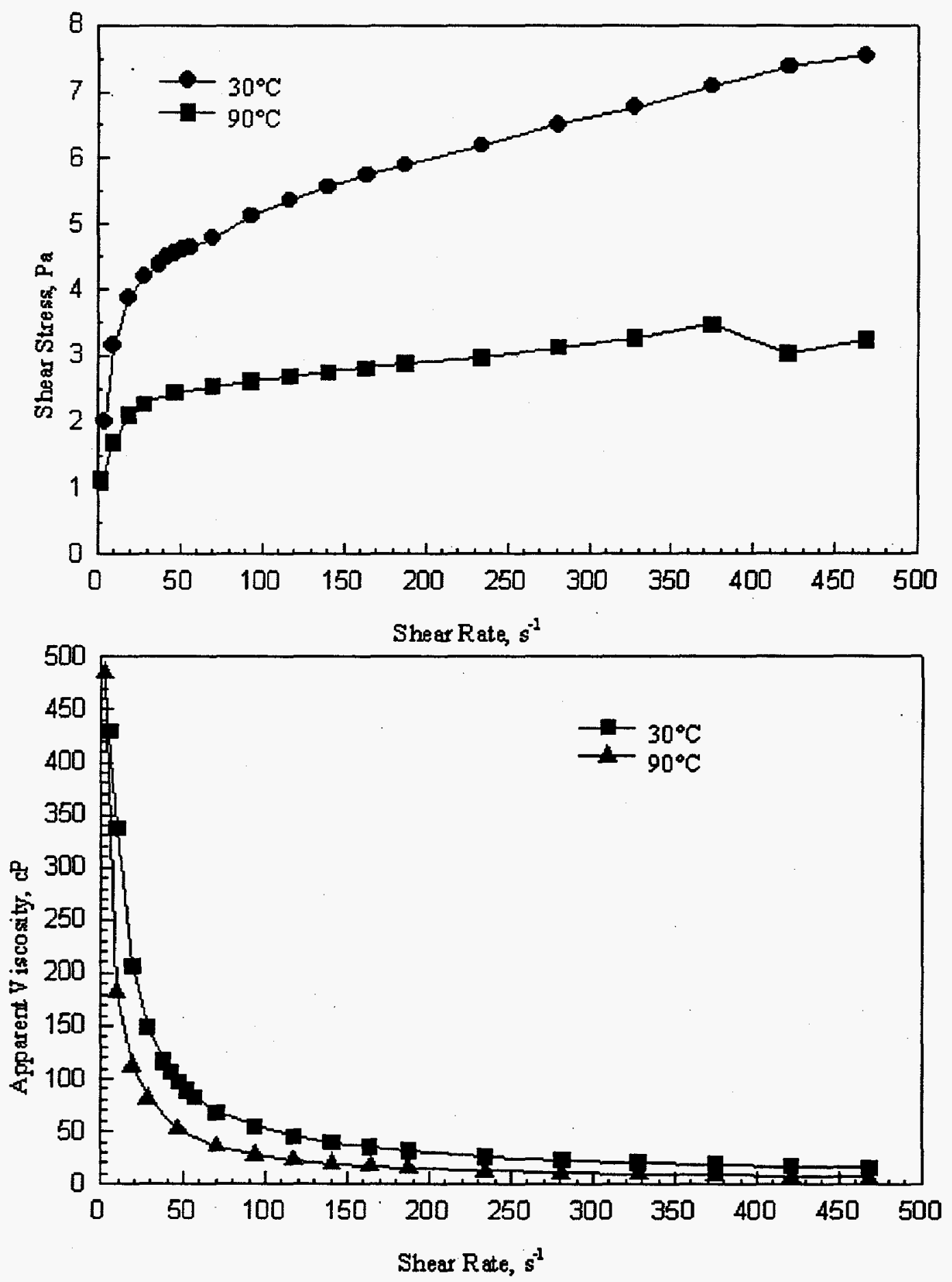

Figure 5.13. Rheological Behavior of 3:1 Water-to-Simulated INFARM-1 Waste Dilution at 30 and $90^{\circ} \mathrm{C}$. 


\subsection{Thermal and Chemical Reactivity Behavior}

The thermal and reactivity behavior of the ferrocyanide wastes is a measure of the reactivity hazard associated with the stored waste. Given the years of storage of the ferrocyanide wastes and the unknown aging reactions that might have occurred during the years of storage, several factors must be considered to establish safe storage operating parameters. Either the current thermal reactivity and reaction energetics of the wastes should be known, or these storage operating parameters should be based on chemical systems having greater reactivities than the actual wastes. To establish these safe operating parameters, studies have been performed at Los Alamos National Laboratory (LANL) (Scheele and Cady 1989; Cady 1992), at Fauske \& Associates (Jeppson and Wong 1993; Postma et al. 1994); at Washington State University (Dodds and Thomson, 1994a; 1994b) and at PNL (Burger and Scheele 1988, 1991; Hallen et al. 1992; Scheele et al. 1991, 1992a,b,c, 1993) to determine the thermal behavior of simulated ferrocyanide wastes and model ferrocyanide and oxidant mixtures, and the energetics of the observed reactions.

These researchers employed a variety of thermoanalytical techniques to determine the thermal behavior of simulated wastes and the reaction energetics. Among the techniques used were differential scanning calorimetry (DSC), thermogravimetric analysis (TGA), differential thermal analysis (DTA), dynamic $x$-ray diffraction spectrometry (DXRD), accelerating rate calorimetry (ARC), the Fauske \& Associates' Reactive System Screening Tool (RSST), and a time-to-explosion (TTX) or Henkin test (Henkin and McGill 1952; Faubian 1984). Barney (Jeppson and Wong 1993) used a DTA/TGA coupled with a mass spectrometer (MS) to analyze the evolved gases to identify the causes for observed reactions.

Differential scanning calorimetry measures enthalpy and TGA measures mass changes when a sample is heated at a known and constant rate. Differential thermal analysis is akin to DSC, except that it measures temperature differences between a sample and reference rather than the enthalpy as the sample and reference are heated at a known and constant rate. Accelerating rate calorimetry is an adiabatic calorimetric method that monitors the sample/sample container system for exothermic behavior; as soon as such behavior is detected, adiabaticity is maintained as the material self-heats. The RSST heats the sample at a nominal $1^{\circ} \mathrm{C} / \mathrm{min}$ and tracks the sample temperature; the method is useful for detecting propagating reactions and Arrhenius behavior. In the TTX test, a sample is submerged into a heated environment and the time to explosion monitored.

The thermal behavior of as-received (undried) subsegments of wastes from C-109 and C-112 and composite samples were determined using DSC and TGA. Therefore, direct comparisons of the observed behavior of simulated INFARM wastes will employ these two methods. However, the reader is referred to Jeppson and Wong (1993) for the extended studies using RSST, and to Cady (1992) for ARC and additional DTA, Henkin testing, and other thermal sensitivity studies. Included in the following discussion are recent results that PNL obtained using ARC and a slightly larger sample $(0.8$ g) than employed by Cady $(0.5 \mathrm{~g})$.

The summary results of PNL's recent DSC and TGA analyses of dried INFARM-2 simulant are presented in Tables 5.9 and 5.10. Table 5.11 summarizes results of Barney's DTA/TGA/MS analyses of (undried) INFARM-2 simulant (Jeppson and Wong 1993). Figure 5.14 presents the DSC and TGA analyses of the (dried) INFARM-2 simulant; the figure also includes the differential of the TGA (DTG) 
Table 5.9. Reaction Ranges, Onset Temperatures, and Reaction Enthalpies Due to Thermally Induced Reactions for Dried INFARM-2 Simulated Waste as Measured by DSC $\left(5^{\circ} \mathrm{C} / \mathrm{min}\right.$, Nitrogen Purge)

\begin{tabular}{|c|c|c|c|c|c|c|c|c|c|c|c|c|}
\hline \multirow[b]{2}{*}{ Sample } & \multicolumn{3}{|c|}{ Transition \#1 } & \multicolumn{3}{|c|}{ Transition $\# 2$} & \multicolumn{3}{|c|}{ Transition \#3 } & \multicolumn{3}{|c|}{ Transition \#4 } \\
\hline & Range, ${ }^{\circ} \mathrm{C}$ & Onset, ${ }^{\circ} \mathrm{C}$ & $\Delta \mathrm{H}, \mathrm{J} / \mathrm{g}$ & Range, 'C & Onset, ${ }^{\circ} \mathrm{C}$ & $\Delta \mathrm{H}, \mathrm{J} / \mathrm{g}$ & Range, 'C & Onset, 'C & $\Delta H, J / g$ & Range, 'C & Onset, ${ }^{\circ} \mathrm{C}$ & $\overline{\Delta H, J / g}$ \\
\hline $\begin{array}{l}\text { INFARM-2 } \\
\text { (Top) \#1 }\end{array}$ & $163-247$ & 174 & 64.9 & $253-292$ & 267 & 37.5 & $292-392$ & 330 & -1060.8 & \multicolumn{3}{|c|}{ None Observed } \\
\hline $\begin{array}{l}\text { INFARM-2 } \\
\text { (Top) } \# 2\end{array}$ & $163-238$ & 175 & 50.8 & $256-293$ & 267 & 33.7 & $293-390$ & 330 & -981.5 & \multicolumn{3}{|c|}{ None Observed } \\
\hline $\begin{array}{l}\text { INFARM-2 } \\
\text { (Bottom) \#1 }\end{array}$ & $163-256$ & 166 & 83.8 & $256-294$ & 270 & 31.1 & $294-400$ & 325 & -1137.6 & $453-547$ & 474 & 858.7 \\
\hline $\begin{array}{l}\text { INFARM-2 } \\
\text { (Bottom) } \$ 2\end{array}$ & $145-248$ & 166 & 78.9 & $256-300$ & 264 & 32.9 & 299-392 & 325 & -1110.3 & $444-542$ & 480 & 871.9 \\
\hline
\end{tabular}

Table 5.10. Reaction Ranges and Mass Losses due to Thermally Induced Reactions for Dried INFARM-2 Simulated Waste as Measured by TGA $\left(5^{\circ} \mathrm{C} / \mathrm{min}\right.$, Nitrogen Purge)

\begin{tabular}{|c|c|c|c|c|c|c|c|c|c|}
\hline \multirow[b]{2}{*}{ Sample } & \multirow[b]{2}{*}{ Run } & \multicolumn{2}{|c|}{ Transition \#1 } & \multicolumn{2}{|c|}{ Transition $\# 2$} & \multicolumn{2}{|c|}{ Transition $\mathbb{\# 3}$} & \multicolumn{2}{|c|}{ Transition \#4 } \\
\hline & & Range, ${ }^{\circ} \mathrm{C}$ & Mass Loss, wt\% & Range, ${ }^{\circ} \mathrm{C}$ & Mass Loss, wt\% & Range, ${ }^{\circ} \mathrm{C}$ & Mass Loss, wt\% & Range, ${ }^{\circ} \mathrm{C}$ & Mass Loss, wt\% \\
\hline \multirow[t]{2}{*}{ INFARM-2 (Top) } & 1 & $50-143$ & 2.5 & $144-278$ & 4.5 & $277-436$ & 18.9 & \multirow{2}{*}{\multicolumn{2}{|c|}{$\begin{array}{l}\text { None observed } \\
\text { None observed }\end{array}$}} \\
\hline & 2 & $50-125$ & 3.3 & $144-275$ & 4.4 & $274-438$ & 18.7 & & \\
\hline \multirow{2}{*}{$\begin{array}{l}\text { INFARM-2 } \\
\text { (Bottom) }\end{array}$} & 1 & $50-136$ & 3.2 & $135-288$ & 6.2 & $288-434$ & 18.4 & $434-410$ & 1.2 \\
\hline & 2 & $50-140$ & 3.2 & $144-294$ & 6.1 & $293-402$ & 17.2 & $402-512$ & 2.2 \\
\hline
\end{tabular}


Table 5.11. Thermal Behavior of Undried Simulated INFARM-2 Wastes as Measured by DTA/TGA/MS (Jeppson and Wong 1993)

\begin{tabular}{|c|c|c|c|c|c|}
\hline Sample & $\begin{array}{c}\text { Reaction Range, } \\
{ }^{\mathrm{C}}\end{array}$ & Mass Loss, wt\% & DTA Results & Gas Evolved & $\begin{array}{c}\text { Likely } \\
\text { Processes }\end{array}$ \\
\hline \multirow[t]{6}{*}{$\begin{array}{l}\text { INFARM-2 } \\
\text { (Top) }\end{array}$} & $20-140$ & 40 & Large Endo & $\mathrm{H}_{2} \mathrm{O}$ & $\begin{array}{l}\text { Free Water } \\
\text { Evaporation }\end{array}$ \\
\hline & $140-210$ & 8 & Endo & $\mathrm{H}_{2} \mathrm{O}$ & $\begin{array}{c}\text { Free + Bound } \\
\text { Water Loss }\end{array}$ \\
\hline & $210-250$ & 2 & Small Endo & $\mathrm{H}_{2} \mathrm{O}, \mathrm{NO}, \mathrm{CO}_{2}$ & $\begin{array}{l}\mathrm{NaNO}_{3} / \mathrm{NaNO}_{2} \\
\mathrm{Rx} \text { with } \mathrm{FECN}\end{array}$ \\
\hline & $250-280$ & 0 & Small Endo & None & $\begin{array}{c}\mathrm{NaNO}_{3} / \mathrm{NaNO}_{2} \\
\text { Melt }\end{array}$ \\
\hline & $280-320$ & 0 & -- & None & None \\
\hline & $320-350$ & 24 & Large Exo & $\mathrm{NO}, \mathrm{CO}_{2}$ & $\begin{array}{l}\mathrm{NaNO}_{3} / \mathrm{NaNO}_{2} \\
\mathrm{Rx} \text { with FECN }\end{array}$ \\
\hline \multirow[t]{6}{*}{$\begin{array}{l}\text { INFARM-2 } \\
\text { (Bottom) }\end{array}$} & $20-130$ & 38 & Large Endo & $\mathrm{H}_{2} \mathrm{O}$ & $\begin{array}{l}\text { Free Water } \\
\text { Evaporation }\end{array}$ \\
\hline & $130-220$ & 8 & - & $\mathrm{H}_{2} \mathrm{O}$ & $\begin{array}{c}\text { Free + Bound } \\
\text { Water Loss }\end{array}$ \\
\hline & $220-250$ & 3 & Small Exo & $\mathrm{H}_{2} \mathrm{O}, \mathrm{NO}, \mathrm{CO}_{2}$ & $\begin{array}{l}\mathrm{NaNO}_{3} / \mathrm{NaNO}_{2} \\
\mathrm{Rx} \text { with } \mathrm{FECN}\end{array}$ \\
\hline & $250-290$ & $\mathbf{0}$ & Small Endo & None & $\begin{array}{c}\mathrm{NaNO}_{3} / \mathrm{NaNO}_{2} \\
\text { Melt }\end{array}$ \\
\hline & $290-330$ & 0 & - & None & None \\
\hline & $330-350$ & 9 & Large Exo & $\mathrm{NO}, \mathrm{CO}_{2}$ & $\begin{array}{l}\mathrm{NaNO}_{3} / \mathrm{NaNO}_{2} \\
\mathrm{Rx} \text { with FECN }\end{array}$ \\
\hline
\end{tabular}

which makes it easier to compare the mass change data with the DSC. Figure 5.15 presents the results of the ARC analysis of (dried) INFARM-2. We vacuum dried the INFARM-2 simulant at $50^{\circ} \mathrm{C}$ and for 130 torr for $24 \mathrm{~h}$.

As can be seen from the DSC, TGA, and DTA/TGA/MS analyses of INFARM-2 simulant, there are four or five major reactions that can occur as the sample is heated to $500^{\circ} \mathrm{C}$. The first, from 30 to about $150^{\circ} \mathrm{C}$, is endothermic and is likely due to the evaporation of loosely bound water. The second, from 150 to about $270^{\circ} \mathrm{C}$, is endothermic with a mass loss and is likely due to loss of more tightly bound water and some reaction between ferrocyanide and nitrate and/or nitrite. The third is endothermic with no mass loss and is likely due to the melting of the nitrate and nitrite salts in the simulant. A strong multistep exotherm occurs beginning at about $270^{\circ} \mathrm{C}$, producing about $1100 \mathrm{~J} / \mathrm{g}$ simulant. The final reaction is not observed in all cases, as can be seen from Figure 5.14 when it occurs, it starts near $450^{\circ} \mathrm{C}$, is endothermic, and produces gases expected from the reaction of a reduced carbon and nitrate and/or nitrite.

The ARC of the 0.8-g sample of dried INFARM-2 presented in Figure 5.15 indicates that an exothermic reaction capable of producing a self-heat rate of $0.02^{\circ} \mathrm{C} / \mathrm{min}\left(28^{\circ} \mathrm{C} /\right.$ day $)$ begins near $200^{\circ} \mathrm{C}$ compared to the $223^{\circ}$ measured by Cady (1992). As observed by Cady and shown in Figure 5.15, the 


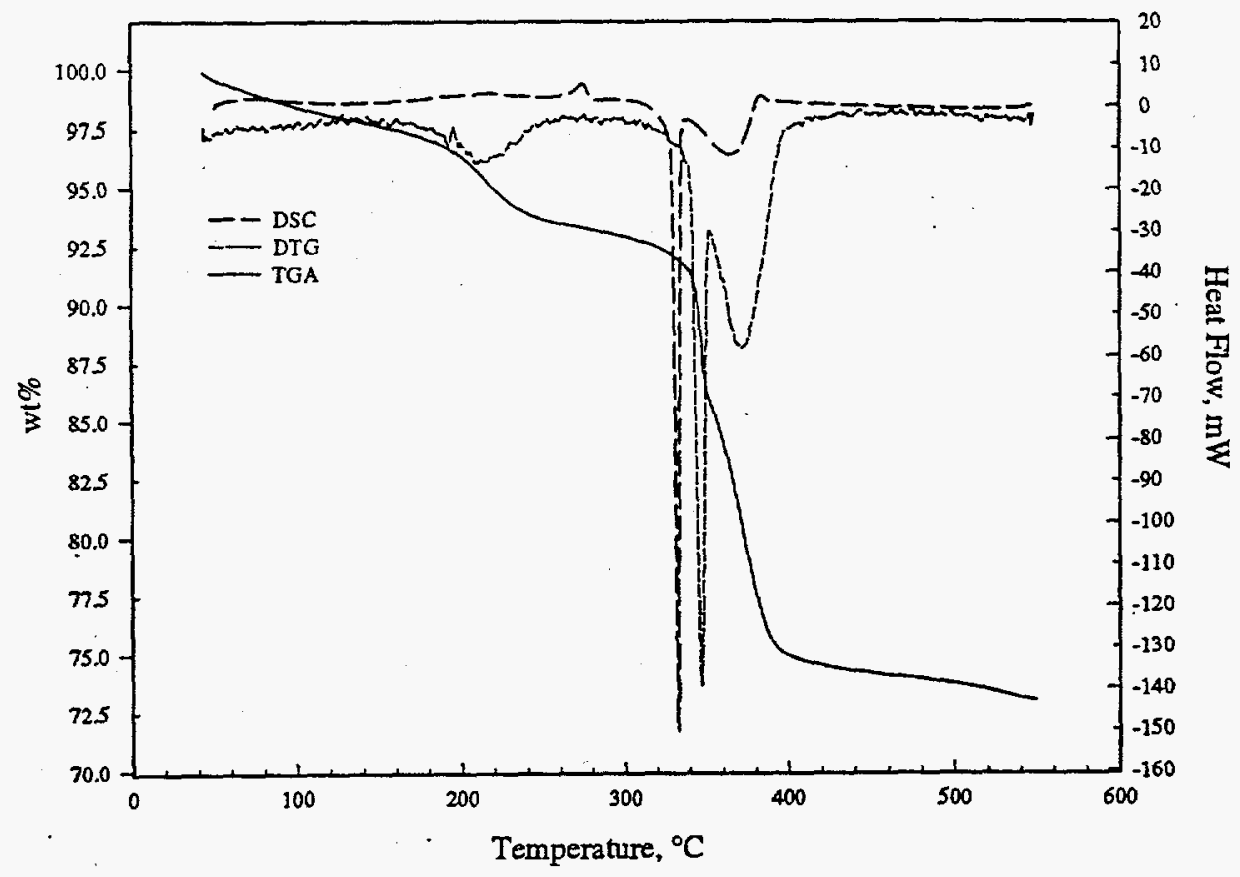

Figure 5.14. Thermal Behavior as Measured by DSC and TGA/DTG of Dried INFARM-2 Simulated Ferrocyanide Waste

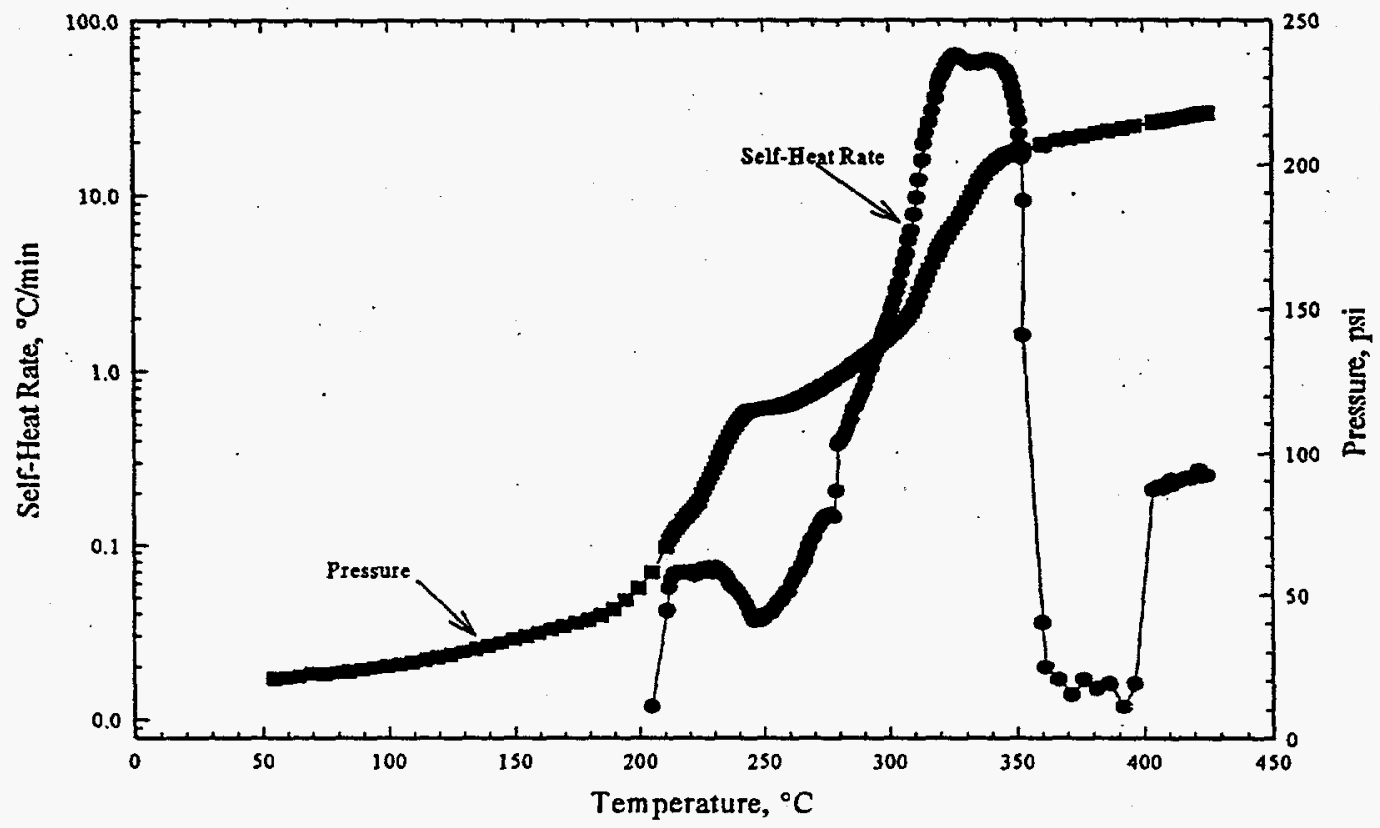

Figure 5.15. Thermal Behavior as Measured by ARC of Dried INFARM-2 Simulated Ferrocyanide Waste 
oxidation proceeds via at least two reaction steps. Based on PNL's ARC analysis, the reactionenthalpy for this oxidation, assuming a nominal solids heat capacity of $1.7 \mathrm{~J} /\left(\mathrm{g}-{ }^{-} \mathrm{C}\right)$, was $790 \mathrm{~J} / \mathrm{g} \mathrm{drysimulant,} \mathrm{or}$ about $3.9 \mathrm{~kJ} / \mathrm{g}$ sodium nickel ferrocyanide, which is about $40 \%$ of the maximum theoretical energy (9.5 kJ/g sodium nickel ferrocyanide) (Burger 1993) for the reaction between nitrate and ferrocyanide. Cady (1992) estimated the reaction enthalpy for the total two-step oxidation to be $1.2 \mathrm{~kJ} / \mathrm{g}$ of the freeze-dried simulant assuming a heat capacity of $1.05 \mathrm{~J} /\left(\mathrm{g}-{ }^{\circ} \mathrm{C}\right)$. The RSST (Jeppson and Wong 1993) detected an onset for a self-heating reaction of about $190^{\circ} \mathrm{C}$ for both the top and bottom segments from centrifuged INFARM-2 sludge and reaction. No reaction enthalpy, based on the RSST analyses, was reported for the INFARM-2 samples; however, the reaction enthalpy estimated based on the RSST analysis of U-Plant- 2 simulated waste was $4 \mathrm{k} / \mathrm{Jg}$ sodium nickel ferrocyanide.

As we begin discussing the thermal behaviors observed for the waste samples from C-109 and C-112 and comparing them with the thermal behavior observed for the INFARM-2 simulant, it must be noted that any comparisons are complicated by the different amounts of water in each sample when analyzed. Because water is a major constituent in the waste samples, its evaporative loss will be a major determinant of ordinate scaling in the figures to ensure that all thermal events are captured. Because the water contents in these samples, when analyzed, ranged from 15 to $50 \mathrm{wt} \%$ based on TGA, water loss will be a major scaling determinant potentially causing loss of detail.

The presence of differing amounts of water has an additional complication, because TGA and DSC analyses of the waste samples were performed on different aliquots using different and independent instruments. Different gas flows and slightly different sample sizes were used. These factors affect the release rate of water from the system, which will subsequently affect the release rate of water from the sample. The TGA used for the analysis employs a higher gas flow than the DSC; thus in the cases where the release rate would be affected by the removal rate the temperature at which the peak minimum observed for the DTG would be lower than the endothermic peak maximum observed for the corresponding event. This occurs several times during the waste sample analyses. We recommend that future TGA and DSC analyses of Hanford wastes be performed on dried samples.

The observed thermal behavior of the as-received actual waste subsegment samples from C-109, presented in Tables 5.12 and 5.13 and Figures 5.16 and 5.25, differs substantially from that observed for dried INFARM-2. The strong exothermic reactions beginning near $300^{\circ} \mathrm{C}$ for the INFARM-2 simulated waste are absent or nearly absent for the waste samples from C-109, as can be seen by comparing Tables 5.9 and 5.10 with Tables 5.12 and 5.13, and Figure 5.14 with Figures 5.16 to 5.25 . In fact, the only exothermic behavior reported by the analysts (Sprouse 1993) for C-109 samples was in the core 48 subsegment $1 \mathrm{D}$.

The analysts identified three transitions in C-109 waste by TGA and four by DSC, as shown in Tables 5.12 and 5.13. The figures for the $\mathrm{C}-109$ samples suggest that the thermal behavior differs from core to core; qualified by the limited availablility of DSC analyses of Core 48 waste samples; direct core-by-core comparison of the individual analyses presented in Figures 5.16 to 5.25 are complicated by the varying amounts of water present in each of the different samples. For example, the TGA of the core 48 sample indicates, based on the mass loss between 30 and $150^{\circ} \mathrm{C}$, that the analyzed sample from core 48 contained about $50 \mathrm{wt} \%$ water while the core 47 and core 49 samples normally contained between 15 and $30 \mathrm{wt} \%$ water. Cores 47 and 49 exhibit similar behavior, with a large endothermic peak occurring between 220 and $320^{\circ} \mathrm{C}$; this peak is absent for subsegment 1D of core 48 . Expanding the ordinate scale for the analysis of the core 48 sample to allow closer inspection of this temperature region does not reveal any additional discernable activity. 
Table 5.12. Reaction Ranges, Onset Temperatures, and Mass Losses for Thermally Induced Reactions in As-Received Wastes from C-109 (Cores 47, 48, and 49) by Subsegment (Sprouse 1993)

\begin{tabular}{|c|c|c|c|c|c|c|c|}
\hline & & & sition \#1 & & sition \#2 & & sition \#3 \\
\hline Sample & Run & Range, ${ }^{\circ} \mathrm{C}$ & Mass Loss, wt\% & Range, ${ }^{\circ} \mathrm{C}$ & Mass Loss, wt\% & Range, ${ }^{\circ} \mathrm{C}$ & Mass Loss wt \% ${ }^{(a)}$ \\
\hline $\begin{array}{l}\text { Core } 47 \\
\text { Comp. }\end{array}$ & 1 & $31-150$ & 15.6 & $150-336$ & 14.7 & $370-500$ & 3.4 \\
\hline & 2 & $31-150$ & 14 & $150-336$ & 15.1 & $370-500$ & 4 \\
\hline $\begin{array}{l}\text { Core } 47 \\
\text { 1B }\end{array}$ & 1 & $31-150$ & 10 & $150-336$ & 18 & $336-500$ & 3.5 \\
\hline & 2 & $31-150$ & 10.4 & $150-336$ & 17.8 & $336-500$ & 3.1 \\
\hline $\begin{array}{l}\text { Core } 47 \\
\text { 1C }\end{array}$ & 1 & $31-150$ & 18.1 & $150-336$ & 17.8 & $336-500$ & 3.7 \\
\hline & 2 & $31-150$ & 18 & $150-336$ & 17.4 & $336-500$ & 3.7 \\
\hline $\begin{array}{l}\text { Core } 47 \\
\text { ID }\end{array}$ & 1 & $31-150$ & 19.7 & $150-370$ & 7 & $370-500$ & 1.5 \\
\hline & 2 & $31-150$ & 19.7 & $150-370$ & 6.5 & $370-500$ & 1.8 \\
\hline $\begin{array}{l}\text { Core } 48 \\
\text { 1D }\end{array}$ & 1 & $31-180$ & 46.4 & $180-425$ & 3.2 & $425-500$ & -0.2 \\
\hline & 2 & $31-180$ & 43.8 & $180-425$ & 3.1 & $425-500$ & -0.2 \\
\hline $\begin{array}{l}\text { Core } 49 \\
\text { Comp. }\end{array}$ & 1 & $31-180$ & 27.5 & $180-336$ & 15.1 & $336-500$ & 3.5 \\
\hline & 2 & $31-180$ & 25.6 & $180-336$ & 16.4 & $336-500$ & 3.9 \\
\hline $\begin{array}{l}\text { Core } 49 \\
\text { 1B }\end{array}$ & 1 & $31-180$ & 2.4 & $180-336$ & 26.3 & $336-500$ & 4.3 \\
\hline & 2 & $31-180$ & 6 & $180-336$ & 25.3 & $336-500$ & 3.8 \\
\hline $\begin{array}{l}\text { Core } 49 \\
\text { iC }\end{array}$ & 1 & $31-180$ & 28.6 & $180-336$ & 14.3 & $336-500$ & 2.7 \\
\hline & 2 & $31-180$ & 30.6 & $180-336$ & 14.1 & $336-500$ & 2.9 \\
\hline $\begin{array}{l}\text { Core } 49 \\
\text { 1D }\end{array}$ & 1 & $31-180$ & 29.6 & $180-350$ & 9.4 & $350-500$ & 1.1 \\
\hline & 2 & $31-180$ & 29 & $180-350$ & 9.7 & $350-500$ & 1.1 \\
\hline
\end{tabular}

(a) A negative mass loss is a weight gain. 
Table 5.13. Peak Maximum and Minimum Temperatures, and Reaction Enthalpies for As-Received Wastes from C-109 (Cores 47, 48, and 49)as Measured by DSC (Sprouse 1993)

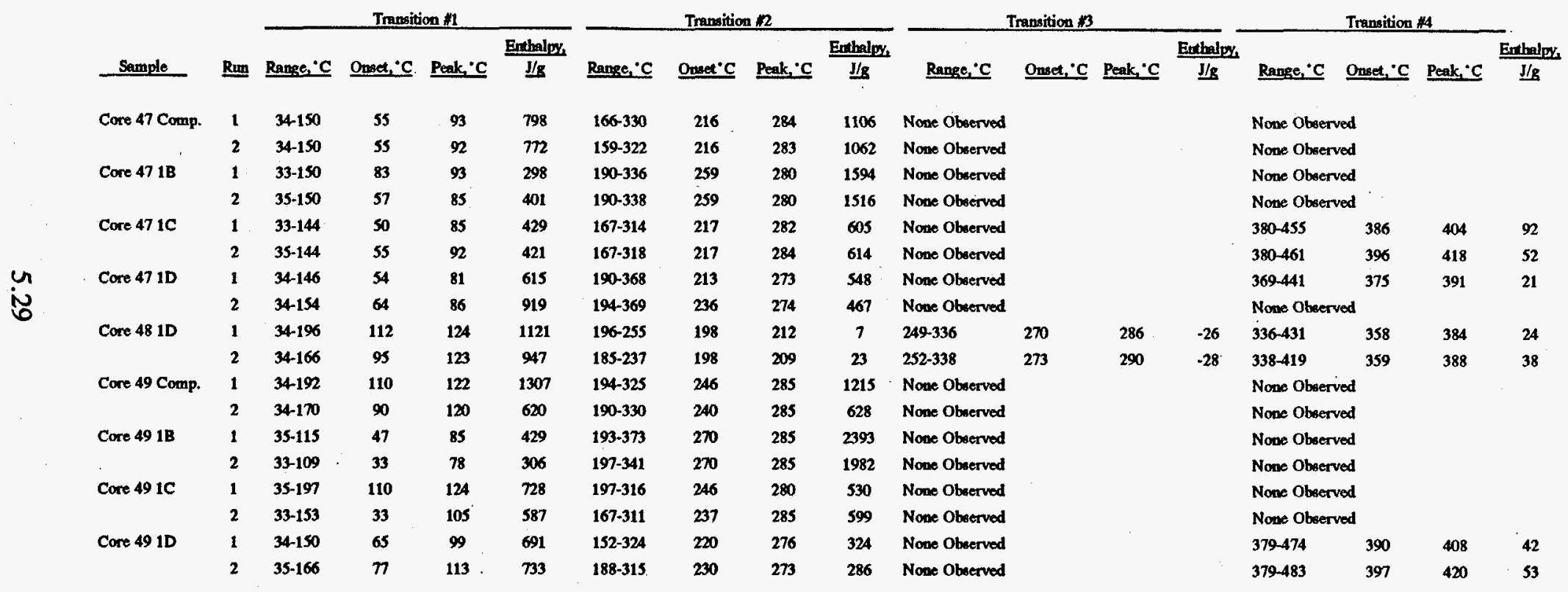




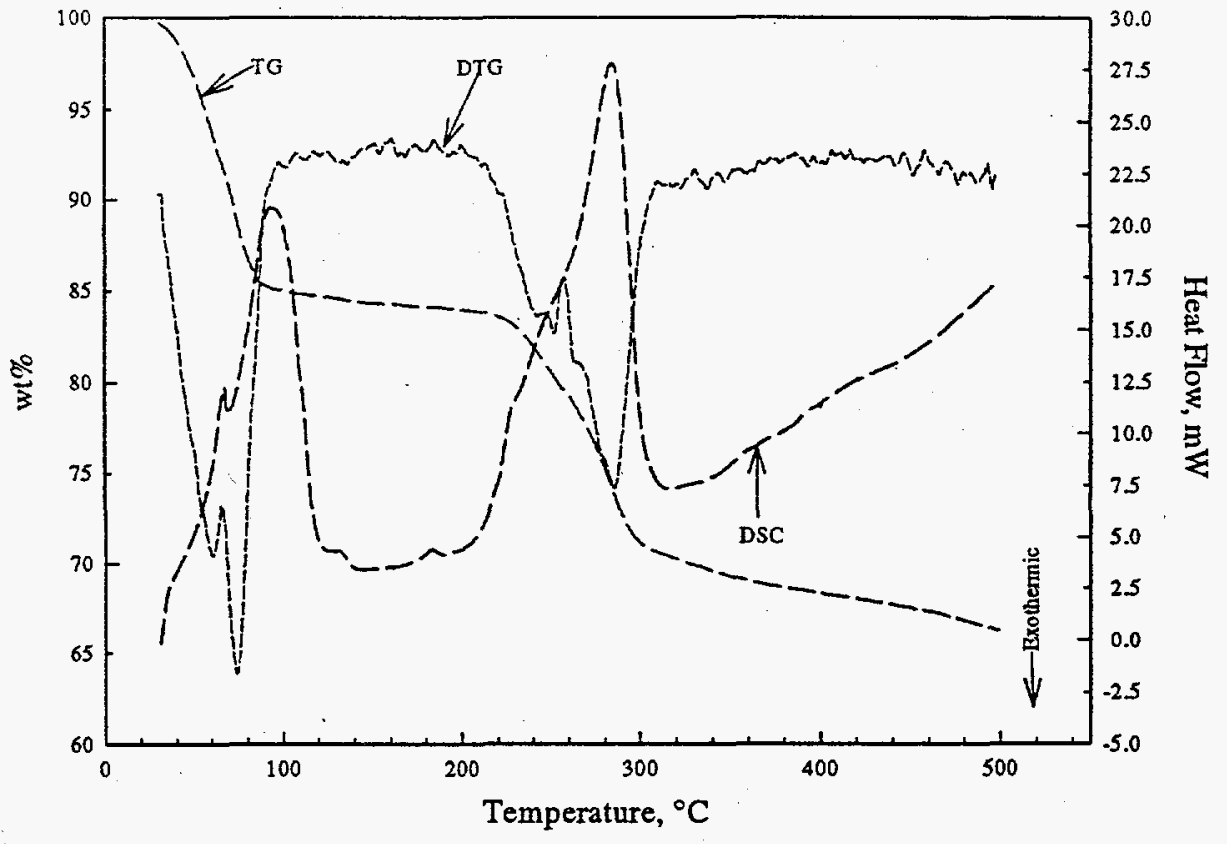

Figure 5.16. Thermal Behavior as Measured by DSC and TGA/DTG of As-Received Waste from Core 47 Composite Obtained from 241-C-109

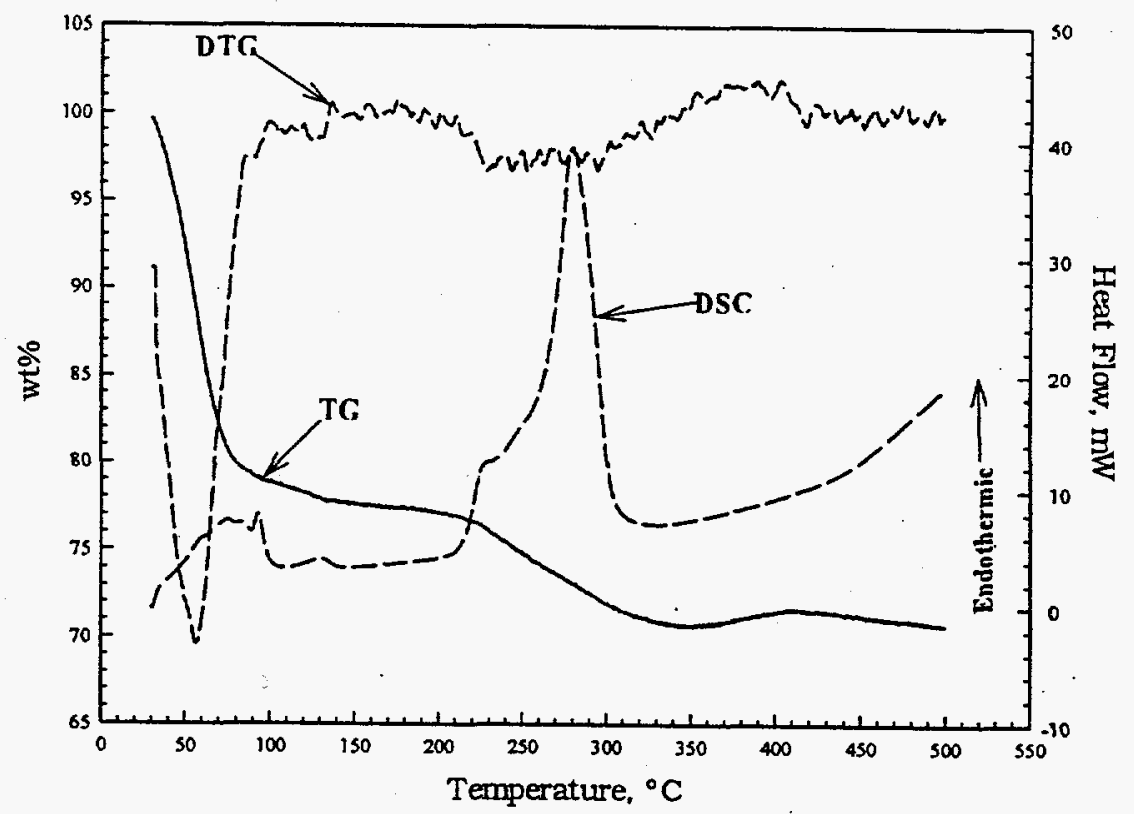

Figure 5.17. Thermal Behavior as Measured by DSC and TGA/DTG of As-Received Waste from Core 47 Subsegment 1B Obtained from 241-C-109 


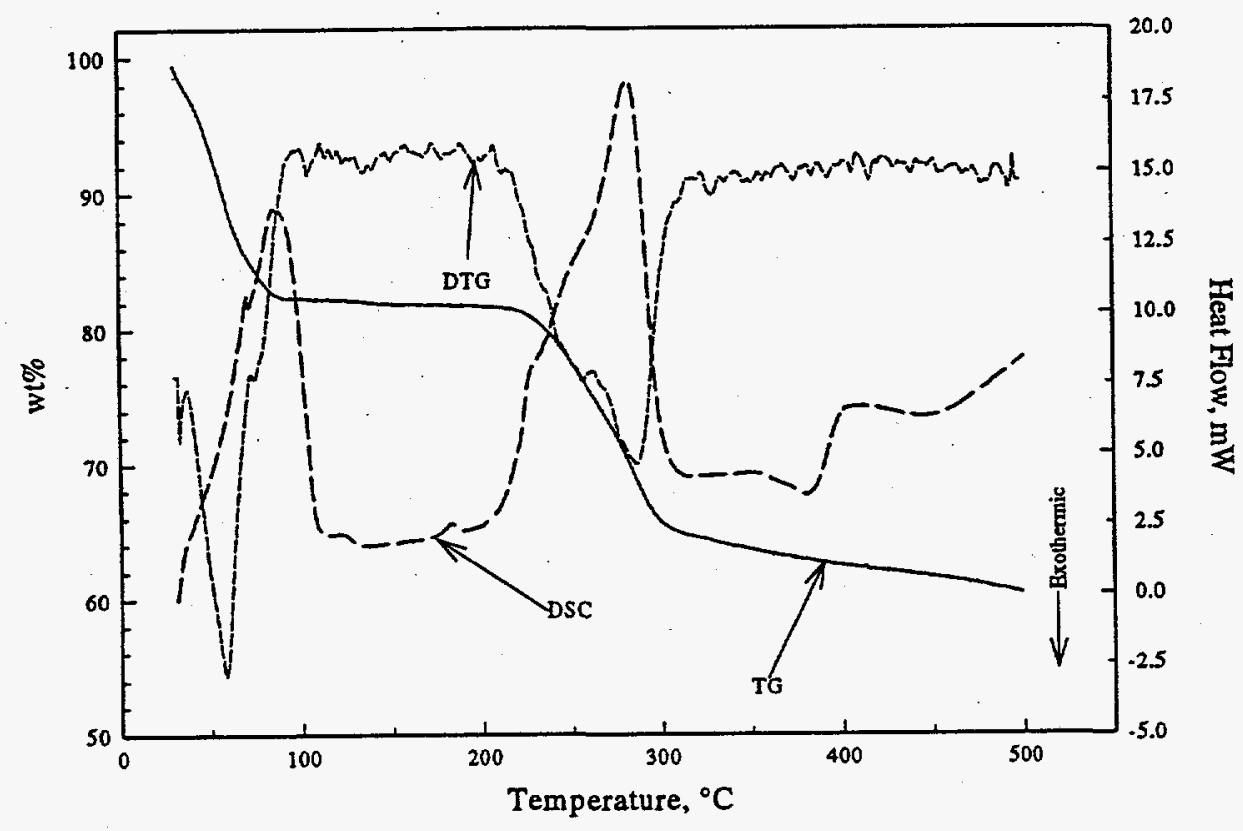

Figure 5.18. Thermal Behavior as Measured by DSC and TGA/DTG of As-Received Waste from Core 47 Subsegment 1C Obtained from 241-C-109

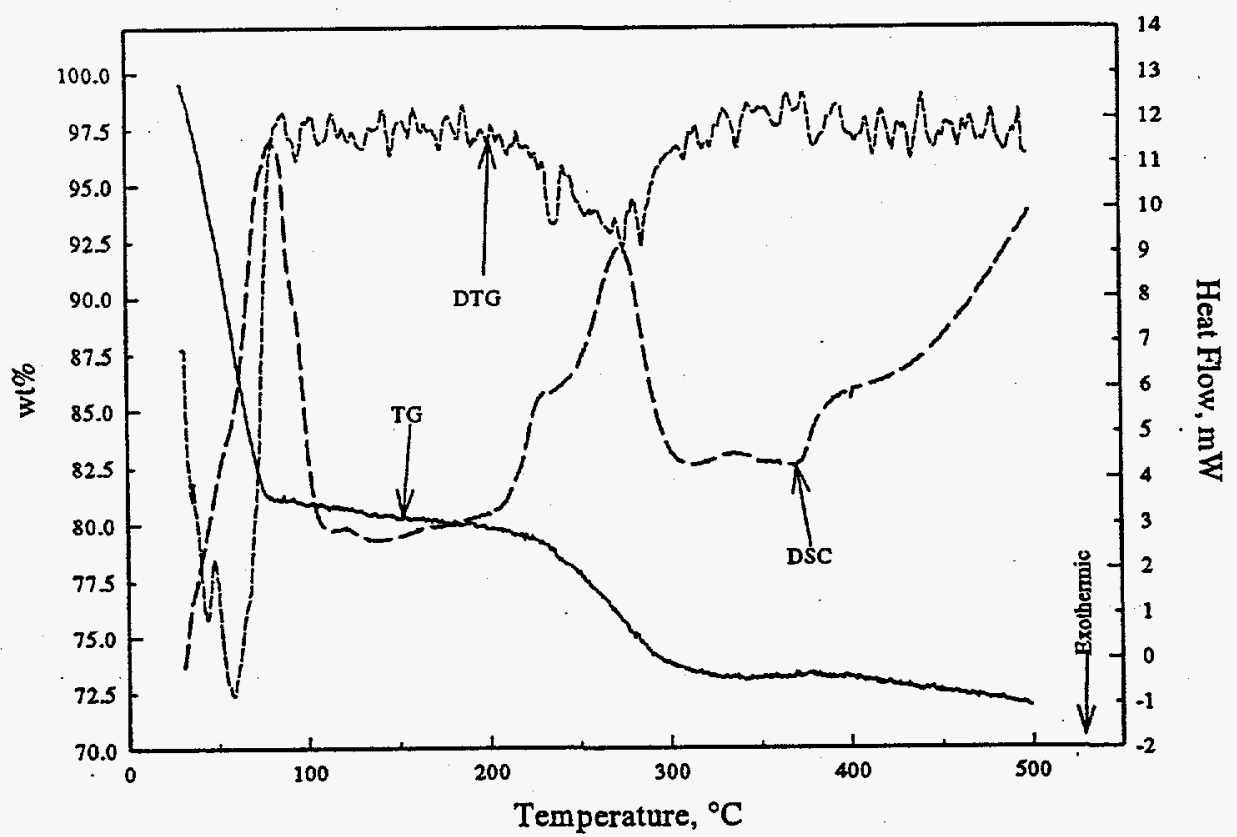

Figure 5.19. Thermal Behavior as Measured by DSC and TGA/DTG of As-Received Waste from Core 47 Subsegment 1D Obtained from 241-C-109 


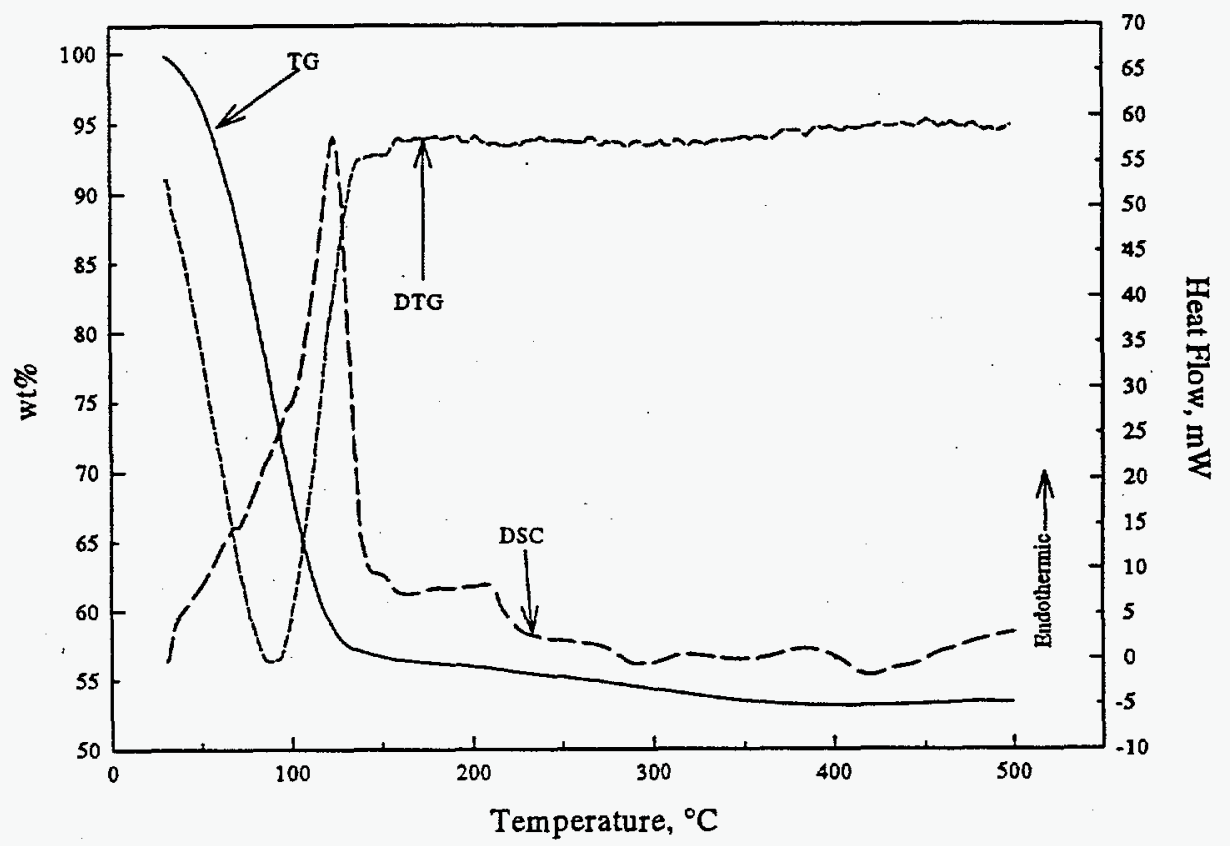

Figure 5.20. Thermal Behavior as Measured by DSC and TGA/DTG of As-Received Waste from Core 48 Subsegment 1D Obtained from 241-C-109

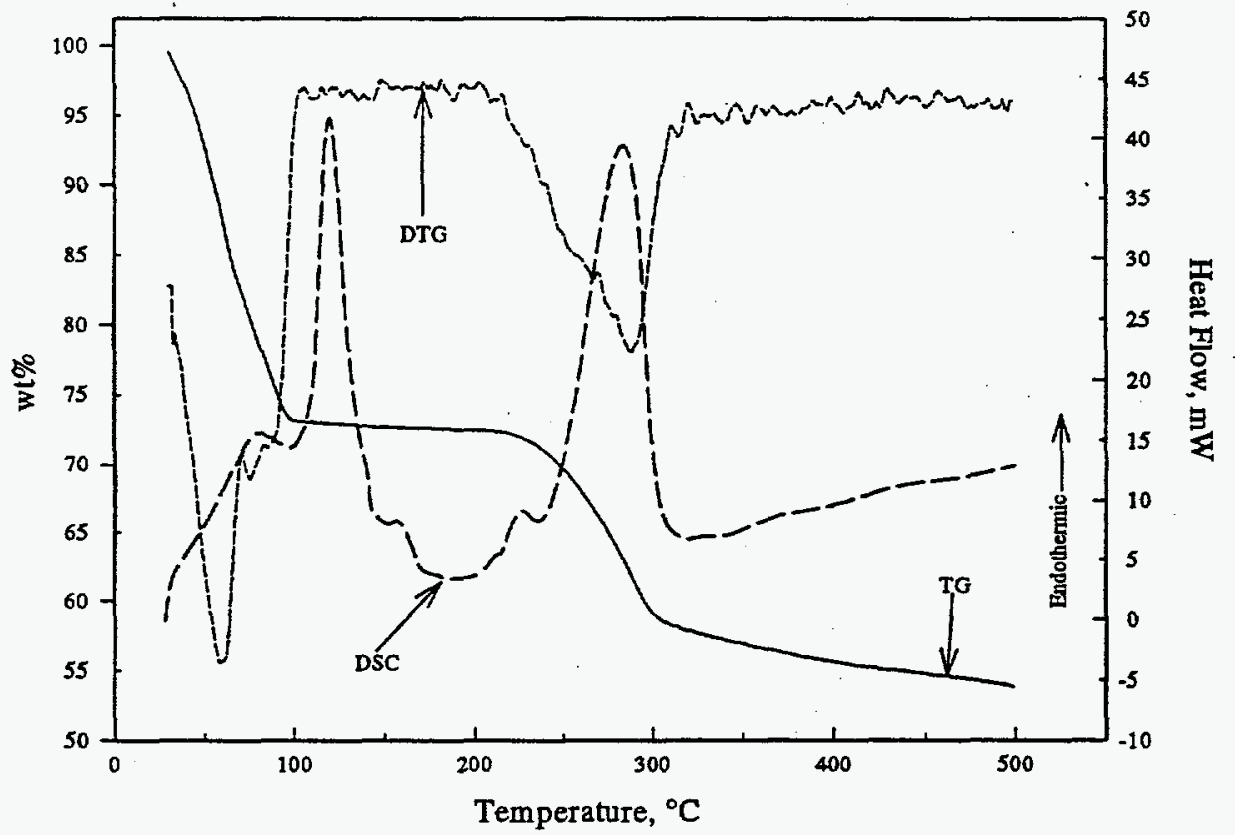

Figure 5.21. Thermal Behavior as Measured by DSC and TGA/DTG of As-Received Waste from Core 49 Composite Obtained from 241-C-109 


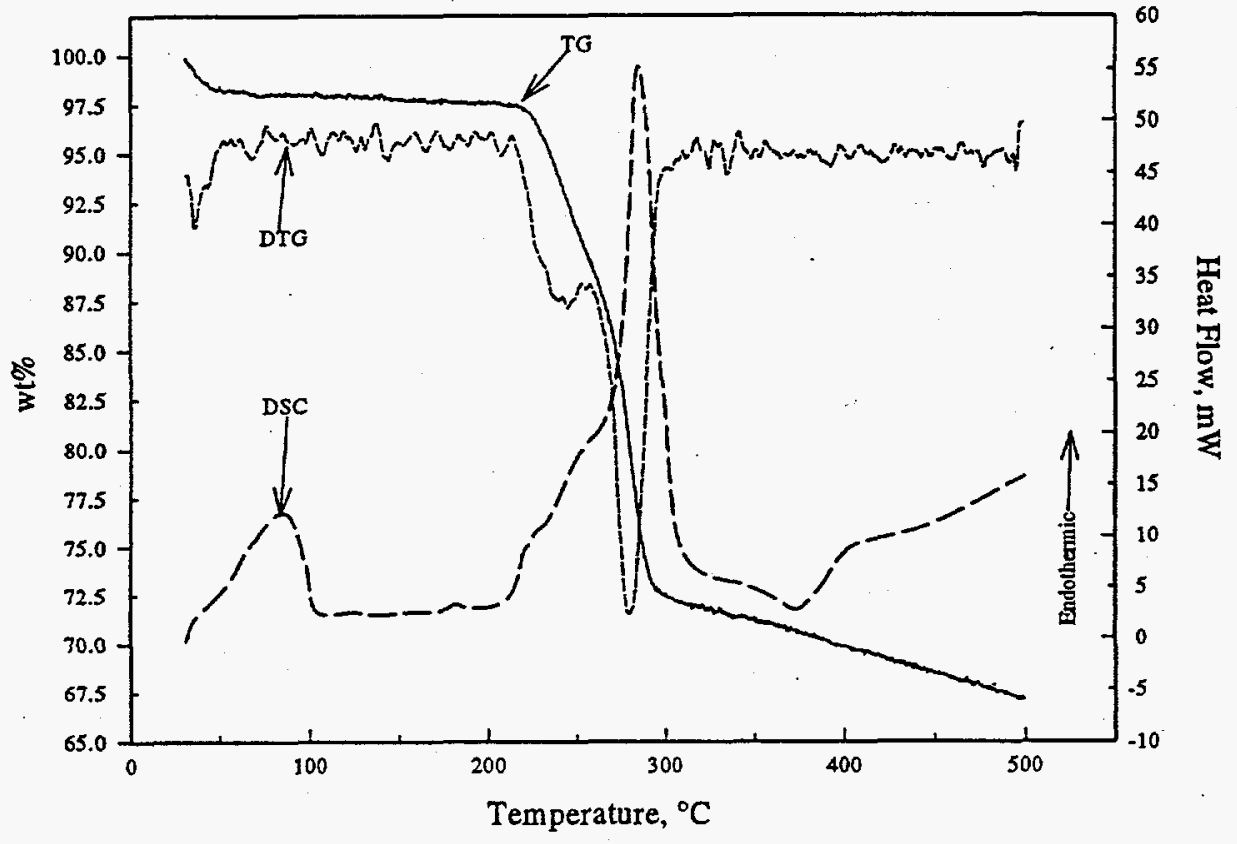

Figure 5.22. Thermal Behavior as Measured by DSC and TGA/DTG of As-Received Waste from Core 49 Subsegment 1B Obtained from 241-C-109

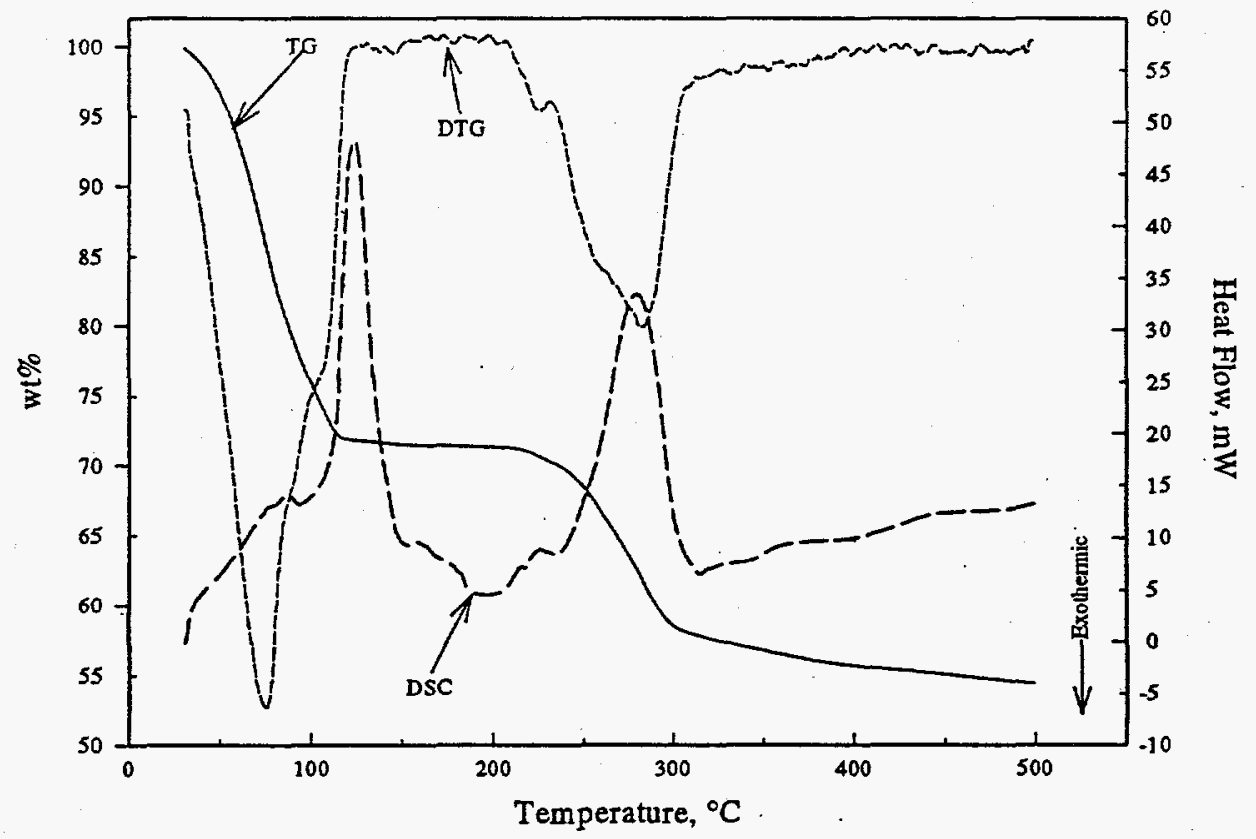

Figure 5.23. Thermal Behavior as Measured by DSC and TGA/DIG of As-Received Waste trom Core 49 Subsegment 1C Obtained from 241-C-109 


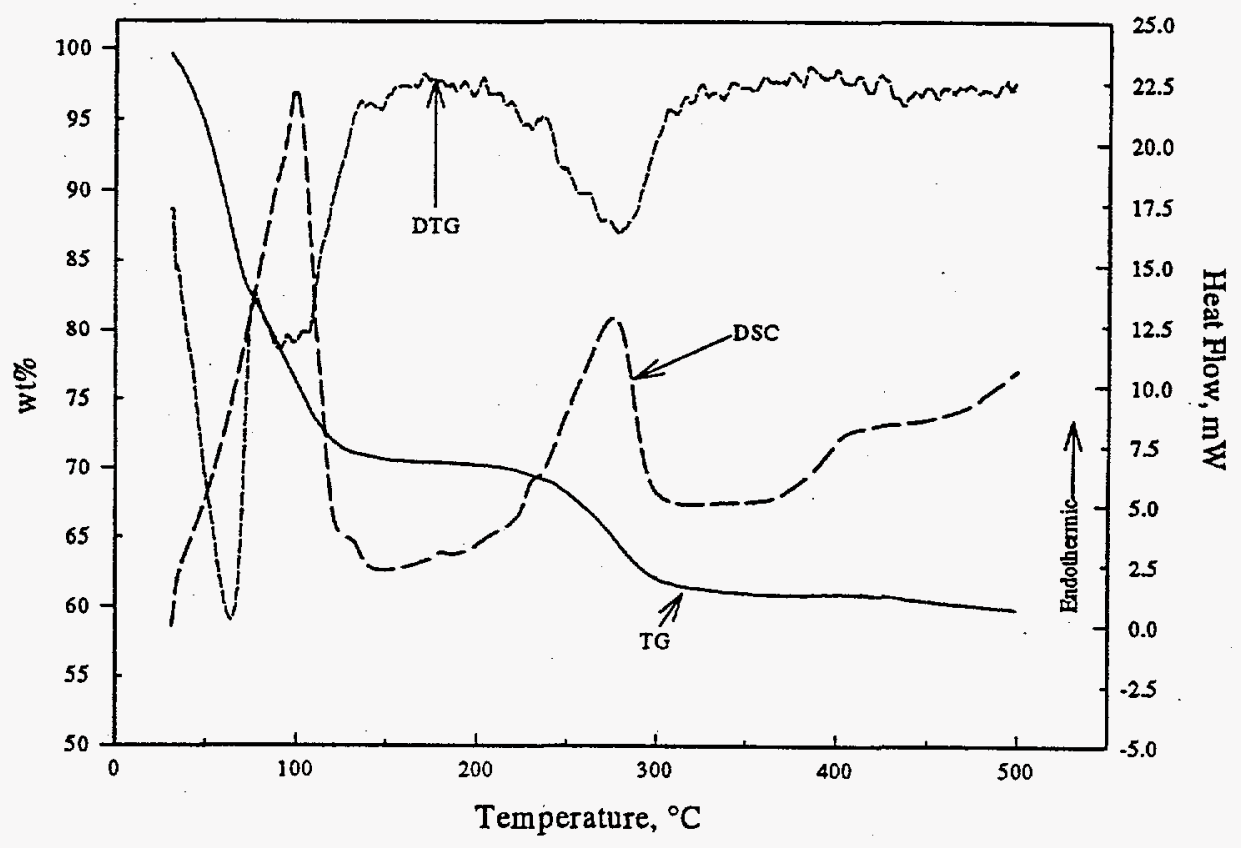

Figure 5.24. Thermal Behavior as Measured by DSC and TGA/DTG of As-Received Waste from Core 49 Subsegment 1D Obtained from 241-C-109

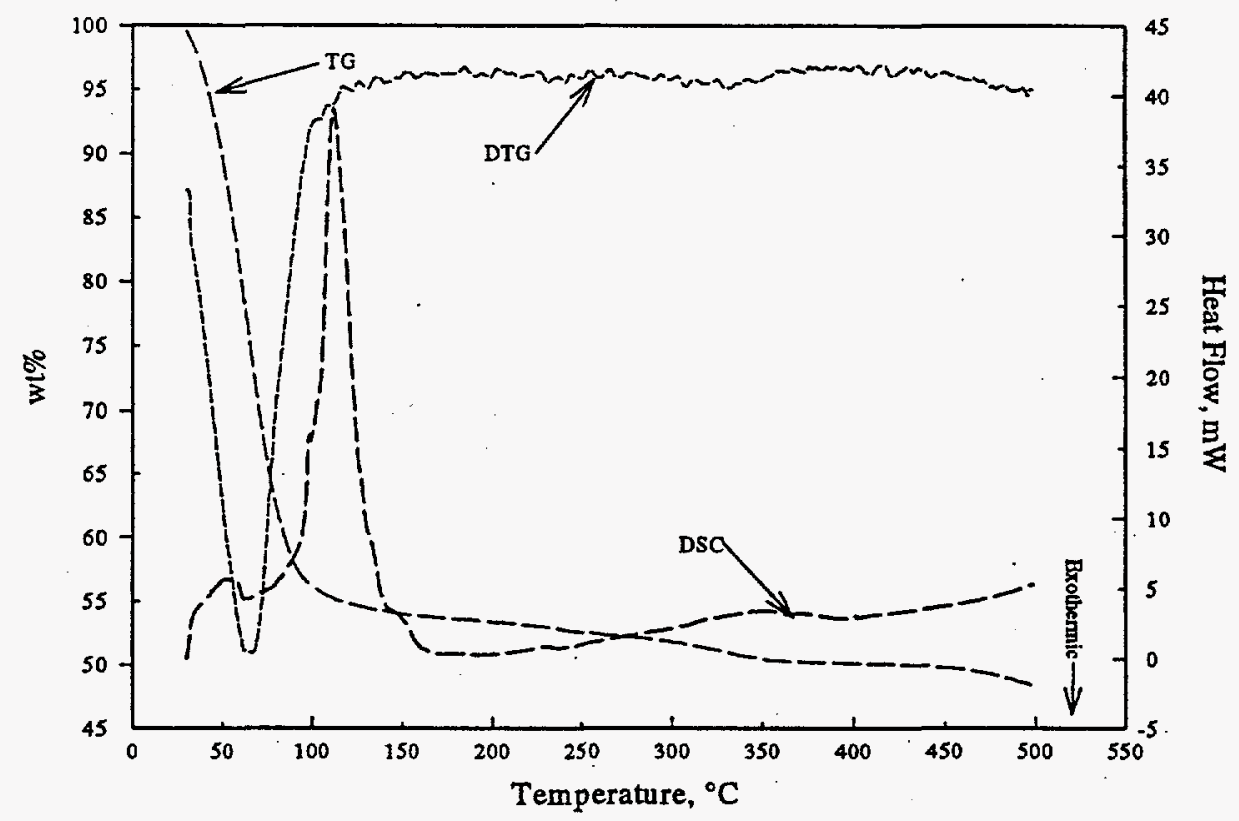

Figure 5.25. Thermal Behavior as Measured by DSC and TGA/DTG of As-Received Waste from Core 34 Subsegment 2D Taken from 241-C-112 
The causes for this endothermic behavior and associated mass loss observed between 220 and $320^{\circ} \mathrm{C}$ for core 47 and core 49 samples are unknown. Possibilities include decomposition of $\mathrm{Al}(\mathrm{oH})_{3}$ as suggested by Simpson et al. 1993b, melting with the simultaneous loss of waters of hydration, or perhaps solid transformation reactions and loss of water by stable hydrates. It is interesting that this endothermic reaction is near where exothermic behavior is observed for INFARM-2 simulant; this endotherm could mask any low-grade exothermic behavior. All of the analyzed core samples from C109 have a large endothermic peak with a maxima near $135^{\circ} \mathrm{C}$, with the exception of the $1 \mathrm{~B}$ samples which likely had little water present in the analyzed samples. This mass loss and endothermic reaction is likely due to the evaporation of free or loosely bound water. To determine when reactions of concern occur in actual wastes, it would be necessary to have an instrument similar to the DTA/TGA/MS used by Barney to identify the thermally evolved gases.

The observed thermal behavior of the actual wastes from C-112 differs substantially from that observed for INFARM-2 and the samples obtained by core 47 and 49 from C-109. For INFARM-2, a comparison can be made of Tables 5.9 and 5.10 with Tables 5.14 and 5.15 , which summarize the DSC and TGA analyses of the waste samples from C-112. It should be noted that the data presented in Tables 5.14 and 5.15 are those reported by Tingey et al. (1993), instead of those reported by Bell 1993, as they are the analysts most recent interpretation of the DSC and TGA analyses. Similarly, a comparison can be made of Figure 5.14 (thermal analysis of INFARM-2) with Figures 5.25 to 5.33, which include DSC and TGA analyses of C-112 waste in core 34 subsegment 2D, composite core 35 , the composite core 36 sample, and all of the core 36 subsegments. It should be noted that Figure 5.33 does not include the DTG because Bell (1993) does not provide it, nor was it available elsewhere. These results suggest that there is a little thermally induced exothermic behavior for the C-112 waste in contrast to the significant exothermicity observed for the INFARM-2 simulated waste. The analysts (Tingey et al. 1993) report the release of 10 to $20 \mathrm{~J} / \mathrm{g}$ as-received sample for the waste samples from C- 112 beginning at about 250 to $290^{\circ} \mathrm{C}$. This level is roughly 2 to $4 \%$ of that measured for dry INFARM-2, nominally $1000 \mathrm{~kJ} / \mathrm{g}$ dry INFARM-2.

As shown for C-112 wastes in Figures 5.25 to 5.32, the thermal reaction profile does not resemble that of INFARM-2. The strong exothermic reaction observed above $300^{\circ} \mathrm{C}$ for INFARM-2 is much stronger than observed for the $\mathrm{C}-112$ waste samples. The thermal reaction profiles of the different $\mathrm{C}$ 112 samples are similar to each other with a strong endotherm occurring between 30 and $160^{\circ} \mathrm{C}$ that is most likely due to the evaporation of loosely held water. There is some minor endothermic behavior and mass loss between 200 and $300^{\circ} \mathrm{C}$, which could be due to melting or solid transformation reactions with the release of waters of hydration. It should be noted that the low-grade activity observed between 200 and $300^{\circ} \mathrm{C}$ makes it very difficult to determine whether exothermic reactions are occurring and to quantify their magnitude. Low temperature drying of samples prior to analysis would improve the analysts' ability to determine if a reaction is occurring and to measure the enthalpy change.

The waste samples from C-112 and C-109 exhibit largely dissimilar thermal behaviors. Both sets of waste samples have the endothermic mass loss between 30 and $150^{\circ} \mathrm{C}$; however, while exothermic behavior is observed for most of the analyzed C-112 samples, the only C-109 subsegment that exhibited reportable exothermic behavior was core 48 subsegment 1D. The C-112 samples also do not have the endothermic peak that occurs between 200 and $300^{\circ} \mathrm{C}$ in the core 47 and 49 samples from $\mathrm{C}-109$. 
Table 5.14. Reaction Ranges, Onset Temperatures, and Mass Losses for Thermally Induced Reactions in As-Received Wastes from C-112 (Cores 34, 35, and 36) by Subsegment

(Tingey et al. 1993).

\begin{tabular}{|c|c|c|c|c|c|c|}
\hline \multirow[b]{2}{*}{ Sample } & \multicolumn{2}{|c|}{ Transition \#1 } & \multicolumn{2}{|c|}{ Transition $\# 2$} & \multicolumn{2}{|c|}{ Transition \#3 } \\
\hline & Range, ${ }^{\circ} \mathrm{C}$ & $\begin{array}{c}\text { Mass Loss, } \\
\text { wt } \%\end{array}$ & Range, ${ }^{\circ} \mathrm{C}$ & $\begin{array}{c}\text { Mass Loss, } \\
\text { wt } \%\end{array}$ & Range, ${ }^{\circ} \mathrm{C}$ & $\begin{array}{c}\text { Mass Loss, } \\
\text { wt } \%\end{array}$ \\
\hline Core 34 Comp. & $30-240$ & 35 & $260-300$ & 6.1 & $300-400$ & -0.6 \\
\hline Core 34-2B & $30-240$ & 52 & $260-300$ & 5.4 & $300-400$ & -0.6 \\
\hline Core $34-2 C$ & $30-240$ & 45 & $260-300$ & 4.0 & $300-400$ & -0.3 \\
\hline Core 34-2D & $30-240$ & 33 & $260-300$ & 6.3 & $300-400$ & 0 \\
\hline Core 35-2D & 34-195 & 42 & $225-290$ & 6.0 & $300-400$ & 0 \\
\hline Core 36 Comp & $34-240$ & 44 & $270-325$ & 2.9 & $300-400$ & 0.3 \\
\hline Core $36-1 \mathrm{C}$ & $34-240$ & 46 & $260-300$ & 8.9 & $300-380$ & -0.3 \\
\hline Core 36-1D & $32-230$ & 52 & $260-310$ & 2.0 & $300-400$ & -0.2 \\
\hline Core $36-2 A$ & $30-230$ & 52 & $277-300$ & 1.9 & $300-400$ & -0.2 \\
\hline Core $36-2 B$ & $30-235$ & 38 & $260-325$ & $\$$ & $325-400$ & -0.4 \\
\hline Core $36-2 C$ & $30-240$ & 41 & $204-380^{(n)}$ & $3.8^{(0)}$ & $380-500^{(a)}$ & $1.8^{(a)}$ \\
\hline Core $36-2 C$ & $30-172$ & 47 & $260-300$ & 3.5 & $300-395$ & 0.3 \\
\hline
\end{tabular}
(a) Bell (1993)
(b) NR $=$ Not Reported

The low exothermic behavior exhibited by the waste samples from $\mathrm{C}-109$ and $\mathrm{C}-112$ are consistent with the low concentrations of cyanide found in the samples as shown in Table 5.16. Table 5.16 presents on a dry basis the total cyanide concentrations, the DSC measured exothermic enthalpies, and the reaction enthalpies that would be expected for the INFARM-2 simulant and samples from C-109 and $\mathrm{C}-112$ if the cyanide were present as sodium nickel ferrocyanide and the cyanide reacted via the postulated most energetic reactions with nitrate or nitrite. Inspection of Table 5.16 finds that the measured enthalpies for the INFARM-1 samples were about 55 and $45 \%$ of the expected heat from reaction with nitrate or nitrite, respectively. The C-109 samples would be expected to yield between 110 and $340 \mathrm{~J} / \mathrm{g}$ based on the cyanide concentration, however, only the core 48 subsegment-D sample had an observable exotherm yielding $56 \mathrm{~J} / \mathrm{g}$ or about $30 \%$ of that predicted for the reactions with nitrate or nitrite. In contrast to the $C-109$ results, the $C-112$ samples yielded between 10 and $30 \%$ of the heat expected based on reactions of the measured cyanide with nitrate or nitrite.

In summary: With respect to thermal reactivity and energetics, the INFARM-2 simulated waste is a much more reactive and energetic chemical system than the wastes stored in C-109 and C-112; thus providing an upper bound for the reactivity and energetics of wastes from these two tanks. The wastes 
Table 5.15. Onset Temperatures, Peak Maximum and Minimum Temperatures, and Reaction Enthalpies for As-Received Wastes from C-112 (Cores 34, 35, and 36) as measured by DSC (Tingey et al. 1993).

\begin{tabular}{|c|c|c|c|c|c|c|c|c|c|}
\hline \multirow[b]{2}{*}{ Sample } & \multicolumn{3}{|c|}{ Transition 1} & \multicolumn{3}{|c|}{ Transition 2} & \multicolumn{3}{|c|}{ Transition 3} \\
\hline & $\begin{array}{c}\text { Range, } \\
{ }^{\circ} \mathrm{C}\end{array}$ & $\begin{array}{l}\text { Onset, } \\
{ }^{\circ} \mathrm{C}\end{array}$ & $\begin{array}{c}\text { Enthalpy, } \\
\quad J / g\end{array}$ & $\begin{array}{l}\text { Range, } \\
{ }^{\circ} \mathrm{C}\end{array}$ & $\begin{array}{l}\text { Onset, } \\
{ }^{\circ} \mathrm{C}\end{array}$ & $\begin{array}{c}\text { Enthalpy, } \\
\mathrm{J} / \mathrm{g}\end{array}$ & $\begin{array}{c}\text { Range, }^{\circ} \\
\text { C }\end{array}$ & $\begin{array}{c}\text { Onset, } \\
{ }^{\circ} \mathrm{C}\end{array}$ & $\begin{array}{c}\text { Enthalp } \\
y, J / g\end{array}$ \\
\hline C34 Comp & $34-240$ & 34 & 734 & $\overline{260-300}$ & 276 & -11 & $\overline{300-400}$ & 357 & 10 \\
\hline C34-2B & $30-240$ & 30 & 847 & $260-300$ & 276 & -12 & $300-400$ & 349 & 30 \\
\hline $\mathrm{C} 34-2 \mathrm{C}$ & $30-240$ & 30 & 795 & $260-300$ & 267 & -13 & $300-400$ & 360 & 13 \\
\hline C34-2D & $33-240$ & 33 & 930 & $260-300$ & 289 & -17 & $300-400$ & 347 & 13 \\
\hline C35-2D & 34-195 & 34 & 780 & $225-290$ & 230 & -12 & \multicolumn{3}{|c|}{ This transition not quantifiable } \\
\hline C36 Comp & $34-240$ & 34 & 890 & $270-325$ & 288 & -19 & \multicolumn{3}{|c|}{ This transition not quantifiable } \\
\hline $\mathrm{C} 36-1 \mathrm{C}$ & $34-240$ & 34 & 1070 & $260-300$ & 267 & -11 & $300-380$ & 301 & 31 \\
\hline C36-1D & $32-230$ & 32 & 1310 & $260-310$ & 277 & -16 & \multicolumn{3}{|c|}{ This transition not quantifiable } \\
\hline $\mathrm{C} 36-2 \mathrm{~A}$ & $30-230$ & 30 & 1110 & $277-300$ & 280 & -10 & $300-400$ & 305 & 35 \\
\hline C36-2B & $33-235$ & 30 & 870 & $260-325$ & 298. & -9 & $325-400$ & 330 & 28 \\
\hline $\mathrm{C} 36-2 \mathrm{C}$ & $32-240$ & 32 & 830 & \multicolumn{3}{|c|}{ This transition not quantifiable } & $305-407$ & 320 & 36 \\
\hline C36-2D & $34-172$ & 34 & 1056 & \multicolumn{3}{|c|}{ This transition not quantifiable } & $300-395$ & 328 & 45 \\
\hline
\end{tabular}

stored in C-109 and C-112 exhibit largely dissimilar thermal behaviors with 1) most of the subsegment samples from C-109 exhibiting significant endothermicity between 200 and $300^{\circ} \mathrm{C}$ while the wastes from C-112 exhibited little endothermicity in this region and 2) only one subsegment sample from C109 having any detectable exothermicity while most of the subsegments from C-112 exhibited measurable exothermicity. In terms of thermal behavior as a function of the waste location, the available data indicate that the wastes stored in C-112 exhibit largely similar qualitative thermal behavior independent of location while the wastes in C-109 appear to exhibit similar qualitative thermal behavior independent of depth, but, based on the one DSC and TGA analysis of Core 48 subsegments, differences exist relative to horizontal location in C-109. 
Table 5.16. Comparison of Predicted and DSC Measured Reaction Enthalpies on a Dry Basis for INFARM-2 Simulant and Waste Samples from C-109 and C-112 Based on Total Cyanide Concentration

\begin{tabular}{|c|c|c|c|}
\hline Sample & $\begin{array}{l}\text { Theoretical DH for } \mathrm{RX} \\
\text { with } \mathrm{NaNO}_{3}, \mathrm{~J} / \mathrm{g}^{\text {(b) }}\end{array}$ & $\begin{array}{c}\text { Theoretical DH for RX } \\
\text { with } \mathrm{NaNO}_{2}, \mathrm{~J} / \mathrm{g}^{(\mathrm{b})}\end{array}$ & $\begin{array}{c}\text { Measured exothermic } \\
\mathrm{DH}, \mathrm{J} / \mathbf{g}^{(0)(\mathrm{d})}\end{array}$ \\
\hline INFARM-2, Top & -1760 & -2160 & -1020 \\
\hline INFARM-2, Bottom & -2160 & -2660 & -1120 \\
\hline \multicolumn{4}{|l|}{ C-109 } \\
\hline Core 47 Composite & -110 & -130 & None Observed \\
\hline Core 47 1B & -60 & -70 & None Observed \\
\hline Core $471 \mathrm{C}$ & -90 & -110 & None Observed \\
\hline Core 47 1D & -110 & -140 & None Observed \\
\hline Core 48 Composite & -280 & -340 & NM \\
\hline Core $481 \mathrm{C}$ & -220 & -270 & NM \\
\hline Core 48 1D & -170 & -200 & -55 \\
\hline Core 49 Composite & -110 & -140 & None Observed \\
\hline Core 49 1B & -70 & -80 & None Observed \\
\hline Core $491 \mathrm{C}$ & -160 & -190 & None Observed \\
\hline Core 49 1D & -110 & -130 & None Observed \\
\hline \multicolumn{4}{|l|}{ C-112 } \\
\hline Core 34 Composite & -190 & -230 & -18 \\
\hline Core 34 1D & -100 & -120 & $-21^{(0)}$ \\
\hline Core 34 2B & -90 & -110 & -25 \\
\hline Core 34 2C & -160 & -200 & -31 \\
\hline Core 34 2D & -150 & -180 & -35 \\
\hline Core 35 Composite (2D) & & & -18 \\
\hline Core 36 Composite & -140 & -170 & -35 \\
\hline Core 36 1C & & & -22 \\
\hline Core 36 1D & -140 & -170 & -38 \\
\hline Core $362 \mathrm{~A}$ & -180 & -220 & -23 \\
\hline Core 36 2B & -150 & -180 & -15 \\
\hline Core $362 \mathrm{C}$ & -80 & -90 & Not Quantifiable \\
\hline Core 36 2D & -110 & -140 & Not Quantifiable \\
\hline
\end{tabular}

(a) From Bell (1993) and Sprouse (1993) with the exception of INFARM-2, which is from Jeppson and Simpson (1994).

(b) Assumes stoichiometric oxidation of ferrocyanide via the most energetic postulated reaction pathway (Burger 1993).

(c) Reported total exothermicity; for C-109 and C-112 samples adjusted measured enthalpies for water content using water content measured gravimetrically.

(d) INFARM-2 recent PNL analyses; C-109 (Sprouse 1993); C-112 (Tingey et al. 1993).

(e) Simpson et al. (1993a). 


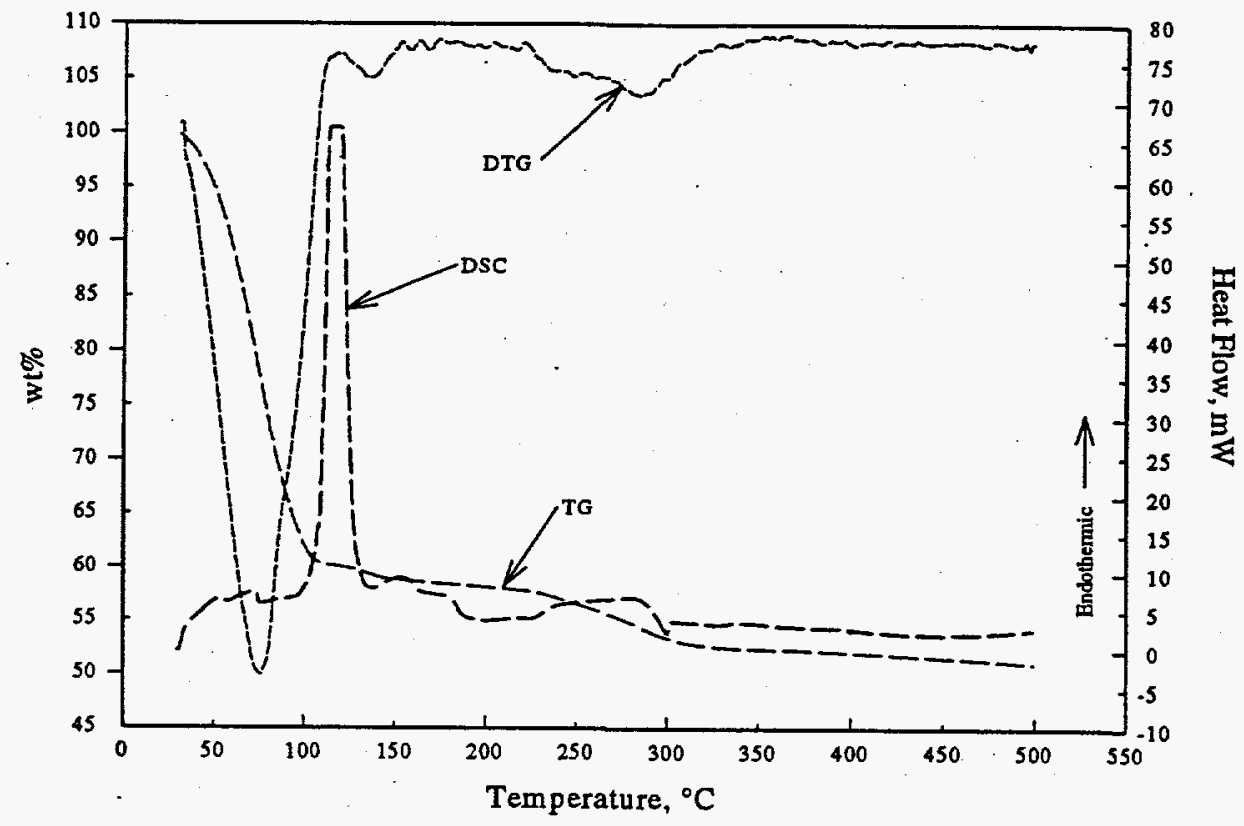

Figure 5.26. Thermal Behavior as Measured by DSC and TGA/DTG of As-Received Waste from Core 35 Composite Taken from 241-C-112

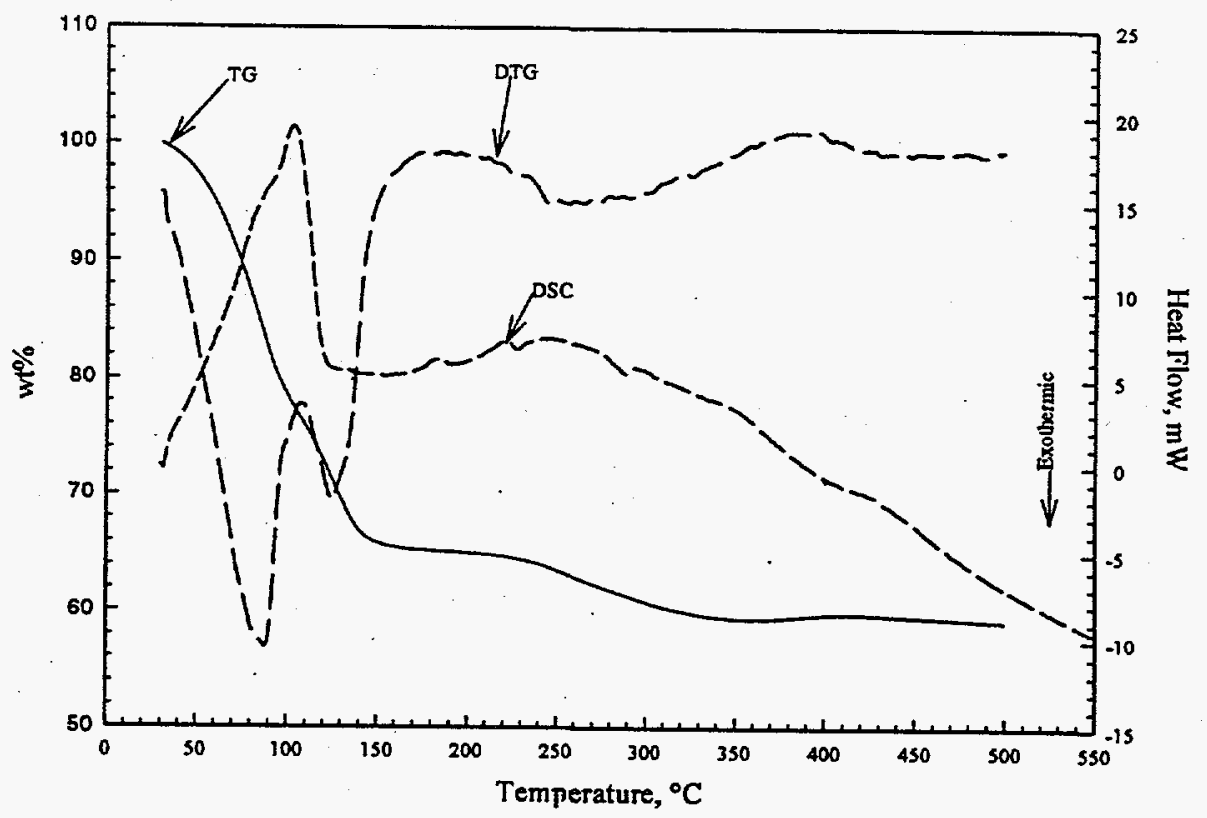

Figure 5.27. Thermal Behavior as Measured by DSC and TGA/DTG of As-Received Waste from Core 36 Composite Taken from 241-C-112 


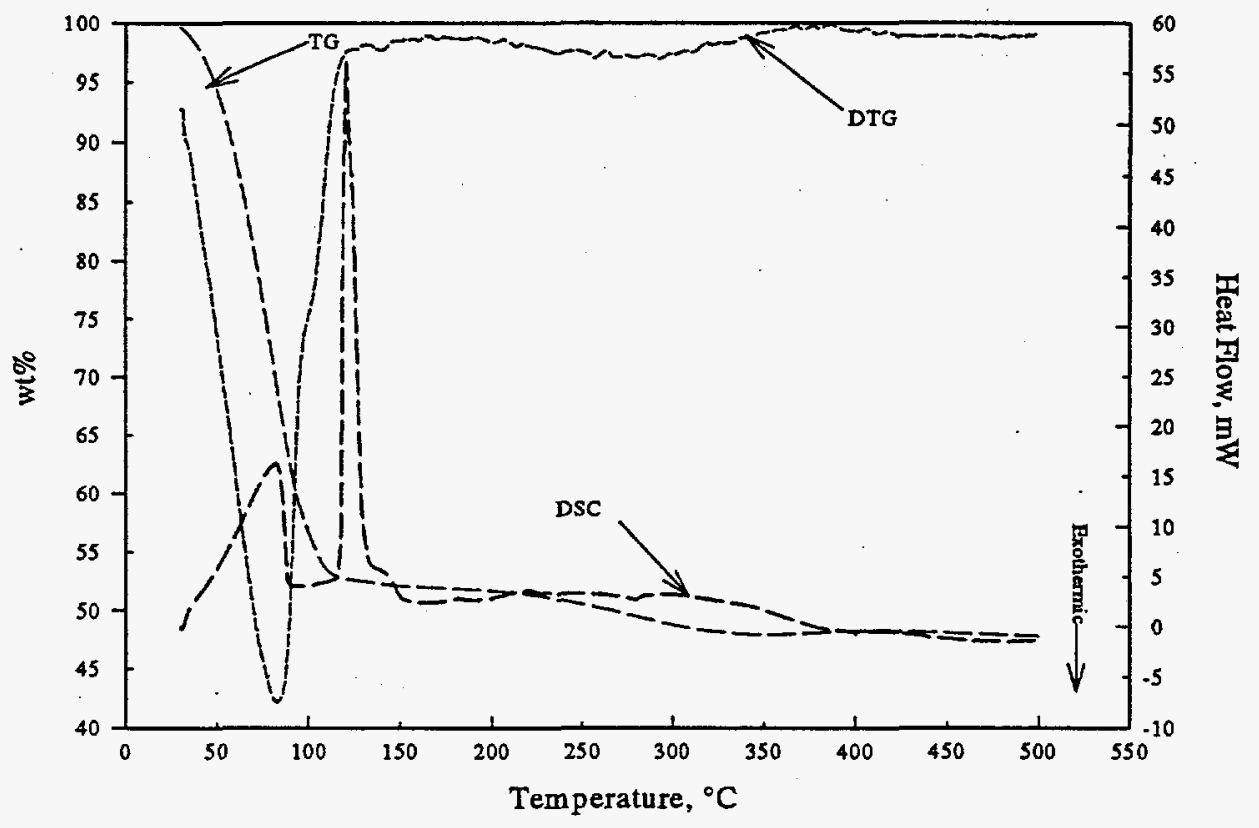

Figure 5.28. Thermal Behavior as Measured by DSC and TGA/DTG of As-Received Waste from Core 36 Subsegment 1C Taken from 241-C-112

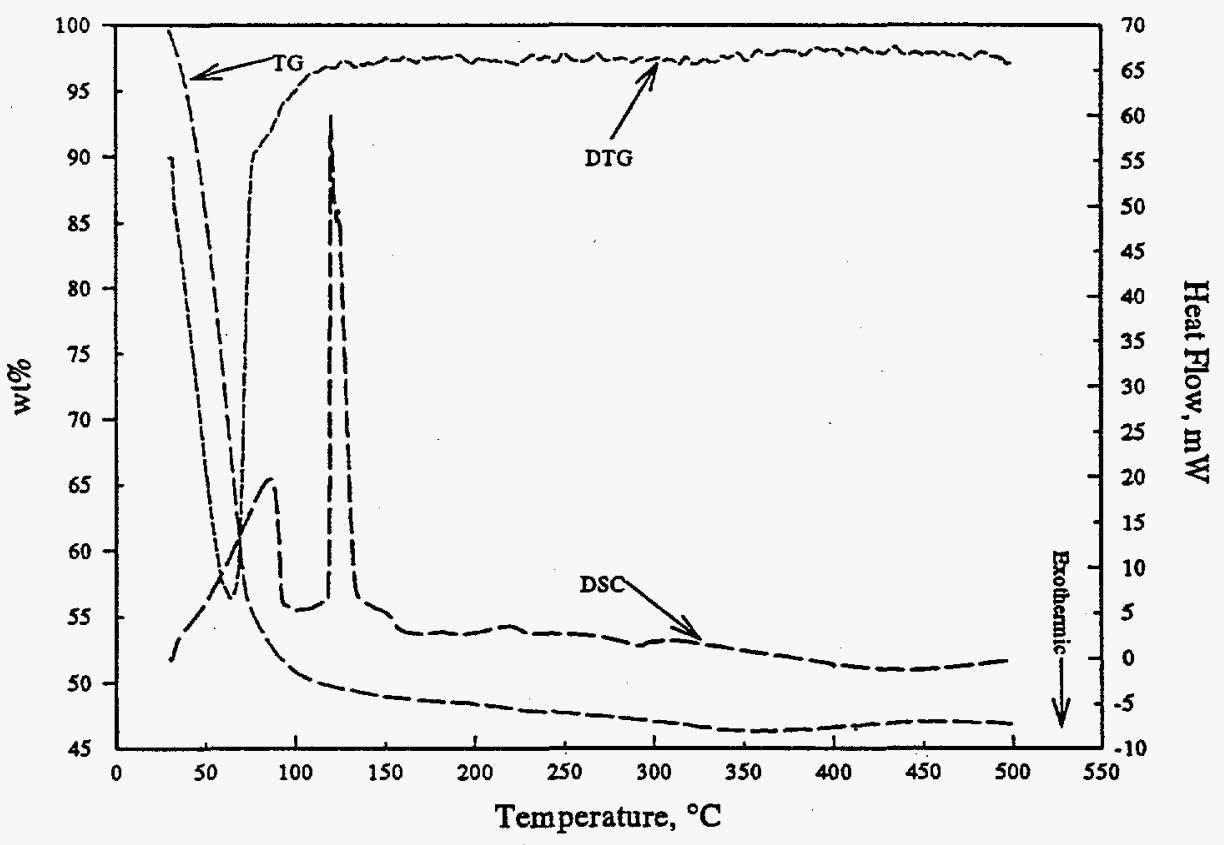

Figure 5.29. Thermal Behavior as Measured by DSC and TGA/DTG of As-Received Waste from Core 36 Subsegment 1D Taken from 241-C-109 


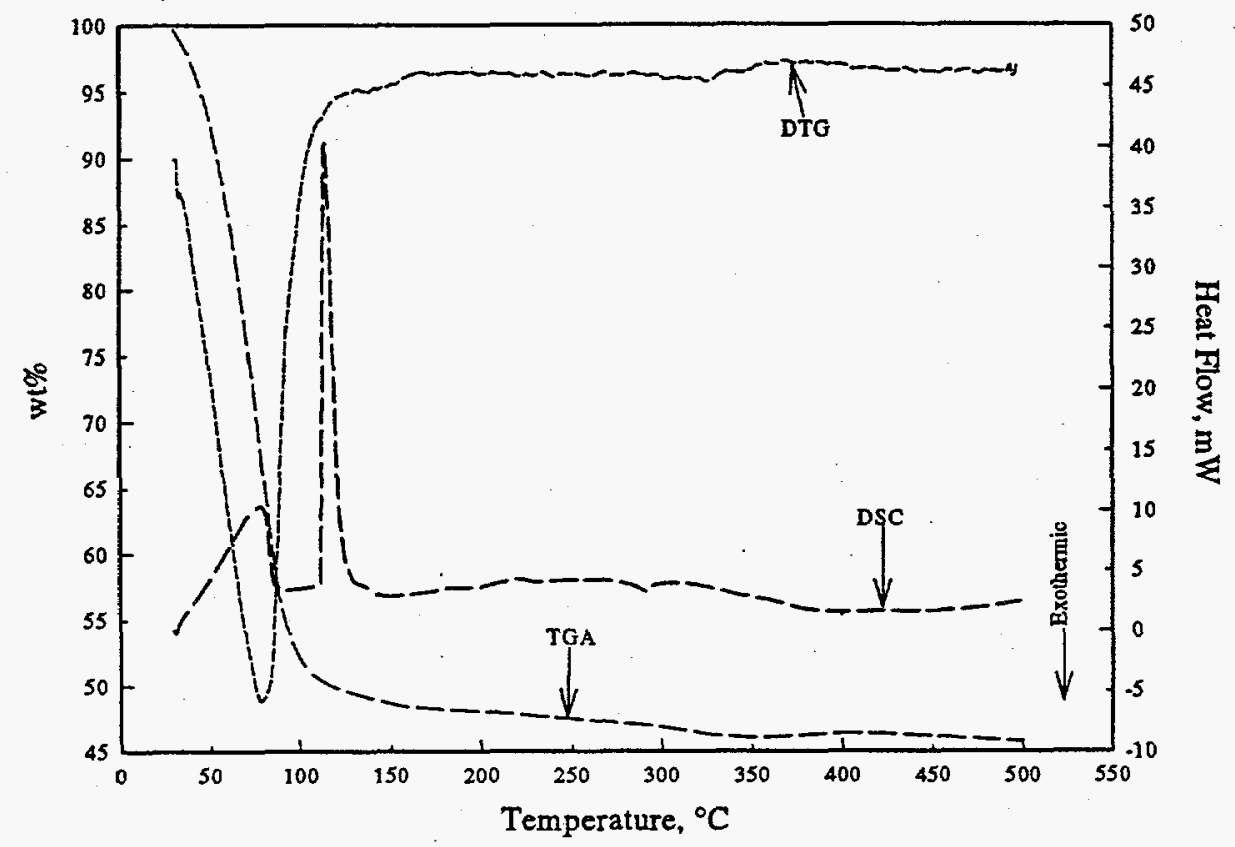

Figure 5.30. Thermal Behavior as Measured by DSC and TGA/DTG of As-Received Waste from Core 36 Subsegment 2A Taken from 241-C-112

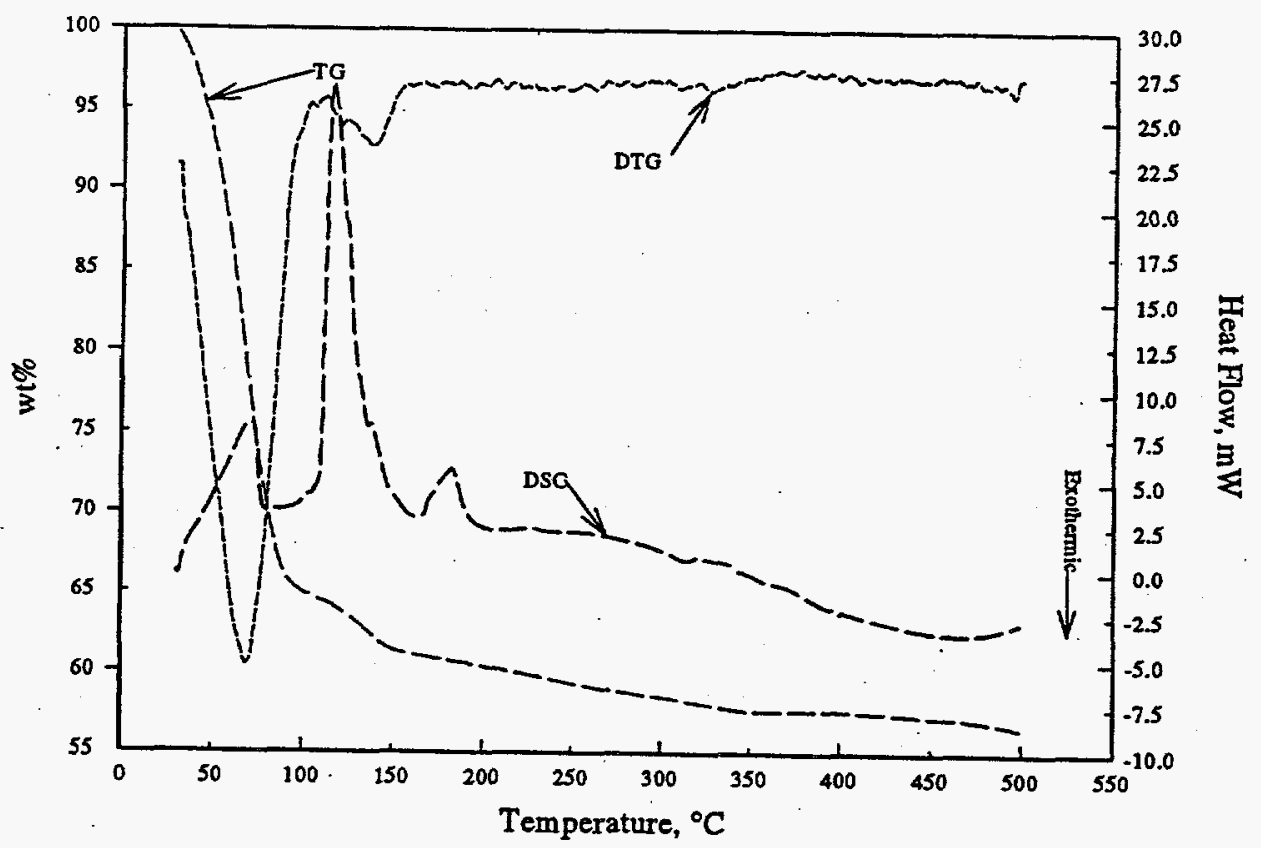

Figure 5.31. Thermal Behavior as Measured by DSC and TGA/DTG of As-Received Waste from Core 36 Subsegment 2B Taken from 241-C-112 


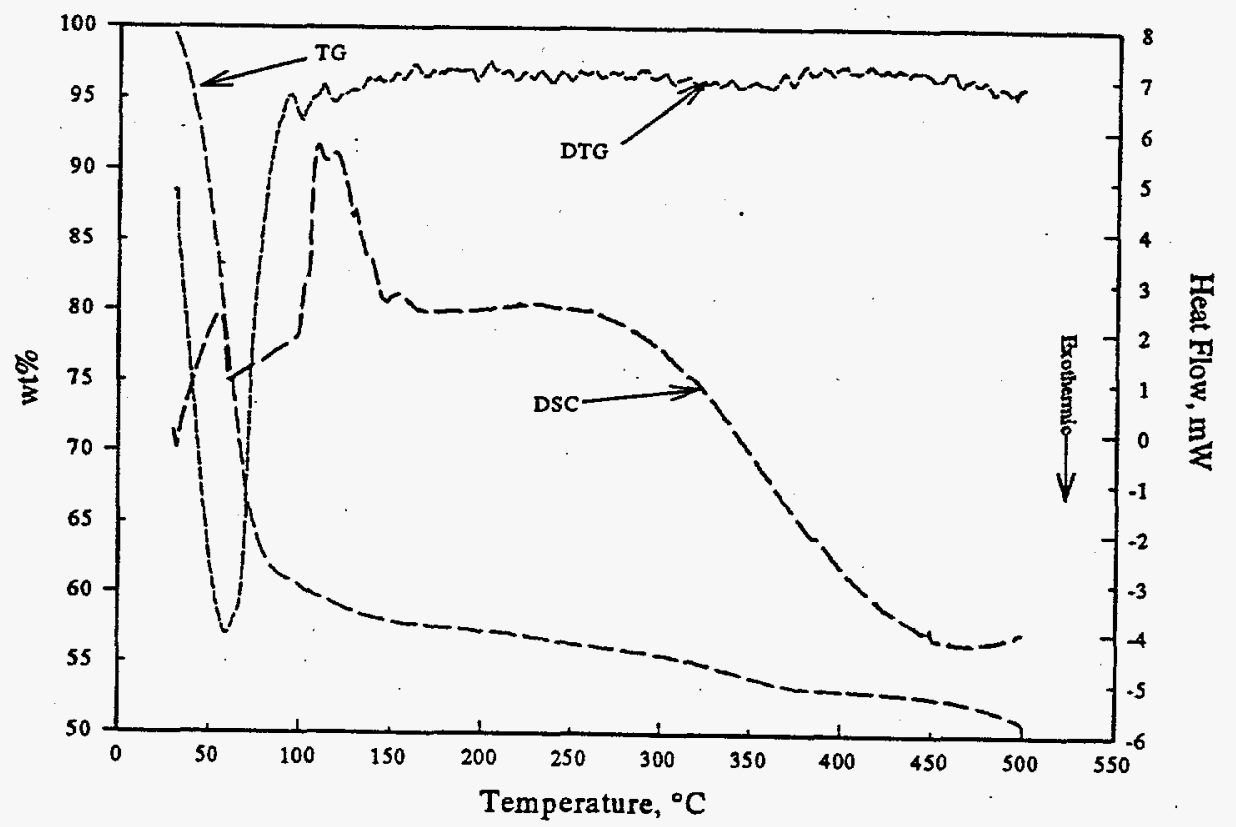

Figure 5.32. Thermal Behavior as Measured by DSC and TGA/DTG of As-Received Waste from Core 36 Subsegment 2C Taken from 241-C-112

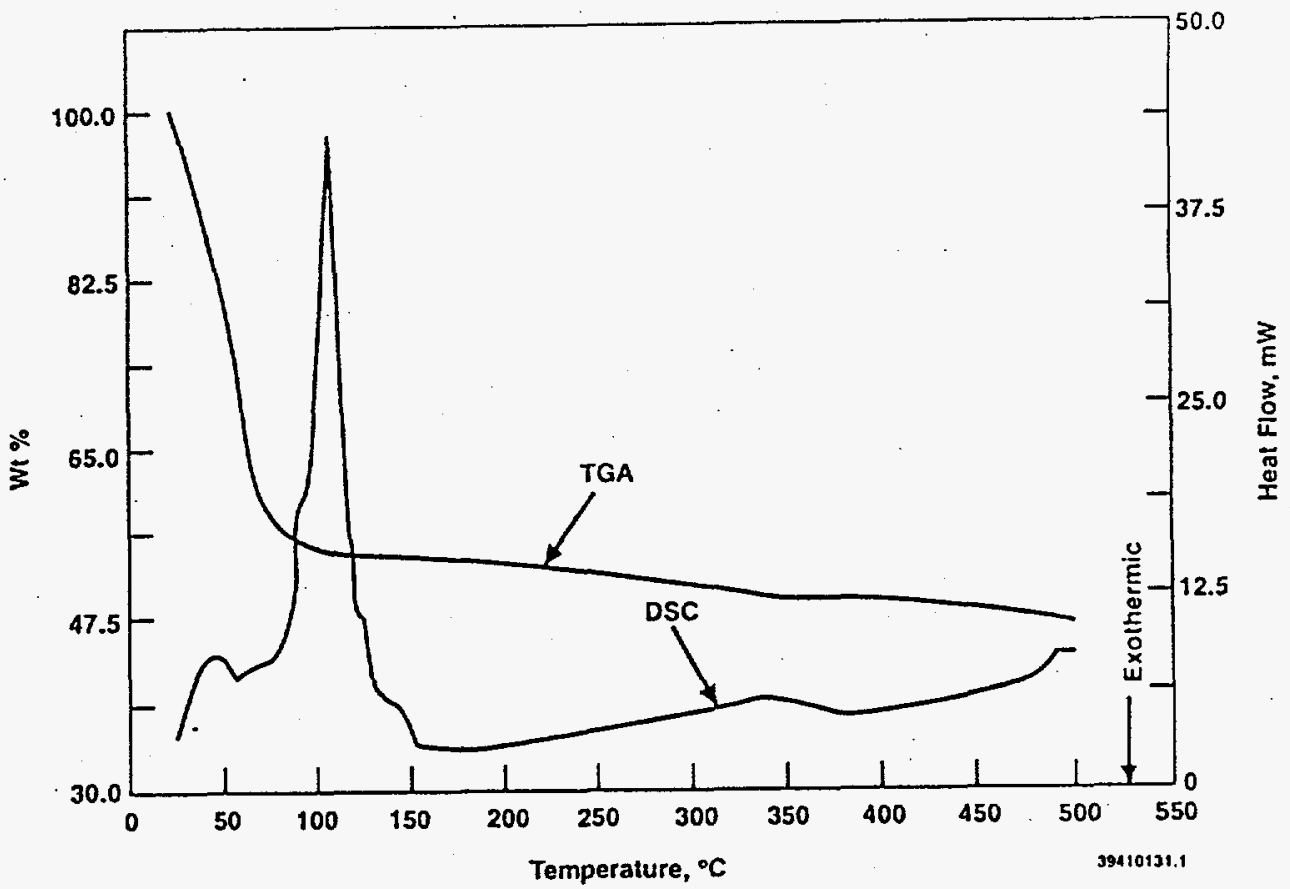

Figure 5.33. Thermal Behavior as Measured by DSC and TGA of a Sample of As-Received Waste from Core 36 Subsegment of 2D Taken from 241-C-112. 


\subsection{Conclusions}

The objective of this effort is to establish whether the ferrocyanide waste simulants prepared by WHC are representative of and/or bound the reactivities and behavior of actual ferrocyanide wastes. To date, analytical data are available for samples from only two ferrocyanide Watch List tanks: Tanks 241-C-112 and 241-C-109. Based on historical operations records, the wastes stored in these tanks were principally ferrocyanide wastes generated using the INFARM flowsheet, which based on predicted chemistry should contain the highest concentration of cyano species. Therefore, these tanks should represent some of the most reactive and energetic of the ferrocyanide wastes.

Of prime importance is whether ferrocyanide waste simulants bound the reactivity and energetics of ferrocyanide tank wastes. Historical records, and the strong similarities between the elemental concentrations in the tank wastes and INFARM-2 waste simulant, indicate that the ferrocyanide wastes stored in C-109 and C-112 were generated using the INFARM flowsheet. Comparison, then, of the largely endothermic thermal behavior of the tank waste samples with the highly exothermic thermal behavior of INFARM-2 waste simulant indicates that the reactivity and energetics of the tank wastes are much less, as well as well bounded by the reactivity and energetics of the comparable simulated waste. The extrapolation of this conclusion to other locations within the stored wastes in the two tanks must be tempered, given the variability in tank waste composition with depth and the waste's relative location with respect to the inlet. The low fuel or cyanide content in the tank wastes relative to the simulant is another indication that the tank waste samples are bounded in terms of reactivity and energetics by the simulant. The tank wastes contain substantially less cyanide than the INFARM-2 simulant, indicating that the cyanide has disappeared during the over 30 years of storage. The work of Lilga suggests that a likely mechanism for this disappearance is hydrolysis or radiolytic oxidation.

The elemental concentrations in the different core subsegments vary substantially, indicating that mixing of the different wastes added to the tanks has occurred. The low solubility of radiocesium in the subsegments from core 36 taken from C-112 and the composite core samples is consistent with the postulates that physical mixing has occurred or that ferrocyanide has migrated.

Consistent with the much lower cyanide content in the wastes from C-109 and C-112, the energetic behavior of the simulant contrasts sharply with that of the actual waste. The simulated INFARM wastes exhibit significant exothermicity and a proclivity for sustaining self-heating reactions if heated to sufficiently high temperatures. In contrast, the actual wastes exhibit little exothermicity or energetic behavior similar to that of the simulants, indicating that much of the ferrocyanide fuel no longer remains in the actual wastes.

In terms of physical properties and behavior, whether the simulant is representative of actual ferrocyanide waste depends on the property. For example, the particle sizes of the simulant are similar to the solids in the actual wastes, with the actual wastes tending to be slightly larger than in the INFARM simulant. As an example of differing behavior, the solids in the water dilutions of an INFARM simulant do not settle after four days, yet the solids in dilutions of the wastes from C-109 and C-112 do settle. Qualitatively, the water dilutions of the INFARM waste simulant and the comparable tank waste dilution exhibit yield-pseudoplastic rheological behaviors; quantitatively, the simulant exhibits higher viscosities. 
Given the limited number of samples and the poor core sample recoveries, the INFARM simulants are and are not good approximations of measured chemical and physical properties of the INFARM ferrocyanide wastes stored in C-109 and C-112, depending on the property. In terms of the reactivity, energetics, and cyanide concentrations, three of the most important properties, the simulants' behavior represents a worse case than the actual wastes. In terms of other properties such as rheological behavior, the simulant behaves qualitatively the same as the actual wastes but quantitatively exhibits higher viscosities. 


\subsection{References}

Agnew, S. F. 1993. Analysis of the History of 241-C Farm. LAUR-93-3605, Los Alamos National Laboratory, Los Alamos, New Mexico.

Anderson, J. D. 1990. A History of the 200 Area Tank Farms. WHC-MR-0132, Westinghouse Hanford Company, Richland, Washington.

Bell, M. L. 1993. Single Shell Tank Waste Characterization Project and Safety Analysis Project Core 34, 35, and 36, Validation Report Tank 24I-C-112. WHC-SD-WM-DP-026, Westinghouse Hanford Company, Richland, Washington.

Bryan, S. A., K. H. Pool, L. L. Burger, C. D. Carlson, N. J. Hess, J. D. Matheson, J. L. Ryan, R. D. Scheele, and J. M. Tingey. 1993a. Ferrocyanide Safety Project - Task 3.5 Cyanide Species Analytical Methods Development FY 1992 Annual Report. PNL-8399, Pacific Northwest Laboratory, Richland, Washington.

Bryan, S. A., K. H. Pool, S. L. Bryan, R. L. Sell, and L. M. P. Thomas. 1993b. Ferrocyanide Safety Project - Task 3.5 Cyanide Species Analytical Methods Development FY 1993 Aninual Report. PNL-8887, Pacific Northwest Laboratory, Richland, Washington.

Burger L. L. 1984. Complexant Stability Investigations. Task 1. Ferrocyanide Solids. PNL-5441, Pacific Northwest Laboratory, Richland, Washington.

Burger, L. L., and R. D. Scheele. 1988. Interim Report on Cyanide Safety Studies. PNL-7175, Pacific Northwest Laboratory, Richland, Washington.

Burger, L. L., D. A. Reynolds, W. W. Schulz, and D. M. Strachan. 1991. A Summary of Available Information on Ferrocyanide Tank Wastes. PNL-7822, Pacific Northwest Laboratory, Richland, Washington.

Burger, L. L., and R. D. Scheele. 1991. The Reactivity of Cesium Nickel Ferrocyanide Toward Nitrate and Nitrite Salts-A Status Report. PNL-7550, Pacific Northwest Laboratory, Richland, Washington.

Burger, L. L. 1993. Calculation of Reaction Energies and Adiabatic Temperatures for Waste Tank Reactions. PNL-8557, Pacific Northwest Laboratory, Richland, Washington.

Burns, R. E., R. L. Brandt, and W. E. Clifford. 1954. Removal of Cesium from Uranium Recovery Process Wastes, HW-31442, Hanford Atomic Works Operation Co., Richland, Washington.

Cady, H. H. 1992. Evaluation of Ferrocyanide/Nitrate Explosive Hazard. LA-12589-MS, Los Alamos National Laboratory, Los Alamos, New Mexico. 
Dodds, J. N., and W. J. Thomson. 1994a. Ferrocyanide Safety Project: Dynamic Xray Diffraction Studies of Sodium Nickel Ferrocyanide Reactions with Equimolar Nitrate/Nitrite Salts. PNL-10050, Pacific Northwest Laboratory, Richland, Washington.

Dodds, J. N., and W. J. Thomson. 1994b. "DXRD Studies of Sodium Nickel Ferrocyanide Reactions with Equimolar Nitrate/Nitrite Salts." Environ. Sci. Technol. 28:882-889.

Epstein, M., H. K. Fauske, M. D. Crippen, D. R. Dickenson, J. D. McCormack, R. J. Cash, J. E. Meacham, and C. S. Simmons. 1994. Assessment of the Possibility of Ferrocyanide Sludge Dryout. WHC-EP-0816, Westinghouse Hanford Company, Richland, Washington.

Faubian, B. D. 1984. "Henkin One-Shot Test - A Statistical Approach for Estimating Critical Temperatures." J. Haz. Mater. 9:95.

Fauske, H. K., and R. J. Cash. 1993. Ferrocyanide Safety Program: Waste Tank Sludge Rheology within a Hot Spot or During Draining - Homogeneous Flow Versus Flow Through a Porous Medium. WHC-EP-0713, Westinghouse Hanford Company, Richland, Washington.

Hallen, R. T., L. L. Burger, R. L. Hockey, M. A. Lilga, R. D. Scheele, and J. M. Tingey. 1992. Ferrocyanide Safety Project FY 1991 Annual Report. PNL-8165, Pacific Northwest Laboratory, Richland, Washington.

Hanlon, B. M., 1994. Tank Farm Surveillance and Waste Status Summary Report for April 1992. WHC-EP-0182-74, Westinghouse Hanford Company, Richland, Washington.

Henkin, H., and R. McGill. 1952. "Rates of Explosive Decomposition of Explosives - Experimental and Theroretical Kinetic Study as a Function of Temperature." Ind. Eng. Chem. 44:1391.

Hepworth J. L., E. D. McClanahan, and R. L. Moore. 1957. Cesium Packaging Studies - Conversion of Zinc Ferrocyanide to a Cesium Chloride Product. HW-48832, Hanford Atomic Products Operation, Richland, Washington.

Hepworth, J. L., E. D. McClanahan, Jr., and R. L. Moore. 1957. Cesium Packaging Studies Conversion of Zinc Ferrocyanide to a Cesium Chloride Product. HW-48832, General Electric Company, Richland, Washington.

Jeppson, D. W., and J. J. Wong. 1993. Ferrocyanide Waste Simulant Characterization. WHC-EP-0631, Westinghouse Hanford Company, Richland, Washington.

Jeppson, D. W., and B. C. Simpson. 1994. Characterization and Reaction Behavior of Ferrocyanide Simulants and Hanford Site High-Level Ferrocyanide Waste. WHC-SA-2190-FP, Westinghouse Hanford Company, Richland, Washington.

Lilga, M. A., M. R. Lumetta, W. F. Riemath, R. A. Romine, and G. F. Schiefelbein. 1992. Ferrocyanide Safety Project: Subtask 3.4 Ferrocyanide Aging Studies FY1992 Annual Report. PNL-8387, Pacific Northwest Laboratory, Richland, Washington. 
Lilga, M. A., M. R. Lumetta, and G. F. Schiefelbein. 1993. Ferrocyanide Safety Project: Task 3 Ferrocyanide Aging Studies FY1993 Annual Report. PNL-8888, Pacific Northwest Laboratory, Richland, Washington.

Lumetta, G. J., B. M. Rapko, and N. G. Colton. 1994. Washing and Caustic Leaching of Hanford Tank Sludges. PNL-SA-23598, Pacific Northwest Laboratory, Richland, Washington.

Meacham, J. E., R. J. Cash, and G. T. Dukelow. 1994. Quarterly Report on the Ferrocyanide Safety Program for the Period Ending June 30, 1994. WHC-EP-0474-13, Westinghouse Hanford Company, Richland, Washington.

Peach J. D. 1990 . Letter B-241479 to M. Synar, "Consequences of Explosion of Hanford's SingleShell Tanks are Understated," GAO/RCED-91-34, General Accounting Office, Washington, D.C.

Pool, K. H. 1994. Total Cyanide Analysis of Tank Core Samples: Analytical Results and Supporting Investigation. PNL-8858, Rev. 1. Pacific Northwest Laboratory, Richland, Washington.

Postma, A. K. 1994. Ferrocyanide Safety Program: Safety Criteria for Ferrocyanide Watch List Tanks. WHC-EP-0691, Westinghouse Hanford Company, Richland, Washington.

Scheele, R. D., and H. H. Cady. 1989. Preliminary Safe-Handling Experiments on a Mixture of Cesium Nickel Ferrocyanide and Equimolar Sodium Nitrate/Nitrite. PNL-7928, Pacific Northwest Laboratory, Richland, Washington.

Scheele, R. D., L. L. Burger, J. M. Tingey, S. A. Bryan, G. L. Borsheim, B. C. Simpson, R. J. Cash, and H. H. Cady. 1991. "Ferrocyanide Containing Waste Tanks: Ferrocyanide Chemistry and Reactivity." In the Proceedings of Environmental Restoration '91, University of Arizona, Tucson, Arizona.

Scheele, R. D., L. L. Burger, S. A. Bryan, G. L. Borsheim, B. C. Simpson, R. J. Cash, and H. H. Cady. 1992a. "Ferrocyanide-Containing Waste Tanks: Ferrocyanide Chemistry and Reactivity." In Proceedings of the Symposium on Environmental Remediation at Pasco, Washington, September 8-11, 1991. University of Arizona, Tucson, Arizona.

Scheele, R. D., L. L. Burger, J. M. Tingey, R. T. Hallen, and M. A. Lilga. 1992b. "Chemical Reactivity of Potential Ferrocyanide Precipitates in Hanford Tanks with Nitrate and/or Nitrite." In Proceedings of the Symposium on. Waste Management at Tucson, Arizona, March 1-5, 1992, Vol. 1, p. 835. University of Arizona, Tucson, Arizona.

Scheele, R. D., S. A. Bryan, J. W. Johnston, J. M. Tingey, L. L. Burger, and R. T. Hallen. 1992c. Hanford Ferrocyanide Waste Chemistry and Reactivity Preliminary Catalyst and Initiator Screening Studies. PNL-8089, Pacific Northwest Laboratory, Richland, Washington. 
Scheele, R. D., J. W. Johnston, J. M. Tingey, L. L. Burger, and R. L. Sell. 1993. Effect of Potential Waste Constituents on the Reactivity of Hanford Ferrocyanide Wastes: Diluent, Catalyst, Initiator Studies. PNL-8649, Pacific Northwest Laboratory, Richland, Washington.

Simpson, B. C., G. L. Borshiem, and L. Jensen. 1993a. Tank Characterization Report: Tank 241C-112. WHC-EP-0640, Westinghouse Hanford Company, Richland, Washington.

Simpson, B. C., G. L. Borshiem, and L. Jensen. 1993b. Tank Characterization Report: Tank 241C-109. WHC-EP-0668, Westinghouse Hanford Company, Richland, Washington.

Sloat, R. J. 1955. In-Farm Scavenging Operating Procedures and Control Data, HW-38955, Hanford Atomic Works Operation Co., Richland, Washington.

Smith, R. E., and E. A. Coppinger. 1954. Nickel Ferrocyanide Scavenging Flowsheet for Neutralized Concentrated RAW, HW-33536, Hanford Atomic Works Operation Co., Richland, Washington.

Sprouse, B. S. 1993. Single Shell Tank Waste Characterization Project and Safety Analysis Project Core 47, 48, and 49, Validation Report Tank 241-C-109. WHC-SD-WM-DP-036, Westinghouse Hanford Company, Richland, Washington.

Stedwell, M. J. 1954. Evaluation of Nickel Ferrocyanide Scavenging of Uranium Recovery Plant Solvent Extraction Waste, HW-31428, Hanford Atomic Works Operation, Richland, Washington.

Tingey, J. M., J. D. Matheson, S. G. McKinely, T. E. Jones, and K. H. Pool. 1993.

"Characterization of Hanford tank wastes containing ferrocyanides." In Proceedings of the Symposium on Waste Management at Tuscon, Arizona, February 28-March 4, 1993, Vol. 2, p. 1105. University of Arizona, Tucson, Arizona.

U.S. Department of Energy (DOE). 1987. Final Environmental Impact Statement, Disposal of Hanford Defense High-Level, Transuranic, and Tank Wastes. DOE-EIS-0113, U.S. Department of Energy, Washington, D.C. 


\section{Appendix A}

Comparison of Weight Percent Elemental Concentration on a Dry Basis in Simulated INFARM Waste and Waste from Tank 241-C-109 
A.1. Comparison of Weight Percent Elemental Concentration (Fusion Dissolution) on a Dry Basis in Simulated INFARM Waste and Waste from Tank 241-C-109

\begin{tabular}{|c|c|c|c|c|c|c|}
\hline Element & $\begin{array}{l}\text { INFARM-2 Top } \\
\text { Solids, wt } \%\end{array}$ & $\begin{array}{l}\text { INFARM-2 Bot } \\
\text { Solids, wt \% }\end{array}$ & C47_Comp, wt\% & C47_1B, wt\% & C47_1C, wt\% & C47_1D, wt\% \\
\hline $\mathrm{Al}$ & NA & NA & $1.5 e+01$ & $1.6 e+01$ & $1.7 e+01$ & $5.3 e+00$ \\
\hline $\mathrm{Ba}$ & NA & NA & $<3.3 E-03$ & $<2.1 \mathrm{E}-03$ & $<2.1 \mathrm{E}-04$ & $<2.1 E-05$ \\
\hline $\mathrm{Ca}$ & NR & NR & $3.1 e+00$ & $1.3 e+00$ & $2.5 e+00$ & $4.6 e+00$ \\
\hline $\mathrm{Cr}$ & NA & NA & $3.4 e-02$ & $<2.9 \mathrm{E}-03$ & $<2.9 \mathrm{E}-04$ & $<2.9 \mathrm{E}-05$ \\
\hline Cs & $4.6 \mathrm{e}-01$ & $5.0 \mathrm{e}-01$ & $\mathrm{NM}$ & NM & $\mathrm{NM}$ & NM \\
\hline $\mathrm{Fe}$ & $3.8 \mathrm{e}+00$ & $4.0 \mathrm{e}+00$ & $2.8 \mathrm{e}+00$ & $7.9 e+00$ & $2.9 e+00$ & $2.5 e+00$ \\
\hline $\mathbf{M g}$ & NA & NA & $8.3 e-02$ & $<7.8 \mathrm{E}-05$ & $<7.8 \mathrm{E}-06$ & $<7.8 \mathrm{E}-07$ \\
\hline $\mathbf{M n}$ & NA & NA & $2.1 \mathrm{e}-02$ & $<2.6 \mathrm{E}-04$ & $<2.6 \mathrm{E}-05$ & $<2.6 \mathrm{E}-06$ \\
\hline $\mathrm{Na}$ & $2.2 e+01$ & $2.0 e+01$ & $1.1 e+01$ & $6.3 e+\infty$ & $8.8 \mathrm{e}+\infty 0$ & $1.7 e+01$ \\
\hline $\mathrm{Ni}$ & $4.1 e+00$ & $4.5 e+00$ & $4.1 e+00$ & $2.4 e+00$ & $3.2 e+00$ & $4.2 e+00$ \\
\hline $\mathbf{P}$ & $5.9 e+00$ & $7.8 e+\infty 0$ & $2.5 \mathrm{e}+00$ & $9.4 \mathrm{e}-01$ & $1.7 e+00$ & $5.0 e+00$ \\
\hline $\mathrm{Pb}$ & NA & NA & $9.3 e-01$ & $6.3 e-01$ & $4.1 \mathrm{e}-01$ & $2.4 e+00$ \\
\hline $\mathrm{Si}$ & NA & NA & $2.0 \mathrm{e}+00$ & $2.3 e+00$ & $8.5 e-01$ & $3.7 e+00$ \\
\hline $\mathrm{Sr}$ & NA & NA & $<1.7 \mathrm{E}-04$ & $<1.0 \mathrm{E}-04$ & $<1.0 \mathrm{E}-05$ & $<1.0 \mathrm{E}-06$ \\
\hline Th & NA & NA & $2.6 e-02$ & $<1.9 \mathrm{E}-02$ & $<1.9 \mathrm{E}-03$ & $<1.9 \mathrm{E}-04$ \\
\hline U(ICP) & NA & NA & $1.2 e+00$ & $1.5 e+00$ & $8.5 e-01$ & $9.6 \mathrm{e}-01$ \\
\hline$U$ (LF) & NA & NA & $1.5 e+00$ & NM & $\mathrm{NM}$ & NM \\
\hline Total & $3.0 \mathrm{e}+01$ & $2.9 e+01$ & $4.3 e+01$ & $4.0 e+01$ & $3.8 \mathrm{e}+01$ & $4.6 e+01$ \\
\hline
\end{tabular}


A.1. (contd)

\begin{tabular}{|c|c|c|c|c|c|}
\hline Element & $\begin{array}{l}\text { INFARM-2 Top } \\
\text { Solids, wt } \%\end{array}$ & $\begin{array}{l}\text { INFARM-2 Bot } \\
\text { Solids, wt\% }\end{array}$ & C48_Comp, wt\% & C48_1C, wt \% & C48_1D, wt \% \\
\hline Al & NA & NA & $1.1 e+00$ & $1.0 \mathrm{e}+00$ & $1.6 \mathrm{e}+00$ \\
\hline $\mathrm{Ba}$ & NA & NA & $<2.1 \mathrm{E}-03$ & $<1.7 \mathrm{E}-03$ & $<1.7 \mathrm{E}-04$ \\
\hline $\mathrm{Ca}$ & NR & NR & $2.3 e+00$ & $4.1 e+00$ & $2.8 e+00$ \\
\hline $\mathrm{Cr}$ & NA & NA & $<2.9 \mathrm{E}-03$ & $<2.4 \mathrm{E}-03$ & $<2.4 \mathrm{E}-04$ \\
\hline Cs & $4.6 \mathrm{e}-01$ & $5.0 \mathrm{e}-01$ & NM & NM & NM \\
\hline $\mathrm{Fe}$ & $3.8 \mathrm{e}+00$ & $4.0 \mathrm{e}+00$ & $2.8 \mathrm{e}+00$ & $2.8 \mathrm{e}+00$ & $3.5 \mathrm{e}+00$ \\
\hline $\mathbf{M g}$ & NA & NA & $<7.8 \mathrm{E}-05$ & $<6.4 \mathrm{E}-05$ & $<6.4 \mathrm{E}-06$ \\
\hline $\mathbf{M n}$ & NA & NA & $<2.6 \mathrm{E}-04$ & $<2.1 \mathrm{E}-04$ & $<2.1 \mathrm{E}-05$ \\
\hline $\mathrm{Na}$ & $2.2 \mathrm{e}+01$ & $2.0 e+01$ & $1.3 e+01$ & $1.6 \mathrm{e}+01$ & $1.7 \mathrm{e}+01$ \\
\hline $\mathrm{Ni}$ & $4.1 e+00$ & $4.5 e+00$ & $4.2 \mathrm{e}+00$ & $6.2 e+00$ & $4.0 e+00$ \\
\hline $\mathbf{P}$. & $5.9 e+00$ & $7.8 \mathrm{e}+00$ & $2.6 e+00$ & $3.3 e+00$ & $3.4 e+00$ \\
\hline $\mathrm{Pb}$ & NA & NA & $8.9 \mathrm{e}-02$ & $7.7 e-02$ & $1.1 \mathrm{e}-01$ \\
\hline $\mathbf{S i}$ & NA & NA & $2.8 \mathrm{e}-01$ & $4.1 \mathrm{e}-01$ & $3.6 e-01$ \\
\hline $\mathrm{Sr}$ & NA & NA & $<1.0 \mathrm{E}-04$ & $<8.5 \mathrm{E}-05$ & $<8.5 \mathrm{E}-06$ \\
\hline Th & NA & NA & $<1.9 \mathrm{E}-02$ & $<1.6 \mathrm{E}-02$ & $<1.6 \mathrm{E}-03$ \\
\hline U(ICP) & NA & NA & $3.1 \mathrm{e}+00$ & $2.3 e+\infty 0$ & $2.4 e+00$ \\
\hline U (LF) & NA & NA & $3.5 e+00$ & NM & NM \\
\hline Total & $3.0 \mathrm{e}+01$ & $2.9 e+01$ & $2.9 e+01$ & $3.6 \mathrm{e}+01$ & $3.5 e+01$ \\
\hline
\end{tabular}


A.1. (contd)

\begin{tabular}{|c|c|c|c|c|c|c|}
\hline Element & $\begin{array}{l}\text { INFARM-2 Top } \\
\text { Solids, wt \% } \\
\end{array}$ & $\begin{array}{l}\text { INFARM-2 Bot } \\
\text { Solids, wt\% } \\
\end{array}$ & C49_Comp, wt\% & C49_1B, wt\% & C49_1C, wt\% & C49_1D, wt\% \\
\hline Al & NA & NA & $1.6 e+01$ & $2.3 e+01$ & $1.3 e+01$ & $1.2 \mathrm{e}+01$ \\
\hline $\mathrm{Ba}$ & NA & NA & $<2.1 \mathrm{E}-03$ & $<1.7 \mathrm{E}-03$ & $<1.7 \mathrm{E}-04$ & $<1.7 \mathrm{E}-05$ \\
\hline $\mathrm{Ca}$ & NR & NR & $1.9 \mathrm{e}+00$ & $5.3 e-01$ & $2.6 \mathrm{e}+00$ & $3.7 e+00$ \\
\hline $\mathrm{Cr}$ & NA & NA & $<2.9 \mathrm{E}-03$ & $<2.4 \mathrm{E}-03$ & $<2.4 \mathrm{E}-04$ & $<\dot{2} .4 \mathrm{E}-05$ \\
\hline Cs & $4.6 e-01$ & $5.0 \mathrm{e}-01$ & NM & NM & NM & NM \\
\hline $\mathbf{F e}$ & $3.8 e+00$ & $4.0 \mathrm{e}+00$ & $1.2 e+00$ & $1.9 \mathrm{e}+00$ & $6.4 \mathrm{e}-01$ & $2.5 \mathrm{e}+00$ \\
\hline $\mathbf{M g}$ & NA & NA & $<7.8 \mathrm{E}-05$ & $<6.4 \mathrm{E}-05$ & $<6.4 \mathrm{E}-06$ & $<6.4 \mathrm{E}-07$ \\
\hline $\mathrm{Mn}$ & NA & NA & $<2.6 \mathrm{E}-04$ & $<2.1 \mathrm{E}-04$ & $<2.1 \mathrm{E}-05$ & $<2.1 \mathrm{E}-06$ \\
\hline $\mathrm{Na}$ & $2.2 \mathrm{e}+01$ & $2.0 e+01$ & $9.7 \mathrm{e}+00$ & $5.3 e+00$ & $8.8 e+00$ & $1.5 e+01$ \\
\hline $\mathrm{Ni}$ & $4.1 e+00$ & $4.5 e+00$ & $2.9 \mathrm{e}+00$ & $1.3 e+00$ & $4.5 e+00$ & $5.1 \mathrm{e}+00$ \\
\hline $\mathbf{P}$ & $5.9 e+00$ & $7.8 e+00$ & $1.9 \mathrm{e}+00$ & $5.1 \mathrm{e}-01$ & $1.6 e+00$ & $3.4 \mathrm{e}+00$ \\
\hline $\mathrm{Pb}$ & NA & NA & $1.0 \mathrm{e}-01$ & $2.5 \mathrm{e}-01$ & $5.2 \mathrm{e}-02$ & $1.2 e-01$ \\
\hline $\mathrm{Si}$ & NA & NA & $2.9 \mathrm{e}-01$ & $3.6 \mathrm{e}-01$ & $1.2 \mathrm{e}-01$ & $2.8 \mathrm{e}-01$ \\
\hline $\mathrm{Sr}$ & NA & NA & $<1.0 \mathrm{E}-04$ & $<8.5 \mathrm{E}-05$ & $<8.5 \mathrm{E}-06$ & $<8.5 \mathrm{E}-07$ \\
\hline Th & NA & NA & $<1.9 \mathrm{E}-02$ & $<1.6 \mathrm{E}-02$ & $<1.6 \mathrm{E}-03$ & $<1.6 \mathrm{E}-04$ \\
\hline $\mathrm{U}(\mathrm{ICP})$ & NA & NA & $6.0 \mathrm{e}-01$ & $9.8 \mathrm{e}-01$ & $1.8 \mathrm{e}-01$ & $2.0 \mathrm{e}+00$ \\
\hline U (LF) & NA & $\mathrm{NA}$ & $9.6 e-01$ & NM & NM & NM \\
\hline Total & $3.0 \mathrm{e}+01$ & $2.9 e+01$ & $3.5 e+01$ & $3.4 \mathrm{e}+01$ & $3.2 \mathrm{e}+01$ & $4.4 \mathrm{e}+01$ \\
\hline
\end{tabular}

NA $=$ Not added.

$\mathrm{NR}=$ Not reported 


\section{Appendix B}

Comparison of Weight Percent Anion Concentration on a Dry Basis in Simulated INFARM Waste and Waste from Tank 241-C-109 
B.1. Comparison of Weight Percent Anion Concentration on a Dry Basis in Simulated INFARM Waste and Waste from Tank 241-C-109

\begin{tabular}{|c|c|c|c|c|c|c|}
\hline Analyte & INFARM-2 Top, wt $\%$ & INFARM-2 Bot, wt\% & Composite, wt\% & C47 IB, wt $\%$ & C47 1C, wt\% & C47 1D, wt\% \\
\hline $\mathrm{NO}_{3}^{-}$ & $2.7 e+01$ & $2.5 e+01$ & $4.7 e+\infty$ & $3.4 e+00$ & $5.0 e+\infty$ & $6.4 e+00$ \\
\hline $\mathrm{NO}_{2}^{-}$ & $7.3 e+\infty$ & $6.3 \mathrm{e}+00$ & $5.0 e+\infty 0$ & $3.5 e+00$ & $5.2 \mathrm{e}+\infty 0$ & $6.6 \mathrm{e}+00$ \\
\hline $\mathrm{PO}_{4}^{3-}$ & $2.0 e+\infty 0$ & $2.3 e+\infty$ & $2.8 e+\infty$ & $9.0 e-01$ & $1.3 e+00$ & $7.3 e+00$ \\
\hline $\mathrm{SO}_{4}^{2-}$ & $2.2 e+\infty$ & $2.0 e+\infty$ & $9.3 \mathrm{e}-01$ & $6.3 e-01$ & $9.9 e-01$ & $1.2 e+01$ \\
\hline $\mathrm{CN}^{-}$ & $9.1 e+\infty$ & $1.1 e+01$ & $1.0 \mathrm{e}-01$ & $7.1 e-02$ & $1.2 \mathrm{e}-01$ & $1.5 e-01$ \\
\hline Total $\mathrm{CN}^{-}$ & $1.8 \mathrm{e}+01$ & $2.3 e+01$ & $5.5 \mathrm{e}-01$ & $3.0 \mathrm{e}-01$ & $4.4 \mathrm{e}-01$ & $5.8 \mathrm{e}-01$ \\
\hline $\mathrm{Cl}^{-}$ & $0.0 e+\infty$ & $0.0 e+\infty$ & $8.9 \mathrm{e}-02$ & $7.4 \mathrm{e}-02$ & $9.8 \mathrm{e}-02$ & $1.3 e-01$ \\
\hline$F^{-}$ & $0.0 e+\infty$ & $0.0 e+\infty$ & $5.1 \mathrm{e}-02$ & $3.7 \mathrm{e}-02$ & $4.2 \mathrm{e}-02$ & $5.0 \mathrm{e}-02$ \\
\hline TOC & $0.0 e+\infty$ & $0.0 e+\infty$ & $2.9 \mathrm{e}-01$ & $2.7 e-01$ & $2.8 \mathrm{e}-01$ & $3.6 e-01$ \\
\hline $\mathrm{CO}_{3}^{2-}$ & $0.0 e+\infty$ & $0.0 e+\infty$ & $7.3 \mathrm{e}-01$ & $0.0 e+\infty$ & $0.0 e+\infty 0$ & $4.5 \mathrm{e}-01$ \\
\hline $\mathrm{HCO}_{3}^{-}$ & $0.0 \mathrm{e}+\infty$ & $0.0 e+\infty 0$ & $0.0 e+\infty$ & $6.7 \mathrm{e}-01$ & $7.3 e-01$ & $4.5 \mathrm{e}-01$ \\
\hline Total & $4.8 e+01$ & $4.6 e+01$ & $1.5 e+01$ & $9.8 e+\infty$ & $1.4 e+01$ & $3.5 e+01$ \\
\hline Analyte & INFARM-2 Top, wt\% & INFARM- & & C48 Composite, wt\% & C48 1C, wt\% & C48 1D, wt $\%$ \\
\hline $\mathrm{NO}_{3}^{-}$ & $2.7 e+01$ & 2.5 & & $1.1 e+01$ & $1.2 e+01$ & $1.1 e+01$ \\
\hline $\mathrm{NO}_{2}^{-}$ & $7.3 e+\infty$ & & & $1.1 e+01$ & $1.1 e+01$ & $1.0 e+01$ \\
\hline $\mathrm{PO}_{4}^{3-}$ & $2.0 e+\infty$ & & & $6.3 e+\infty 0$ & $3.4 e+\infty$ & $7.4 e+00$ \\
\hline $\mathrm{SO}_{4}^{2-}$ & $2.2 e+\infty 0$ & & & $2.2 e+00$ & $2.3 e+\infty 0$ & $2.1 e+\infty$ \\
\hline $\mathrm{CN}^{-}$ & $9.1 e+\infty$ & & & 3.1e-01 & $3.2 e-01$ & $2.9 \mathrm{e}-01$ \\
\hline Total $\mathbf{C N}^{-}$ & $1.8 e+01$ & & & $1.4 e+\infty$ & $1.1 e+\infty$ & $8.7 e-01$ \\
\hline $\mathrm{Cl}^{-}$ & $0.0 e+\infty$ & & & $1.9 \mathrm{e}-01$ & $2.0 \mathrm{e}-01$ & $2.1 \mathrm{e}-01$ \\
\hline$F-$ & $0.0 e+\infty$ & & & $3.1 \mathrm{e}-01$ & $1.1 \mathrm{e}-01$ & $1.5 \mathrm{e}-01$ \\
\hline TOC & $0.0 e+\infty$ & & & $7.3 \mathrm{e}-01$ & $7.8 \mathrm{e}-01$ & $7.2 \mathrm{e}-01$ \\
\hline $\mathrm{CO}_{3}^{2-}$ & $0.0 e+\infty$ & & & $6.6 e-01$ & $0.0 e+\infty 0$ & $1.5 \mathrm{e}+00$ \\
\hline $\mathrm{HCO}_{3}^{-}$ & $0.0 e+\infty$ & & & $6.6 \mathrm{e}-01$ & $1.8 e+00$ & $0.0 e+\infty$ \\
\hline Total & $4.8 \mathrm{e}+01$ & & & $3.4 e+01$ & $3.2 e+01$ & $3.4 e+01$ \\
\hline
\end{tabular}


B.1. (contd)

\begin{tabular}{|c|c|c|c|c|c|c|}
\hline Analyte & INFARM-2 Top, wt $\%$ & INFARM-2 Bot, wt\% & Composite, wt\% & C49 1B, wt\% & C49_1C, wt \% & C49 1D, wt \% \\
\hline $\mathrm{NO}_{\mathbf{3}}^{-}$ & $2.7 e+01$ & $2.5 e+01$ & $5.0 e+\infty$ & $3.2 e+\infty$ & $6.8 \theta+00$ & $7.10+\infty 0$ \\
\hline $\mathrm{NO}_{2}^{-}$ & $7.3 e+00$ & $6.3 e+00$ & $5.4 e+\infty 0$ & $3.3 \theta+\infty$ & $7.1 \theta+\infty$ & $7.5 e+00$ \\
\hline $\mathrm{PO}_{4}^{2}$ & $2.0 e+00$ & $2.3 e+\infty$ & $1.8 e+00$ & $7.60-01$ & $1.4 e+00$ & $4.2 e+00$ \\
\hline $\mathrm{SO}_{4}^{2-}$ & $2.2 e+00$ & $2.00+\infty 0$ & $9.10-01$ & $5.8 \mathrm{e}-01$ & $1.3 e+\infty 0$ & $1.2 e+00$ \\
\hline $\mathrm{CN}^{-}$ & $9.1 e+\infty$ & $1.1 e+01$ & $7.6 \mathrm{e}-02$ & $4.6 \mathrm{e}-02$ & $1.1 \mathrm{e}-01$ & $1.2 \mathrm{e}-01$ \\
\hline Total $\mathrm{CN}^{-}$ & $1.8 e+01$ & $2.3 e+01$ & $5.6 \mathrm{e}-01$ & $3.5 \mathrm{e}-01$ & $8.1 \mathrm{e}-01$ & $5.5 \mathrm{e}-01$ \\
\hline $\mathrm{Cr}^{-}$ & $0.0 e+\infty$ & $0.0 \theta+00$ & $1.1 \mathrm{e}-01$ & $6.2 \mathrm{e}-02$ & $1.3 \mathrm{e}-01$ & $1.3 e-01$ \\
\hline$F^{-}$ & $0.0 e+\infty$ & $0.00+00$ & $5.5 e-02$ & $3.7 \mathrm{e}-02$ & $4.9 \mathrm{e}-02$ & $1.7 \mathrm{e}-01$ \\
\hline TOC & $0.0 e+\infty$ & $0.0 e+00$ & $3.2 \mathrm{e}-01$ & $2.2 \mathrm{e}-01$ & $3.6 \mathrm{e}-01$ & $4.3 e-01$ \\
\hline $\mathrm{CO}_{3}^{2}$ & $0.0 e+00$ & $0.0 e+00$ & $0.0 e+\infty$ & $2.4 \mathrm{e}-01$ & $5.3 \mathrm{e}-01$ & $1.1 e+\infty$ \\
\hline $\mathrm{HCO}_{3}^{-}$ & $0.00+00$ & $0.0 e+00$ & $6.1 \mathrm{e} .01$ & $2.4 \mathrm{e}-01$ & $5.3 e-01$ & $0.00+00$ \\
\hline Total & $4.8 e+01$ & $4.6 e+01$ & $1.5 e+01$ & $9.0 e+\infty 0$ & $1.9 e+01$ & $2.2 \theta+01$ \\
\hline
\end{tabular}




\section{Appendix C}

Comparison of Weight Percent Elemental

Concentration on a Dry Basis in Simulated

INFARM Waste and Waste from Tank 241-C-112 
C.1. Comparison of Weight Percent Elemental Concentration (Fusion Dissolution) on a Dry Basis in Simulated INFARM Waste and Waste from Tank 241-C-112

\begin{tabular}{|c|c|c|c|c|c|c|c|}
\hline Element & $\begin{array}{l}\text { INFARM-2 Top } \\
\text { Solids, wt \% } \\
\end{array}$ & $\begin{array}{l}\text { INFARM-2 Bot } \\
\text { Solids, wt \% }\end{array}$ & C34_Comp, wt\% & C34_1D, wt\% & C34_2B, wt\% & C34_2C, wt $\%$ & C34_2D, wt \% \\
\hline Al & NA & NA & $4.8 \mathrm{e}+00$ & $3.2 \mathrm{e}+00$ & $6.9 e+00$ & $4.1 e+00$ & $5.6 e+00$ \\
\hline $\mathrm{Ba}$ & NA & NA & $<2.5 \mathrm{E}-03$ & $<4.1 \mathrm{E}-03$ & $<4.1 \mathrm{E}-03$ & $<4.1 \mathrm{E}-03$ & $<4.1 \mathrm{E}-03$ \\
\hline $\mathrm{Ca}$ & NR & NR & $4.7 e+00$ & $5.1 e+00$ & $4.6 e+00$ & $7.1 e+00$ & $5.0 \mathrm{e}+00$ \\
\hline $\mathrm{Cr}$ & NA & NA & $<3.5 \mathrm{E}+03$ & $<5.8 \mathrm{E}-03$ & $<5.8 \mathrm{E}-03$ & $<5.7 \mathrm{E}-03$ & $<5.7 \mathrm{E}-03$ \\
\hline Cs & $4.6 \mathrm{e}-01$ & $5.0 \mathrm{e}-01$ & NM & NM & NM & NM & NM \\
\hline $\mathrm{Fe}$ & $3.8 \mathrm{e}+00$ & $4.0 \mathrm{e}+00$ & $3.7 \mathrm{e}+00$ & $1.5 e+00$ & $3.1 e+00$ & $2.4 \mathrm{e}+00$ & $4.1 e+00$ \\
\hline $\mathbf{M g}$ & NA & NA & $<9.4 \mathrm{E}-05$ & $<1.5 \mathrm{E}-04$ & $<1.5 \mathrm{E}-04$ & $<1.5 \mathrm{E}-04$ & $<1.5 \mathrm{E}-04$ \\
\hline $\mathrm{Mn}$ & NA & NA & $<3.1 \mathrm{E}-04$ & $<5.1 \mathrm{E}-04$ & $<5.1 \mathrm{E}-04$ & $<5.1 \mathrm{E}-04$ & $<5.1 \mathrm{E}-04$ \\
\hline $\mathrm{Na}$ & $2.2 \mathrm{e}+01$ & $2.0 e+01$ & $1.9 e+01$ & $1.7 e+01$ & $1.9 e+01$ & $2.1 e+01$ & $1.6 \mathrm{e}+01$ \\
\hline $\mathrm{Ni}$ & $4.1 e+00$ & $4.5 e+00$ & $4.8 \mathrm{e}+00$ & $4.1 e+00$ & $4.7 e+00$ & $6.7 e+00$ & $4.9 e+00$ \\
\hline $\mathbf{P}$ & $5.9 e+00$ & $7.8 \mathrm{e}+00$ & $3.5 e+00$ & $2.3 e+00$ & $2.4 \mathrm{e}+00$ & $4.7 e+00$ & $4.1 e+00$ \\
\hline $\mathbf{P b}$ & NA & NA & $2.3 e+00$ & $2.3 e+00$ & $7.7 e-01$ & $2.7 \mathrm{e}-01$ & $5.9 \mathrm{e}-01$ \\
\hline $\mathrm{Si}$ & NA & NA & $2.5 e+00$ & $2.3 e+00$ & $6.8 \mathrm{e}-01$ & $3.4 \mathrm{e}-01$ & $6.0 \mathrm{e}-01$ \\
\hline $\mathrm{Sr}$ & NA & NA & $<1.2 \mathrm{E}-04$ & $<2.0 \mathrm{E}-04$ & $5.8 \mathrm{e}-02$ & $3.6 \mathrm{e}-02$ & $3.9 \mathrm{e}-02$ \\
\hline Th & NA & NA & $<2.3 \mathrm{E}-02$ & $<3.7 \mathrm{E}-02$ & $<3.7 \mathrm{E}-02$ & $<3.7 \mathrm{E}-02$ & $<3.7 \mathrm{E}-02$ \\
\hline U(ICP) & NA & NA & $2.3 e+00$ & $5.1 \mathrm{e}+01$ & $6.3 \mathrm{e}-01$ & $1.3 e+00$ & $4.2 \mathrm{e}-00$ \\
\hline U (LF) & NA & NA & $2.9 e+00$ & NM & $\mathrm{NM}$ & NM & NM \\
\hline Total & $3.0 \mathrm{e}+01$ & $2.9 \mathrm{e}+01$ & $4.7 e+01$ & $3.8 \mathrm{e}+01$ & $4.3 e+01$ & $4.8 \mathrm{e}+01$ & $4.5 e+01$ \\
\hline
\end{tabular}


C.1. (contd)

\begin{tabular}{|c|c|c|c|}
\hline Element & INFARM-2 Top Solids, wt \% & INFARM-2 Bot Solids, wt\% & C35_Comp, wt\% \\
\hline $\mathrm{Al}$ & NA & NA & $6.8 e+00$ \\
\hline $\mathrm{Ba}$ & NA & NA & $<4.4 \mathrm{E}-03$ \\
\hline $\mathrm{Ca}$ & NR & NR & $2.3 e+00$ \\
\hline $\mathrm{Cr}$ & NA & NA & $<6.2 \mathrm{E}-03$ \\
\hline Cs & $4.6 \mathrm{e}-01$ & $5.0 \mathrm{e}-01$ & NM \\
\hline $\mathrm{Fe}$ & $3.8 e+00$ & $4.0 e+00$ & $4.9 e+00$ \\
\hline Mg & NA & NA & $<1.7 \mathrm{E}-04$ \\
\hline Mn & NA & NA & $<5.5 \mathrm{E}-04$ \\
\hline $\mathrm{Na}$ & $2.2 e+01$ & $2.0 \mathrm{e}+01$ & $1.2 \mathrm{e}+01$ \\
\hline $\mathrm{Ni}$ & $4.1 e+00$ & $4.5 e+00$ & $3.0 \mathrm{e}+00$ \\
\hline $\mathbf{P}$ & $5.9 e+\infty 0$ & $7.8 \mathrm{e}+00$ & $3.2 \mathrm{e}+00$ \\
\hline $\mathbf{P b}$ & NA & NA & $<4.6 \mathrm{E}-02$ \\
\hline $\mathbf{S i}$ & NA & NA & $2.4 \mathrm{e}+00$ \\
\hline $\mathrm{Sr}$ & NA & NA. & $<2.2 \mathrm{E}-04$ \\
\hline Th & NA & NA & $<4.0 \mathrm{E}-02$ \\
\hline $\mathrm{U}(\mathrm{ICP})$ & NA & NA & $1.3 e+01$ \\
\hline $\mathrm{U}(\mathrm{LF})$ & NA & NA & $6.7 e+00$ \\
\hline Total & $3.0 e+01$ & $2.9 e+01$ & $6.2 e+01$ \\
\hline
\end{tabular}




\section{C.1. (contd)}

\begin{tabular}{|c|c|c|c|c|c|c|c|c|c|}
\hline Element & $\begin{array}{l}\text { INFARM-2 Top } \\
\text { Solids, wt } \% \\
\end{array}$ & $\begin{array}{l}\text { INFARM-2 Bot } \\
\text { Solids, wt\% }\end{array}$ & $\begin{array}{c}\text { C36_Comp, } \\
\text { wt\% }\end{array}$ & $\begin{array}{c}\text { C36_1C, } \\
\text { wt\% }\end{array}$ & $\begin{array}{c}\text { C36_1D, } \\
\mathrm{wt} \% \\
\end{array}$ & $\begin{array}{c}\mathrm{C} 36 \_2 \mathrm{~A}, \\
\mathrm{wt} \% \\
\end{array}$ & $\begin{array}{c}\text { C36_2B, } \\
w t \%\end{array}$ & $\begin{array}{c}\mathrm{C} 36 \_2 \mathrm{C} \\
\mathrm{wt} \% \\
\end{array}$ & $\begin{array}{c}\text { C36_2D, } \\
\text { wt\% }\end{array}$ \\
\hline Al & NA & NA & $1.2 e+00$ & $2.9 \mathrm{e}+00$ & $1.3 e+01$ & $1.2 \mathrm{e}+01$ & $5.3 e-01$ & $5.8 \mathrm{e}-01$ & $6.8 \mathrm{e}-01$ \\
\hline $\mathrm{Ba}$ & NA & NA & $<1.8 \mathrm{E}-03$ & $2.5 e-02$ & $<1.7 \mathrm{E}-04$ & $<1.7 \mathrm{E}-05$ & $<1.7 \mathrm{E}-03$ & $<1.7 \mathrm{E}-04$ & $<1.6 \mathrm{E}-03$ \\
\hline $\mathrm{Ca}$ & NR & NR & $3.7 e+00$ & $5.7 e+00$ & $2.6 e+00$ & $3.7 e+00$ & $1.5 \mathrm{e}+00$ & $8.3 e-01$ & $4.8 \mathrm{e}-01$ \\
\hline $\mathrm{Cr}$ & NA & NA & $<2.5 \mathrm{E}-03$ & $3.7 \mathrm{e}-02$ & $<2.4 \mathrm{E}-04$ & $<2.4 \mathrm{E}-05$ & $<2.3 \mathrm{E}-03$ & $<2.3 \mathrm{E}-04$ & $<2.3 \mathrm{E}-03$ \\
\hline Cs & $4.6 \mathrm{e}-01$ & $5.0 \mathrm{e}-01$ & NM & NM & NM & NM & NM & NM & NM \\
\hline $\mathrm{Fe}$ & $3.8 \mathrm{e}+00$ & $4.0 e+00$ & $4.7 e+00$ & $7.1 \mathrm{e}+00$ & $6.4 \mathrm{e}-01$ & $2.5 \mathrm{e}+00$ & $1.5 e+00$ & $4.2 \mathrm{e}+00$ & $7.1 \mathrm{e}+00$ \\
\hline $\mathbf{M g}$ & NA & NA & $<6.4 \mathrm{E}-05$ & $1.1 e-01$ & $<6.4 \mathrm{E}-06$ & $<6.4 \mathrm{E}-07$ & $<6.2 \mathrm{E}-05$ & $<6.2 \mathrm{E}-06$ & $<6.0 \mathrm{E}-05$ \\
\hline $\mathrm{Mn}$ & NA & NA & $<2.2 \mathrm{E}-04$ & $6.7 e-02$ & $<2.1 \mathrm{E}-05$ & $<2.1 \mathrm{E}-06$ & $<2.1 \mathrm{E}-04$ & $<2.1 \mathrm{E}-05$ & $<2.0 \mathrm{E}-04$ \\
\hline $\mathrm{Na}$ & $2.2 e+01$ & $2.0 \mathrm{e}+01$ & $2.2 \mathrm{e}+01$ & $1.6 e+01$ & $8.8 e+00$ & $1.5 \mathrm{e}+01$ & $1.5 e+01$ & $2.9 e+01$ & $2.4 \mathrm{e}+01$ \\
\hline $\mathrm{Ni}$ & $4.1 e+00$ & $4.5 e+00$ & $2.3 e+00$ & $4.3 e+00$ & $4.5 e+00$ & $5.1 \mathrm{e}+00$ & $8.1 e-01$ & $2.8 \mathrm{e}-01$ & $2,0 e-01$ \\
\hline $\mathbf{P}$ & $5.9 e+00$ & $7.8 \mathrm{e}+00$ & $6.7 e+00$ & $3.8 \mathrm{e}+00$ & $1.6 \mathrm{e}+00$ & $3.4 \mathrm{e}+00$ & $4.3 e+\infty 0$ & $9.3 e+00$ & $6.8 \mathrm{e}+00$ \\
\hline $\mathrm{Pb}$ & NA & NA & $1.9 e+01$ & $5.7 \mathrm{e}-01$ & $5.2 \mathrm{e}-02$ & $1.2 \mathrm{e}-01$ & $<1.7 \mathrm{E}-02$ & $<1.7 \mathrm{E}-03$ & $1.8 \mathrm{e}-01$ \\
\hline $\mathrm{Si}$ & $\mathrm{NA}$ & NA & $2.9 e+00$ & $3.1 \mathrm{e}+00$ & $1.2 \mathrm{e}-01$ & $2.8 \mathrm{e}-01$ & $2.2 \mathrm{e}-01$ & $2.4 \mathrm{e}-01$ & $3.2 \mathrm{e}-01$ \\
\hline $\mathrm{Sr}$ & NA & NA & $<8.9 \mathrm{E}-05$ & $2.8 \mathrm{e}-02$ & $<8.5 \mathrm{E}-06$ & $<8.5 \mathrm{E}-07$ & $2.8 \mathrm{e}-02$ & $8.6 e-02$ & $1.4 \mathrm{e}-01$ \\
\hline Th & NA & NA & $<1.6 \mathrm{E}-02$ & $<3.3 \mathrm{E}-02$ & $<1.6 \mathrm{E}-03$ & $<1.6 \mathrm{E}-04$ & $<1.5 \mathrm{E}-02$ & $<1.5 \mathrm{E}-03$ & $<1.5 \mathrm{E}-02$ \\
\hline U(ICP) & NA & NA & $1.9 e+01$ & $5.6 \mathrm{e}-01$ & $1.8 \mathrm{e}-01$ & $2.0 \mathrm{e}+00$ & $3.0 e+01$ & $3.1 \mathrm{e}+01$ & $1.3 e+01$ \\
\hline U (LF) & NA & NA & $1.7 e+01$ & NM & NM & $\mathrm{NM}$ & NM & NM & NM \\
\hline Total & $3.0 \mathrm{e}+01$ & $2.9 e+01$ & $8.2 e+01$ & $4.4 e+01$ & $3.2 \mathrm{e}+01$ & $4.4 e+01$ & $5.4 e+01$ & $7.6 \mathrm{e}+01$ & $5.3 e+01$ \\
\hline
\end{tabular}

$\mathrm{NA}=$ Not added.

$\mathrm{NR}=$ Not reported. 


\section{Appendix D}

Comparison of Weight Percent Anion Concentration on a Dry Basis in Simulated INFARM Waste and Waste from Tank 241-C-112 
D.1. Comparison of Weight Percent Anion Concentration on a Dry Basis in Simulated INFARM Waste and Waste from Tank 241-C-112

\begin{tabular}{|c|c|c|c|c|c|c|c|}
\hline Analyte & INFARM-2 Top, wt $\%$ & INFARM-2 Bot, wt\% & Composite, wt\% & C34 1D, wt\% & C34 2B, wt \% & C34 2C, wt\% & C34 2D,wt\% \\
\hline No; & $2.7 e+01$ & $2.5 e+01$ & $1.3 e+01$ & $1.4 e+01$ & $1.5 \mathrm{e}+01$ & $1.5 e+01$ & $1.2 e+01$ \\
\hline $\mathrm{NO}_{2}^{-}$ & $7.3 e+00$ & $6.3 e+\infty$ & $1.0 e+01$ & $1.1 e+01$ & $1.1 e+01$ & $1.2 e+01$ & $9.5 e+\infty$ \\
\hline $\mathrm{PO}_{4}^{3-}$ & $2.0 e+\infty 0$ & $2.3 e+\infty$ & $3.1 e+\infty$ & $2.1 e+\infty 0$ & $2.6 e+00$ & $2.7 e+\infty$ & $3.6 e+\infty$ \\
\hline $\mathrm{SO}_{4}^{2-}$ & $2.2 e+\infty 0$ & $2.0 e+\infty 0$ & $2.5 e+\infty$ & $2.6 e+00$ & $2.8 \mathrm{e}+00$ & $2.8 e+00$ & $2.3 e+\infty$ \\
\hline $\mathrm{CN}^{-}$ & $9.1 e+00$ & $1.1 e+01$ & $3.3 e-01$ & $3.5 \mathrm{e}-01$ & $3.4 \mathrm{e}-01$ & $3.3 \mathrm{e}-01$ & $2.5 \mathrm{e}-01$ \\
\hline Total $\mathrm{CN}^{-}$ & $1.8 e+01$ & $2.3 e+01$ & $9.7 \mathrm{e}-01$ & $5.2 \mathrm{e}-01$ & $4.3 \mathrm{e}-01$ & $8.3 e-01$ & $7.5 e-01$ \\
\hline $\mathrm{Cl}^{-}$ & $0.0 \mathrm{e}+00$ & $0.0 e+\infty$ & $2.1 e-01$ & $2.0 e-01$ & $2.1 \mathrm{e}-01$ & 2. $1 \mathrm{e}-01$ & $1.8 \mathrm{e}-01$ \\
\hline$F$ & $0.0 e+\infty$ & $0.0 e+\infty$ & $1.6 e-01$ & $1.8 \mathrm{e}-01$ & $1.9 \mathrm{e}-01$ & 2. $1 \mathrm{e}-01$ & $2.0 \mathrm{e}-01$ \\
\hline TOC & $0.0 e+\infty$ & $0.0 e+\infty$ & $5.0 e-01$ & $8.9 \mathrm{e}-01$ & $6.4 \mathrm{e}-01$ & $7.4 \mathrm{e}-01$ & $8.3 \mathrm{e}-01$ \\
\hline $\mathrm{CO}_{3}^{2-}$ & $0.0 e+\infty$ & $0.0 e+\infty$ & $6.9 \mathrm{e}-01$ & $0.0 e+\infty 0$ & $0.0 e+\infty$ & $0.0 e+\infty$ & $0.0 e+\infty$ \\
\hline $\mathrm{HCO}_{3}^{-}$ & $0.0 e+\infty$ & $0.0 e+\infty$ & $6.9 \mathrm{e}-01$ & $1.4 e+\infty$ & 1. $1 e+\infty$ & $1.2 e+\infty$ & $1.4 \mathrm{e}+\infty$ \\
\hline Total & $4.8 e+01$ & $4.6 e+01$ & $3.2 e+01$ & $3.3 e+01$ & $3.4 \mathrm{e}+01$ & $3.6 \mathrm{e}+01$ & $3.1 e+01$ \\
\hline Analyte & \multicolumn{3}{|c|}{ INFARM-2 Top, wt $\%$} & INFARM-2 Bot, wt\% & & \multicolumn{2}{|c|}{ C35 Composite, wt\% } \\
\hline $\mathrm{NO}_{3}^{-}$ & \multicolumn{3}{|c|}{$2.7 e+01$} & $2.5 e+01$ & & \multicolumn{2}{|c|}{$6.6 e+\infty 0$} \\
\hline $\mathrm{NO}_{2}^{-}$ & \multicolumn{3}{|c|}{$7.3 e+\infty$} & $6.3 e+00$ & & \multicolumn{2}{|c|}{$5.2 e+\infty$} \\
\hline $\mathrm{PO}_{4}^{--}$ & \multicolumn{3}{|c|}{$2.0 e+\infty 0$} & $2.3 e+\infty$ & & \multicolumn{2}{|c|}{$2.7 e+\infty$} \\
\hline $\mathrm{SO}_{4}^{2-}$ & \multicolumn{3}{|c|}{$2.2 e+\infty$} & $2.0 e+\infty$ & & \multicolumn{2}{|c|}{$1.3 \mathrm{e}+\infty$} \\
\hline $\mathrm{CN}^{-}$ & \multicolumn{3}{|c|}{$9.1 e+\infty$} & $1.1 e+01$ & & \multicolumn{2}{|c|}{$1.2 \mathrm{e}-01$} \\
\hline Total $\mathrm{CN}^{-}$ & \multicolumn{3}{|c|}{$1.8 e+01$} & $2.3 e+01$ & & \multicolumn{2}{|c|}{ NM } \\
\hline $\mathrm{Cl}^{-}$ & \multicolumn{2}{|r|}{$0.0 e+\infty$} & & $0.0 e+\infty$ & & \multicolumn{2}{|c|}{$1.3 \mathrm{e}-01$} \\
\hline$F$ & \multicolumn{2}{|r|}{$0.0 e+\infty$} & & $0.0 e+\infty$ & & \multicolumn{2}{|c|}{$4.5 e-02$} \\
\hline TOC & \multicolumn{2}{|r|}{$0.0 e+\infty$} & & $0.0 e+\infty 0$ & & \multicolumn{2}{|c|}{$3.8 \mathrm{e}-01$} \\
\hline $\mathrm{CO}_{3}^{2-}$ & \multicolumn{2}{|r|}{$0.0 e+\infty 0$} & & $0.0 e+\infty$ & & \multicolumn{2}{|c|}{$0.0 \mathrm{e}+\infty$} \\
\hline $\mathrm{HCO}_{3}^{-}$ & \multicolumn{2}{|r|}{$0.0 e+\infty$} & & $0.0 e+\infty$ & & \multicolumn{2}{|c|}{$5.6 e-01$} \\
\hline Total & \multicolumn{2}{|r|}{$4.8 \mathrm{e}+01$} & & $4.6 e+01$ & & \multicolumn{2}{|c|}{$1.7 e+01$} \\
\hline
\end{tabular}


D.1. (contd)

\begin{tabular}{|c|c|c|c|c|c|c|c|c|c|}
\hline Analyte & INFARM-2 Top, wt $\%$ & INFARM-2 Bot, $w \mathscr{F}$ & C-36 Comp, wt $\%$ & C36 1C, wt\% & C36 1D, wt\% & C36 2A, wt\% & C36 2B, wt \% & C36 2C, wt\% & C36 2D, wt \% \\
\hline $\mathrm{NO}_{3}^{-}$ & $2.7 e+01$ & $2.5 e+01$ & $1.3 e+01$ & $1.2 e+01$ & $1.6 e+01$ & $1.5 \mathrm{e}+01$ & $7.2 e+\infty 0$ & $1.3 e+01$ & $1.2 e+01$ \\
\hline $\mathrm{NO}_{2}^{-}$ & $7.3 e+00$ & $6.3 e+\infty$ & $9.5 e+00$ & $9.4 e+00$ & $1.2 e+01$ & $1.10+01$ & $5.1 e+\infty$ & $8.9 e+00$ & $8.0 e+00$ \\
\hline $\mathrm{PO}_{4}^{3-}$ & $2.0 e+\infty 0$ & $2.3 e+\infty$ & $9.0 e+\infty$ & $3.3 e+\infty$ & $4.2 \mathrm{e}+00$ & $5.3 e+00$ & $3.5 e+00$ & $1.1 e+01$ & $1.3 e+01$ \\
\hline $\mathrm{SO}_{4}^{2-}$ & $2.2 e+00$ & $2.0 e+\infty 0$ & $2.5 e+00$ & $2.4 e+\infty 0$ & $3.1 e+00$ & $2.9 e+00$ & $1.4 \mathrm{e}+\infty 0$ & $2.4 \mathrm{e}+\infty 0$ & $2.2 e+00$ \\
\hline $\mathrm{CN}^{-}$ & $9.1 e+\infty 0$ & $1.1 e+01$ & $2.4 \mathrm{e}-01$ & $2.2 \mathrm{e}-01$ & $2.9 \mathrm{e}-01$ & $2.8 \mathrm{e}-01$ & $1.2 \mathrm{e}-01$ & $2.2 \mathrm{e}-01$ & $2.0 \mathrm{e}-01$ \\
\hline Total $\mathrm{CN}^{-}$ & $1.8 e+01$ & $2.3 e+01$ & $7.1 \mathrm{e}-01$ & $0.0 e+00$ & $0.0 e+00$ & $9.2 \mathrm{e}-01$ & $7.5 e-01$ & $4.0 \mathrm{e}-01$ & $5.6 \mathrm{e}-01$ \\
\hline $\mathrm{Cl}^{-}$ & $0.0 e+\infty 0$ & $0.0 e+\infty$ & $1.9 e-01$ & $1.8 \mathrm{e}-01$ & $2.4 \mathrm{e}-01$ & $2.1 \mathrm{e}-01$ & $1.0 \mathrm{e}-01$ & $1.8 e-01$ & $1.3 \mathrm{e}-01$ \\
\hline$F^{-}$ & $0.0 e+00$ & $0.0 e+\infty$ & $8.2 e-02$ & $8.8 \mathrm{e}-02$ & $1.2 \mathrm{e}-01$ & $1.2 \mathrm{e}-01$ & $6.8 \mathrm{e}-02$ & $1.1 \mathrm{e}-01$ & $2.1 \mathrm{e}-01$ \\
\hline TOC & $0.0 e+\infty$ & $0.0 e+\infty 0$ & $5.6 \mathrm{e}-01$ & $1.6 e+\infty$ & $1.2 e+\infty$ & $9.1 e-01$ & $4.6 \mathrm{e}-01$ & 8. le-01 & 4. $1 e-01$ \\
\hline $\mathrm{CO}_{3}^{2-}$ & $0.0 e+00$ & $0.0 e+\infty$ & $0.0 e+\infty$ & $0.0 e+00$ & $0.0 e+\infty$ & $0.0 e+\infty$ & $0.0 e+00$ & $0.0 e+\infty$ & $0.0 e+\infty 0$ \\
\hline $\mathrm{HCO}_{3}^{-}$ & $0.0 e+\infty$ & $0.0 e+\infty$ & $7.3 \mathrm{e}-01$ & $7.8 \mathrm{e}-01$ & $1.3 e+\infty$ & $1.3 e+\infty$ & $4.2 e-01$ & $9.4 e-01$ & $5.2 \mathrm{e}-01$ \\
\hline Total & $4.8 e+01$ & $4.6 e+01$ & $3.6 e+01$ & $3.0 e+01$ & $3.8 e+01$ & $3.8 e+01$ & $1.9 e+01$ & $3.8 e+01$ & $3.6 e+01$ \\
\hline
\end{tabular}




\section{Distribution}

No. of

Copies

Offsite

12. U.S. Department of Energy

Office of Scientific and

Technical Information

Charles S. Abrams

1987 Virginia

Idaho Falls, ID 83404

Shirley Campbell-Grizzel

U.S. Department of Energy

EH-15, Trevion II

12800 Middlebrook Road

Germantown, MD 20874

George E. Schmauch

Air Products \& Chemicals, Inc.

7201 Hamilton Blvd.

Allentown, PA 18195-1501

James A. Gieseke

Battelle Columbus Division

505 King Avenue

Columbus, OH 43201-2693

Kamal K. Bandyopadhyay

Brookhaven National Laboratory

Upton, NY 11973

David O. Campbell

102 Windham Road

Oak Ridge, TN 37830

Fred N. Carlson

6965 North 5th West

Idaho Falls, ID 83401
No. of

Copies

Gary Powers

Design Science, Inc.

163 Witherow Road

Sewickley, PA 15143

Hans K. Fauske

Fauske and Associates, Inc.

16W070 W. 83rd St.

Burr Ridge, IL 60521

Gregory R. Choppin

Florida State University

Department of Chemistry B-164

Tallahassee, FL 32306

Melvin W. First

Harvard University

295 Upland Avenue

Newton Highlands, MA 02161

Chester Grelecki

Hazards Research Corporation

200 Valley Road, Suite 301

Mt. Arlington, NJ 07856

Billy Hudson

202 Northridge Court

Lindsborg, KS 67456

Thomas S. Kress

P.O. Box 2009

9108, MS-8088

Oak Ridge, TN 37831-8088

3 Los Alamos National Laboratory

P.O. Box 1663

Los Alamos, NM 87545

Attn: Steve F. Agnew

Attn: Steve Eisenhawer

Attn: Thomas E, Larson 
No. of

Copies

Mujid S. Kazimi

MIT/Dept of Nuclear Eng.

77 Massachusetts Avenue

Room 24-102

Cambridge, MA 02139

Louis Kovach

Nuclear Consulting Serices, Inc.

P.O. Box 29151

Columbus, $\mathrm{OH}$ 43229-0151

2 Oak Ridge National Laboratory

P.O. Box 2008

Oak Ridge, TN 37831-6385

Attn: Emory D. Collins, MS-6385

Attn: Charles W. Forsberg, MS-6495

Arlin K. Postma

3640 Ballard Road

Dallas, OR 97338

William R. Prindle

1556 Crestline Drive

Santa Barbara, CA 93105

Andrew S. Veletsos

Rice University

5211 Paisley

Houston, TX 77096

2 Sandia National Laboratory

P.O. Box 5800

Albuquerque, NM 87185

Attn: Scott E. Slezak, MS-0741

Attn: Dana Powers, MS-0744

Alfred Schneider

5005 Hidden Branches Drive

Dunwoody, GA 30338

3 Ray S. Daniels

Science Applications International

Corporation

20300 Century Blvd., Suite 200-B

Germantown, MD 20874
No. of

Copies

Michael T. Gordon

State of Washington

Department of Ecology

P. O. Box 47600

Olympia, WA $98504-7600$

Alex Stone

1105 W. 10th Ave., \#236

Kennewick, WA 99336-6018

6 U.S. Department of Energy

EM-36, Trevion II

12800 Middlebrook Road

Germantown, MD 20874

Attn: James V. Antizzo

Attn: Charles O'Dell (5)

Thomas C. Temple

U.S. Department of Energy

Savannah River Operations Office

P.O. Box A

Aiken, SC 29808

Bruce R. Kowalski

University of Washington

Center for Process Analytical

Chemistry

Chemistry Department BG-10

Seattle, WA 98195

Joseph S. Byrd

University of South Carolina

Department of Electrical and

Computer Engineering

Swearingen Engineering Center

Columbia, SC 29208

Frank L. Parker

Vanderbilt University

P.O. Box 1596, Station B

Nashville, TN 37235 
No. of

Copies

Donald T. Oakley

Waste Policy Institute

555 Quince Orchard Road, Ste 600

Gaithersburg, MD 20878-1437

\section{Onsite}

37 Westinghouse Hanford Company

H. Babad

J. B. Billetdeaux

D. C. Board

G. L. Borsheim

R. J. Cash (2)

M. D. Crippen

D. R. Dickinson

G. T. Dukelow

J. M. Grigsby

M. E. Huda

M. N. Islam

D. W. Jeppson

N. W. Kirch

C. A. Kuhlman

M. Kummerer

J. M. McLaren

J. E. Meacham

N. J. Milliken

S. R. Moreno

M. A. Payne

F. R. Reich

C. P. Schroeder

B. C. Simpson
No. of

Copies

H. Toffer

H0-38

W. T. Watson

W. D. Winkelman

H0-38

D. D. Wodrich

L5-55

S7-84

W. F. Zuroff

S7-12

Central Files

Document Processing and

Distribution (2)

EDMC

Information Release

Administration (3)

TFIC

L8-04

L8-15

H6-08

R1-05

R1-20

S7-16

S1-57

H5-27

S7-15

L5-31

L5-31

S7-15

H4-62

R3-08

R3-08

L5-31

R2-11

B3-30

H4-62

H0-34

S7-15

H4-63

B3-06

S7-14

L5-55

L7-06

R2-12
28 Pacific Northwest Laboratory

R. M. Bean

K8-18

J. W. Brothers

K5-22

S. A. Bryan

P7-25

L. L. Eyler

L. L. Fassbender

A. R. Felmy

S. C. Goheen

B. M. Johnson

M. A. Lilga

B. P. McGrail

A. W. Prichard

D. Rai

R. D. Scheele (5)

G. F. Schiefelbein (2)

C. W. Stewart

D. M. Strachan

J. M. Tingey

Publishing Coordination

Technical Report Files (5)
K7-15

K8-18

K6-82

P8-08

K9-70

P8-38

K2-38

K8-34

K6-82

P7-25

P8-38

K7-15

K9-78

P7-25 